\title{
A Compendium of Energy Conservation
}

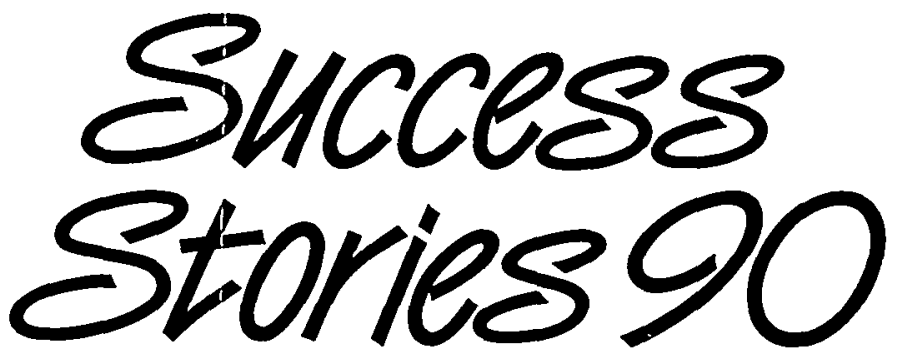

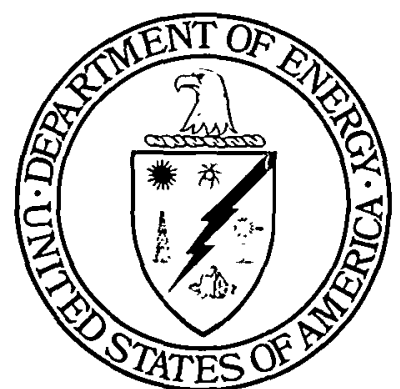

U.S. Department of Energy

Office of Conservation and Renewable Energy Washington, DC

December 1990
Contents

I ...Introduction

5 .... New Success Stories in Conservation

17 .... Ongoing Success Stories in the Buildings Sector

27 ....Ongoing Success Stories in the Transportation Sector

39 ....Ongoing Success Stories in the Industrial Sector 


\section{DISCLAIMER}

This report was prepared as an account of work sponsored by an agency of the United States Government. Neither the United States Government nor any agency thereof, nor any of their employees, make any warranty, express or implied, or assumes any legal liability or responsibility for the accuracy, completeness, or usefulness of any information, apparatus, product, or process disclosed, or represents that its use would not infringe privately owned rights. Reference herein to any specific commercial product, process, or service by trade name, trademark, manufacturer, or otherwise does not necessarily constitute or imply its endorsement, recommendation, or favoring by the United States Government or any agency thereof. The views and opinions of authors expressed herein do not necessarily state or reflect those of the United States Government or any agency thereof. 


\section{DISCLAIMER}

Portions of this document may be illegible in electronic image products. Images are produced from the best available original document. 


\section{Introduction}

The Department of Energy's (DOE's) Office of Conservation and Renewable Energy proudly presents this summary of some of its most successful projects and activities. The projects included in this document have made significant contributions to improving energy efficiency and fuel flexibility in the United States.

The energy savings that can be realized from these projects are considerable. Americans have shown an impressive ability to reduce energy consumption since 1973. Studies show that 34 quadrillion Btus (quads) of energy were saved in 1988 alone as a result of energy conservation and other factors. * These savings, worth approximately $\$ 180$ billion, represent more energy than the United States obtains from any other single source. The availability of new, energy-efficient technologies has been an important ingredient in achieving these savings.

Federal efforts to develop and commercialize energysaving technologies and processes are a part of the reason for this progress. Over the past 10 years, DOE has carefully invested more than $\$ 2$ billion in hundreds of research and development $(R \& D)$ projects to ensure the availability of advanced technology in the marketplace. These energy-efficient projects are carried out through DOE's Office of Conservation and Renewable Energy and reflect opportunities in the three energy-consuming, end-use sectors of the economy: buildings, transportation, and industry.

*From Energy Conservation Trends, September 1989, DOE/PE-0092, Washington, DC: U.S. Department of Energy, Office of Conservation and Renewable Energy.
Once energy-saving developments are successfully transferred to the private sector, market forces allow companies and consumers to select the best technologies. The nation reaps the rewards from these research investments in the form of energy savings, reduced dependence on foreign oil, cleaner air and water, improved industrial productivity, new jobs, and cost savings, which accumulate year after year.

There is ample evidence that the energy technologies from the Office of Conservation and Renewable Energy are having a favorable impact in all economic sectors. For example, by systematically tracking the use of these technologies, the office determined that more than 46 trillion Btus were saved during 1989 alone. Similarly, private companies paid more than a half-million dollars in royalties and licensing fees for transportation technologies developed through the office's R\&D programs. Likewise, the 37 licenses granted to private companies for a variety of energysaving building equipment testify to the commercial value of those technologies.

Since this document, $A$ Compendium of Energy Conservation Success Stories, was first published in September 1988, more projects have been added to the list of successes. In addition, new information has become available about further energy savings achieved by the projects described in that first publication. This edition of the Compendium updates the success stories summarized in the earlier document and showcases a number of successful new projects in energy efficiency.

\section{What is a Btu?}

A British thermal unit, abbreviated Btu, is the quantity of heat required to raise the temperature of one pound of water one degjee Fahrenheit at or near $39.2^{\circ} \mathrm{F}$. In more practical terms, it is approximately equal to the energy provided by one lighted match tip. The annual energy consumption of an average home is approximately 138 million Btus.

To help describe very large quantities of energy, we generally speak in terms of quads. Quad is an abbreviation for one quadrillion Btus $\left(1,000,000,000,000,000\right.$ or $\left.10^{15}\right)$. This measure can be better understood if you think of one quad as the energy in a train of oil tank cars stretching from New York to Denver and back again. One quad is also equivalent to 26 days of U.S. gasoline use or 27 hours of world energy use (1987 data). In 1989, the United States consumed a total of 80 quads of energy. 


\section{What Is a Success Story?}

Success stories consist of a diverse range of projects and activities sponsored by the Office of Conservation and Renewable Energy. Some of the stories are about new, energy-saving technologies or processes that represent major technical achievements but have yet to be commercialized; others are about fully developed products or technologies that are already in the market. Still others are about nonresearch activities or services that promote energy efficiency, including analyses, competitions, and educational activities. Good examples of these can be found among the exciting success stories summarized in this document.

Technical R\&D Achievements-Many DOE projects have led to important technical breakthroughs that hold tremendous promise as the bases for future technical achievements in energy efficiency. DOE's ETX-II Program, for example, made several major technological advances that have brought electric vehicles substantially closer to commercial feasibility. Among other features, the program's second-generation electric propulsion system uses a new permanent magnet motor that is lighter and smaller than conventional induction motors. The system incorporates this motor with integrated vehicle and electrical subsystem controllers, an advanced sodium-sulfur battery subsystem, and an integrated motor and transaxle on a common shaft.

Successfully Commercialized Technologies-An impressive number of technologies have become commercial successes. A good example is the heat-flux dew-point hygrometer, which was designed to withstand the high temperatures and corrosive gases present in industrial drying operations. This hygrometer, developed by Trans-Met Engineering with funding from DOE, is now at work saving energy in the textile, food processing, cement, paper, and chemical industries.

Analysis Tools-In addition to energy-saving products and processes, the Office of Conservation and Renewable Energy supports the development of various engineering and design tools that can be used to help save energy. These tools include design manuals, data bases, and simulation models. KIVA-II, for instance, is the latest in a series of multidimensional computer codes that can simulate the complex chemical and thermal processes that occur in an internal combustion engine. KIVA-II was accepted as the industry standard for developing model automotive engines and is in use worldwide.
Competitions-DOE sponsors several competitions to spark interest in energy-efficient technologies. The best known of these is the Methanol Marathon in which engineering students from competing universities convert and race automobiles (Corsicas donated by General Motors) using a fuel mixture consisting of 85\% methanol. Student teams from 15 different engineering schools participated in the 1989 competition.

Educational Activities-Many DOE activities are designed to help educate people about how to save energy. Some of these activities are directed at high school and university students; others are intended for professionals already in the field. The Summer Institutes on Energy and Design, for example, provide university faculty with resources to teach architecture students how to design energy-efficient buildings and also provide a forum for information exchange among government researchers, private industry, and the academic community.

These examples indicate the broad range of activities and projects that have become success stories. Despite their diversity, all the stories in this document share two common attributes. First, all were identified by individual DOE program managers or national laboratory researchers as representing the most successful projects to showcase in this document. Second, all are efforts that will ultimately help us grow into a more energy-efficient society.

\section{Technology Transfer Mechanisms}

The wide variety of technologies and markets being pursued by DOE to advance energy efficiency and fuel flexibility dictates the need for a similarly wide range of technology transfer mechanisms. These mechanisms reflect the different ways in which new technologies are adopted by our society. The selection of techniques to transfer a particular technology is based on the nature of the research, the comparative risk of the technology, the capabilities and resources of the research partners, and the segment of the economy most likely to benefit. The mix of technology transfer activities undertaken by the Office of Conservation and Renewable Energy is formulated to achieve maximum energy savings.

Licensing Agreements-DOE encourages the development and commercialization of new, energysaving technologies by licensing DOE inventions and technologies to private companies and individuals. Patent rights are commonly granted for inventions that derive from $R \& D$ performed by industry 
contractors. Rights may also be obtained through licensing agreements with the national laboratories. When exclusive rights are licensed, private firms are often more willing to invest in the needed development work to put a product on the market or to apply a new process. This increases the likelihood that new, energy-saving products and processes will actually be put to use and save energy.

Cooperative R\&D with Industry-When research focuses on technology development rather than on exploratory $R \& D$, Federal funding is used as leverage to attract private-sector cost sharing. DOE participates in collaborative and cost-shared research with industry both to maximize research funds and facilitate technology transfer. Private companies will generally invest time and money in only those projects from which they plan to benefit. The continuous involvement of the private sector in cooperative $R \& D$ efforts greatly increases the likelihood that the technology will find application in industry.

Spin-off Companies-On occasion, researchers involved in a successful DOE research project will acquire the rights to the new technology or process and form a new company to develop and market it. Such companies, known as spin-off companies, cannot be planned or designed but nevertheless serve as one of the most direct mechanisms for getting new technologies on the market. Spin-off companies based on DOE laboratory research are rapidly increasing in number.

Technical Assistance-DOE offers technical assistance as another direct means of relaying energyefficiency techniques and knowledge to the private sector. A variety of information and research services are offered at no charge. A good example is the Energy Analysis and Diagnostics Center program, which uses the services of 13 major engineering schools across the nation to provide energy efficiency audits to small and medium-sized manufacturing firms.

Experimental User Facilities-The Office of Conservation and Renewable Energy operates experimental facilities at DOE laboratories to facilitate research by industry, universities, and government agencies. The facilities provide the specialized equipment necessary to advance scientific understanding in governmental and industrial programs. Although the arrangements to carry out the $R \& D$ vary from one facility to the next, in all cases the interaction of scientists from government, academia, and industry is valuable in strengthening the quality of research and the diversity of ideas.

R\&D Working Groups-Technology transfer was made an integral part of many DOE research programs to promote the exchange of knowledge before, during, and after the research process. The involvement of experts and peers in the planning, review, and implementation of research projects ensures that efforts are directed toward useful, achievable goals and also provides one of the most efficient means of transferring research results to the private sector.

Educational Activities and Competitions-Recognizing the important roles that today's students must be prepared to fill in developing and applying tomorrow's energy-efficient technologies, the Office of Conservation and Renewable Energy directs a variety of educational training activities at the high school and university level. These activities, which include development of interdisciplinary curricula and energyoriented competitions, are designed to encourage innovative thinking and problem solving.

Seminars, Publications, and Other Outreach Activities-The more conventional technology transfer activities are valuable when imparting research results to larger audiences. Although the groups targeted by these activities may be less strictly defined, the broad coverage they achieve is often successful in delivering crucial information to the right audience. As an example, someone in industry may enter into a licensing agreement after reading about the new technology in a document prepared for general dissemination.

\section{Organization of This Document}

This document is designed to help both new readers and those familiar with the earlier edition. All the new success stories are placed in the first section. These stories did not appear in the earlier edition and represent the most recent energy-efficiency achievements by the Office of Conservation and Renewable Energy. Following these, the reader will find updated versions of the previously published stories. These are organized by the energy-consuming sectors of the economy: buildings, transportation, and industry. A brief description of the program appears at the beginning of each section. 


\section{New}

Success Stories in Conservation

6 ....New Guide: Affordable Housing through Energy Conservation Design and Compliance Software To Support Building Energy Conservation Standards

7 ....Guidelines for Passive Solar Design Strategies Low-Mass, Purgeable Boiler Low-Cost Analyzer for Oil-Burner Flames

8 ....Thin-Walled Hollow Spheres from Powders

9 ....Miami District Cooling Project Federal Methanol Fleet 1989 Methanol Marathon

10 .....High-Temperałure Liquid Lubricants Spark Plug Instrumented with Fiber Optics

11 ....High-Temperature Materials Laboratory

12 ....Gel Casting

Silicon Nitride Powder Microwave Processing of Ceramic Materials

13 ....Advanced Inverter Technology Battery Combustion-Attenuation Material Hyperfiltration of Food PET Botfle Separato

14 ....Biodegradable Plastics Bioreactions in Nonaqueous Media Dew-Point Hygrometer

15 ....Optical Humidity Sensor Rapid Solidification of Metals

16 ....A Computerized Tribology Information System 


\section{New Success Stories in Conservation}

The 25 success stories presented here reflect the diversity of the activities and projects implemented by the Office of Conservation and Renewable Energy. Projects range from district cooling to biodegradable plastics. Although many of these projects have been under development for some time, they were judged to have become successes or have yielded new energy-saving products or processes during the past year. Through their diversity, these projects provide a comprehensive approach to saving energy in the United States.

\section{New Guide: Affordable Housing through Energy Conservation}

Home builders have needed a simple, reliable way to determine the cost-effectiveness of different energy conservation options for designing and constructing energy-efficient homes. In response to this need, DOE developed a guide that will allow home builders to optimize combinations of design options, fuel choices, building materials, and labor costs for any region of the United States. The user can estimate easily and accurately the energy and dollar savings that will result from various improvements and compare those savings with any resultant increases in construction costs.

The Affordable Housing through Energy Conservation guide, consisting of microcomputer diskettes and technical support documents, comes in four parts: PEAR (Program for the Energy Analysis of Residences), a user-friendly software program that estimates the reductions in energy use for selected design and construction options; a handbook that explains how to specify, install, and operate the various combinations of design and construction options contained in the computer program; a second computer diskette, on which the analysis is to be stored, and a user's manual with full instructions for its use in combination with the software program; and a technical support document that describes the data base, operating assumptions, and algorithms used in the microcomputer program.
The data base developed for the PEAR program was also used to develop guidelines for the Federal Residential Standard for the design of Federally owned buildings and for proposed modifications to the residential portion of Standard 90A-1980 of the American National Standards Institute (ANSI); American Society of Heating, Refrigerating, and Air-Conditioning Engineers (ASHRAE); and the Illumination Engineering Society (IES).

\section{Design and Compliance Software To Support Building Energy Conservation Standards}

DOE has promulgated energy conservation standards for designing new commercial and multifamily highrise buildings. Compliance with these standards is mandatory only for the design of Federal buildings, but $D O E$ recommends that all design professionals voluntarily adopt the guidelines.

Two microcomputer programs, ENVSTD ${ }^{\mathrm{TM}}$ and LTGSTD, were developed to facilitate the use of these standards. ENVSTD ${ }^{\mathrm{TM}}$ confirms that the building design meets the building envelope criteria contained in the standards. This program can also be used to assess the energy effects of a variety of window and wall design options. LTGSTD confirms that the building design meets the lighting standards and serves as a valuable design tool when assessing the lighting needs of a building.

Development of these computer programs was a team effort by ASHRAE, IES of North America, and DOE. The volunteer members of the ASHRAE Standing Standards Project Committee 90R developed the computational algorithms used in the DOE standards, in ASHRAE/IES Standard 90.1-1989, and in this program. The Pacific Northwest Laboratory programmed these algorithms into user-friendly software. Both computer programs are helpful to architects, designers, and engineers who must analyze whether new building designs comply with DOE's new energy-conserving standards. 


\section{Guidelines for Passive Solar Design Strategies}

Through the collaboration of the Passive Solar Industries Council, its member organizations (including the National Association of Home Builders), and the Solar Energy Research Institute, the results of more than 10 years of research on passive solar design were compiled and packaged into a form useful to home builders, developers, and designers. The design strategy packages are site-specific and consist of guidelines and simplified calculation procedures. A computerized "expert system" version of the guidelines is currently being developed at the request of the Passive Solar Industries Council and the National Association of Home Builders. The Passive Solar Design Strategies package represents the first design tool to have the endorsement of the association's Standing Committee on Energy.

During the past year, the Passive Solar Industries Council and the National Association of Home Builders initiated a series of workshops designed to assist builders, developers, and designers in using the guidelines package. These workshops are held following the publication of articles and announcements regarding the availability of the design strategies in trade journals and other media.

\section{Low-Mass, Purgeable Boiler}

Conventional boilers used to heat homes lose a significant amount of energy when the burner shuts off and the energy remaining in the boiler water and the heat exchanger escapes out the flue pipe or chimney. The amount of this "off-period cycling loss" depends on the mass of the heat exchanger and the temperature of the boiler water at the time of burner shut-off. DOE researchers at the Brookhaven National Laboratory suggested a change in the boiler's fundamental design to overcome this energy loss, namely, to purge the hot water from the boiler into a reservoir of usable heat during the off period.

With support from DOE, the Energy Kinetics Corporation developed a prototype low-mass purgeable boiler that was tested successfully at Brookhaven in 1980. The low-mass boiler consists of a 10-foot-long, hollow, coiled section that behaves as a heat exchanger. Water flows internally and is warmed as hot combustion gases pass outside the coil on their way from the firebox to the exhaust stack. Water in the boiler flows counter to the flow of the hot gases with the coolest water on the external loop, minimizing the external jacket heat loss.

The system uses a microprocessor control that purges all the heat remaining in the boiler and allows separate zones of the house to be heated. The purged heat is sent to either the last zone requiring heat or, when the thermostat is satisfied, the water heater tank, which can be connected to receive heat from the boiler water. Because of the low volume of water in the boiler (less than three gallons), the boiler is able to reach the operating temperature in less than one minute and to purge stored heat at a rate of $30^{\circ} \mathrm{F}$ per minute. The boiler operates with a steady-state efficiency of $83.3 \%$, but more importantly, the purging mode increases the cyclic (seasonal) efficiency of the boiler from $71.9 \%$ to $82.5 \%$. Energy Kinetics achieved a market penetration of about 2000 units per year for its System 2000 low-mass purgeable boiler.

\section{Low-Cost Analyzer for Oil-Burner Flames}

Residential oil-fired furnaces usually operate at less than optimal efficiency. During installation and servicing, burners are sometimes improperly adjusted or calibrated. When the furnace is in use, soot accumulates on heat-exchanger surfaces, causing thermal performance to deteriorate by $2 \%$ or more each year between tune-ups.

To improve furnace energy performance, DOE supported development of an optical flame monitor that can be incorporated into a furnace. The monitor,

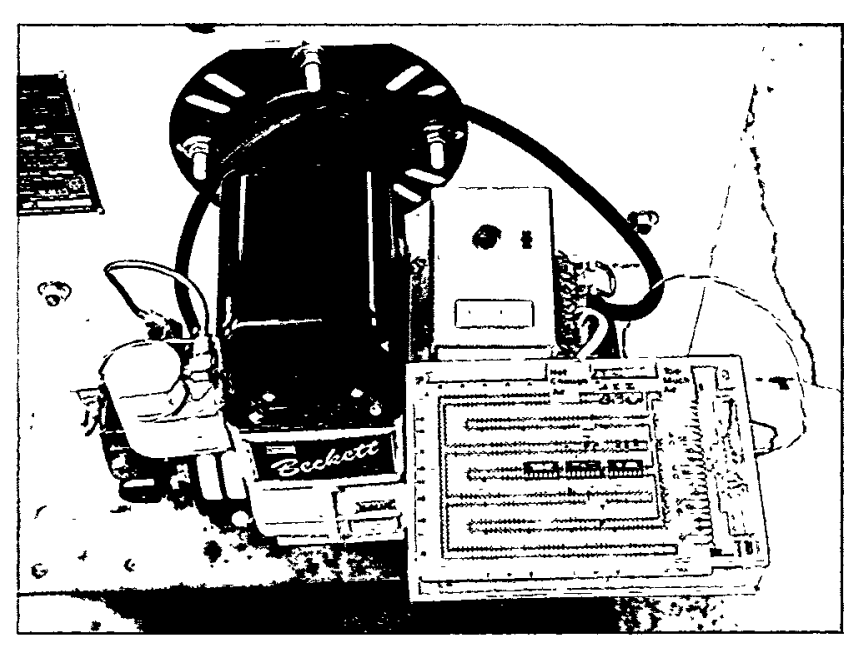

A low-cost monitor helps oil-fired furnaces in homes operate at optimal efficiency. 
developed at the Brookhaven National Laboratory, uses low-cost optical detectors and common electronic devices. It includes a simple display that shows when the combustion air is set for the highest efficiency and indicates when the burner needs adjustment or servicing.

The oil-heat industry responded positively to the monitor. Cooperative field tests were conducted during the 1989-1990 heating season with funding from the Canadian Mortgage and Housing Corp. These field tests will continue during the 1990-1991 heating season, again with cofunding from the Canadian Mortgage and Housing Corp. Several manufacturers and fuel-oil supply companies have also expressed interest in the device, and opportunities for cooperative field tests are being explored. The next research stages will examine automatic control of the burner's air/fuel ratio, allowing the burner to compensate for seasonal variations in chimney draft, as well as dust and lint accumulation on the air-inlet passages.

\section{Thin-Walled Hollow Spheres from Powders}

There is great potential to reduce energy loss in homes and in industry by using improved, economical insulating materials. Through DOE-sponsored research, an innovative process was developed to fabricate small, hollow spheres (aerospheres) for use as thermal insulation.

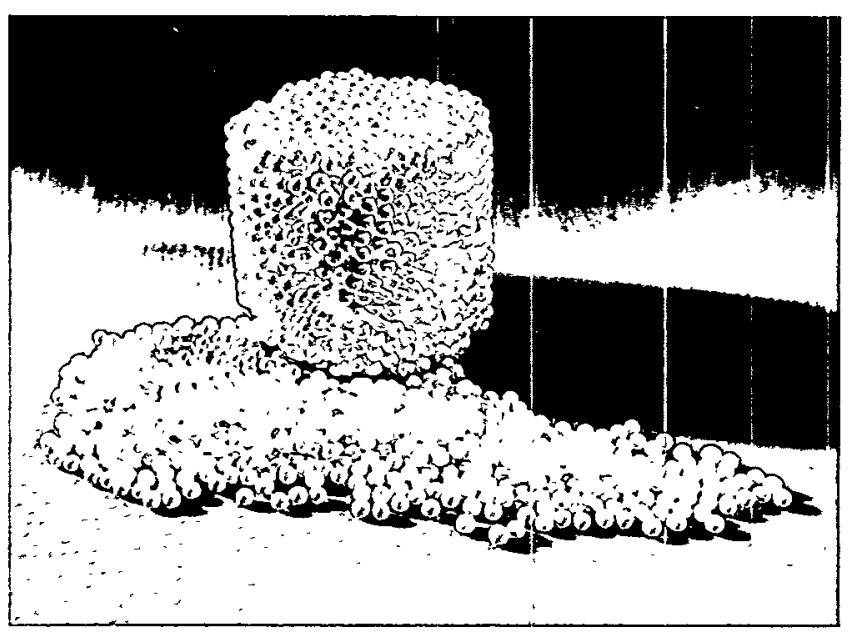

An inexpensive, continuous fluid flow process produces a new type of thermal insulation consisting of thin-walled hollow spheres known as "aerospheres."
Aerospheres appear to be the best candidate insulation for very high temperature applications (greater than $1500^{\circ} \mathrm{C}$ ) because of their durability and low cost. For lower temperature applications, aerospheres are also economical, noncarcinogenic, ecologically safe, and noncompressible over time. Their application as thermal insulators and structural materials is broad and includes use as room insulators; hightemperature insulators; fire proof materials; loose, free-flowing building shells; low-density structural fillers; plastic fillers for density control; and uniformwall, closed-cell foams. Potentially, aerospheres may also be used as inert supports (catalysts, molecular sieves) and encapsulants for biological culturing.

The thin-walled hollow spheres are blown by a coaxial nozzle using highly volatile powder slurries. These liquid spheres are then dried in an updraft tower and subsequently fired to $1600^{\circ} \mathrm{C}$ to produce low-density, impervious shells. The thermal conductivity of these shells has been measured to be as low as 0.13 watts per meter-kelvin, and the production cost may be reduced with novel processing (under development) to approximately $50 \notin$ per pound (compared with fiberglass fabrication costs at $45 \notin$ per pound).

This innovative concept was used successfully to produce spheres from alumina, partially stabilized zirconia, ferrite, and Kaolin clay powder slurries. In addition to the flexibility of using different materials, this process allows the uniformity, density, and quality of the spheres to be controlled during their production. Spheres of high specific strength and viable thermal conductivity can be produced economically.

Modeling studies are under way to characterize the apparent thermal conductivity of beds of thin-walled, hollow ceramic spheres and to assess their energyconserving potential. These studies will provide predictive models for property dependence on gas, gas pressure, temperature, sphere material, and sphere size. A data base will be developed to predict the behavior of new materials used for hollow-sphere processing. Development was expanded to include spheres composed of mullite, silicon carbide, silicon nitride, titanates, and metals.

Further development and characterization of these novel spherical insulators will yield alternative materials that are economical to produce and that have outstanding insulating properties. It is expected that these new insulators will have broad industrial and residential application. 


\section{Miami District Cooling Project}

Hospitals in the Civic Center Hospital Complex in Miami, Florida, sought to link their primary, chilledwater plants through a common underground distribution system. This concept offered the energy savings associated with district cooling systems without the high capital costs of installing new, centralized equipment.

With a grant from DOE, a feasibility study for the Hospital Chilled-Water Loop Assessment-Miami District Cooling Project was conducted jointly by the Burns and Roe Company and the Joseph Technology Corporation. When a comparison was made between total electric consumption under the current operating conditions and the district cooling alternative, the integrated loop realized a savings of about $15 \%$.

The capital cost of new piping and mechanical room retrofits will be about $\$ 3.5$ million. However, this cost will be recovered in only six years through energy savings and reduced operation and maintenance costs.

\section{Federal Methanol Fleet}

DOE sponsored a variety of alternative-fuel research initiatives designed to reduce dependency on imported petroleum and simultaneously offer environmental benefits. The Federal Methanol Fleet was established in 1985 to demonstrate the technological feasibility of methanol-fueled vehicles. The program is designed to compare the performance of these vehicles with gasoline-fueled vehicles in areas such as fuel economy, emissions, vehicle safety, and operation and maintenance costs.

The Federal Methanol Fleet of 39 vehicles (20 methanol-and 19 gasoline-fueled vehicles) is now being tested at the Lawrence Berkeley Laboratory, the Argonne National Laboratory, and Oak Ridge National Laboratory. All the methanol vehicles are gasoline vehicles retrofitted to operate on fuel methanol (a mixture of $85 \%$ methanol and 15\% unleaded gasoline). During three years of successful program operation, fleet vehicles have logged more than 700,000 miles. Performance of the vehicles has been virtually trouble-free, although energy consumption by the methanol-fueled cars was slightly higher than that of the gasoline-fueled vehicles because of different driving cycles. Ratings by drivers have been very similar for the two types of fuel, and maintenance statistics also compare well.

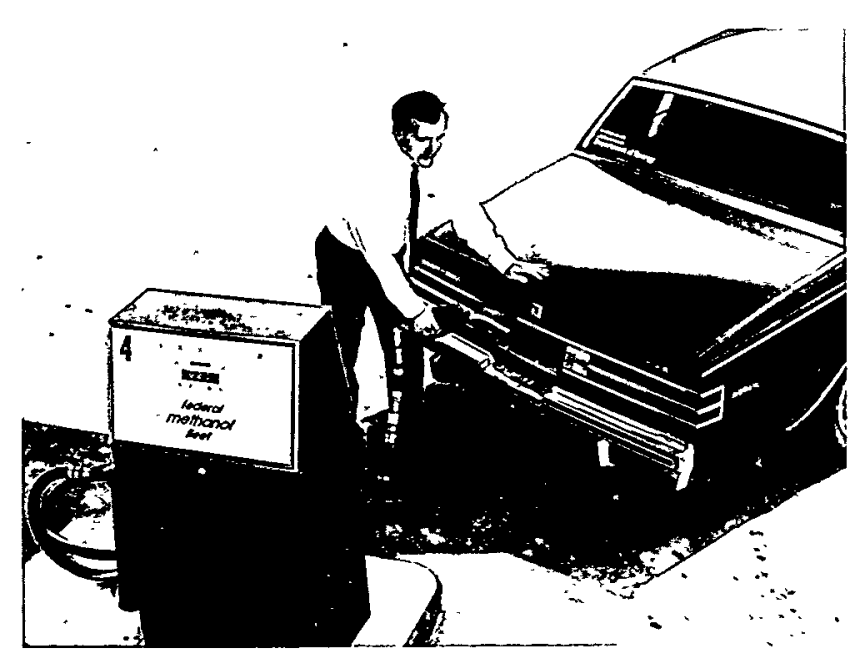

The Federal Methanol Fleet project manager refuels one of the vehicles at the Oak Ridge fleet site, one of three sites in the project.

The project is viewed as highly successful in increasing prospects for the transfer of methanol-fueled vehicles into the civilian fleet and in demonstrating methanol as a viable substitute for imported petroleum products.

\section{Methanol Marathon}

DOE, in cooperation with the Society of Automotive Engineers and other industry sponsors, has an ongoing program that sponsors student competitions to engineer and race methanol-fueled vehicles. The 1989 Methanol Marathon was held to foster student interest in the use of alternative fuels. Student teams from 15 competing engineering schools converted new Chevrolet Corsicas, donated by General Motors, to run on a blend of $85 \%$ methanol and $15 \%$ gasoline. The competition included static tests and a 1100-mile road rally from Detroit, Michigan, to Washington, D.C. Students from the University of Tennessee won the competition. The winner's trophy and $\$ 6,000$ in prize money were awarded during a ceremony at the U.S. Capitol. The winning car averaged 36.7 miles per gallon (gasoline equivalent), representing a substantial improvement over the fuel economy normally achieved by gasoline-fueled cars.

As a result of the competition, more than 200 engineering students became more knowledgeable about an alternative transportation fuel, and national attention was focused on the potential of alternative fuels to reduce U.S. dependence on imported petroleum. 


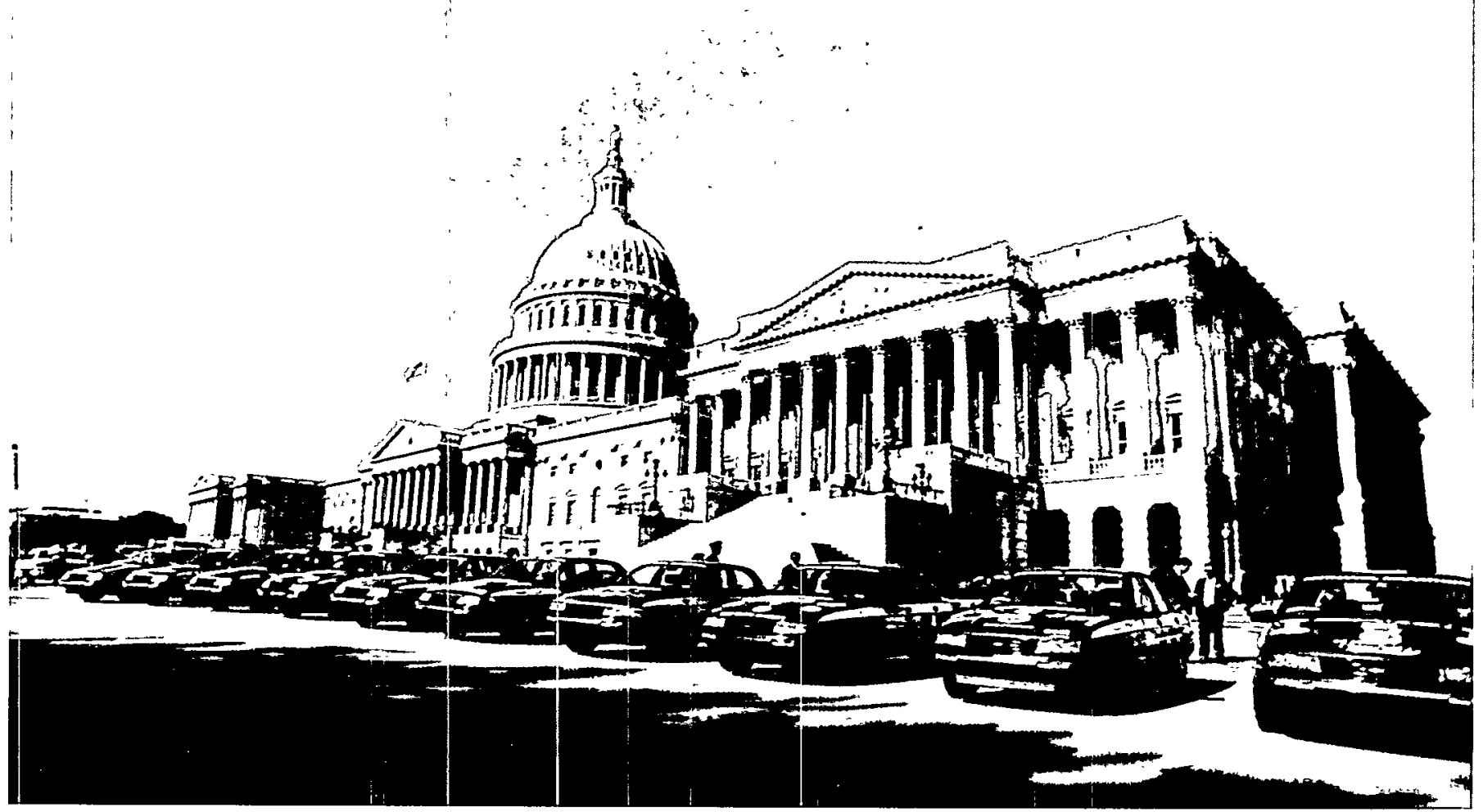

The 1989 Methanol Marathon, jointly sponsored by the Society of Automotive Engineers and DOE, was run from Detroit, Michigan, to Waslington, D.C.

\section{High-Temperature Liquid Lubricants}

Lubricating oils that perform effectively in the harsh environments of high-temperature processes are considered major advances. The high-temperature liquid lubricants being developed under DOE's Heavy Duty Transport Technology Program will enable top ring reversal temperatures to be increased to nearly $500^{\circ} \mathrm{C}$, more than double the capability of conventional lubricating oils. The new lubricants could also dramatically reduce particulate emissions; this is an important characteristic because recent data indicate that $30 \%$ to $60 \%$ of particulate emissions emanate from the lubricating oils currently in use. The new synthetic lubricant is being developed with an additive to decompose the oil cleanly, forming less soot and emitting fewer particulates. The new lubricants also have lower ash formation, which should reduce engine wear and emissions. Finally, the new oil allows engine operation in a temperature range three times that of conventional oils. Laboratory formulation of the lubricants was completed and engine testing began in late 1989.

\section{Spark Plug Instrumented with Fiber Optics}

Currently, there are about 130 million vehicles with internal combustion engines on U.S. highways, consuming about 20 quads of fuel annually at efficiencies ranging from $19 \%$ to $26 \%$. Given this magnitude of fuel consumption, even modest improvements in the efficiency of these engines could yield considerable energy savings. Understanding the physical and chemical processes that control combustion is critical to improving the fuel efficiency and environmental acceptability of gasoline and diesel engines.

A critical issue in the development of fuel-efficient engines is the characterization of the dynamics of flame growth and the mechanical behavior of fluids. Rough idling, for example, can be influenced by cyclic fluid variability on flame development in the 


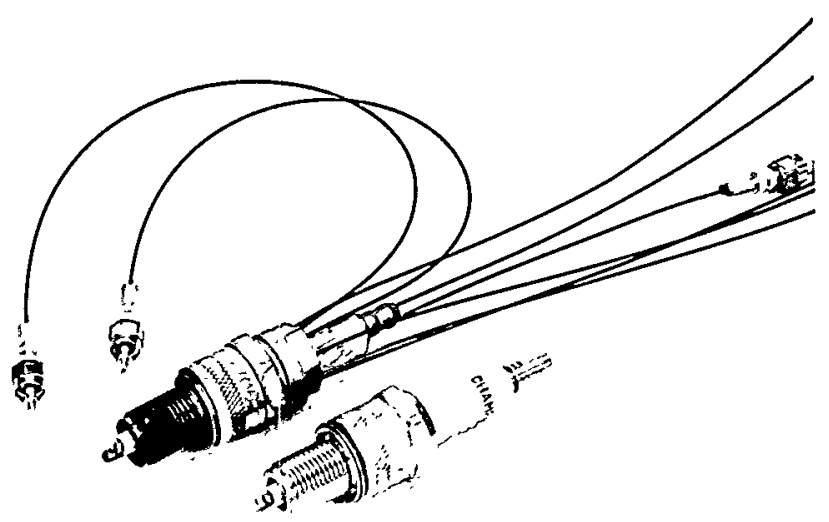

A spark plug instrumented with fiber optics enables researchers to observe combustion events inside production engines.

engine combustion chamber. The laser-based measurement techniques currently used to characterize flame growth, such as laser Doppler velocimetry, require installing optical windows, which may perturb the flow being analyzed and provide inaccurate results.

DOE funded the development of a spark plug, instrumented with fiber optics, to observe flame propagation in the combustion chamber of standard automotive engines. The spark plug may be installed in place of the regular spark plug to make measurements without modifying engine geometry or operating conditions. It was tested in both a research and a production (Chrysler) engine. Flame development measurements obtained for eight successive engine cycles showed the flame to be more asymmetric than expected in currently engineered designs. Research will continue into understanding the effects of this asymmetry on swirl and turbulence intensity by studying polar velocity plots.

The development of this new spark plug as a fundamental measuring tool generated considerable enthusiasm in the auto industry. Chrysler Corporation, which has followed its development since the beginning, is scheduled to conduct more extensive demonstrations in the near future. General Motors and the Ford Motor Company requested complete data and design details. Results of the work were presented at the 1988 Society of Automotive Engineers' International Fuels and Lubricants Meeting.

\section{High-Temperature Materials Laboratory}

DOE's High-Temperature Materials Laboratory at the Oak Ridge National Laboratory completed its first full year of operation during 1989. The laboratory serves as a focal point for multidisciplinary research on new ceramics and metal alloys that show potential for high-temperature applications. Research at the materials laboratory is designed to help solve hightemperature materials problems that now limit the efficiency and reliability of advanced energyconversion systems.

The materials laboratory is a DOE User Facility and provides easy access to users from industry and academia. The laboratory operates four User Centers: Materials Analysis, X-Ray Diffraction, Physical Properties, and Mechanical Properties. Investments in instrumentation for the User Centers represent about $\$ 6.5$ million, or $34 \%$ of the total appropriations (\$19.1 million) for the facility.

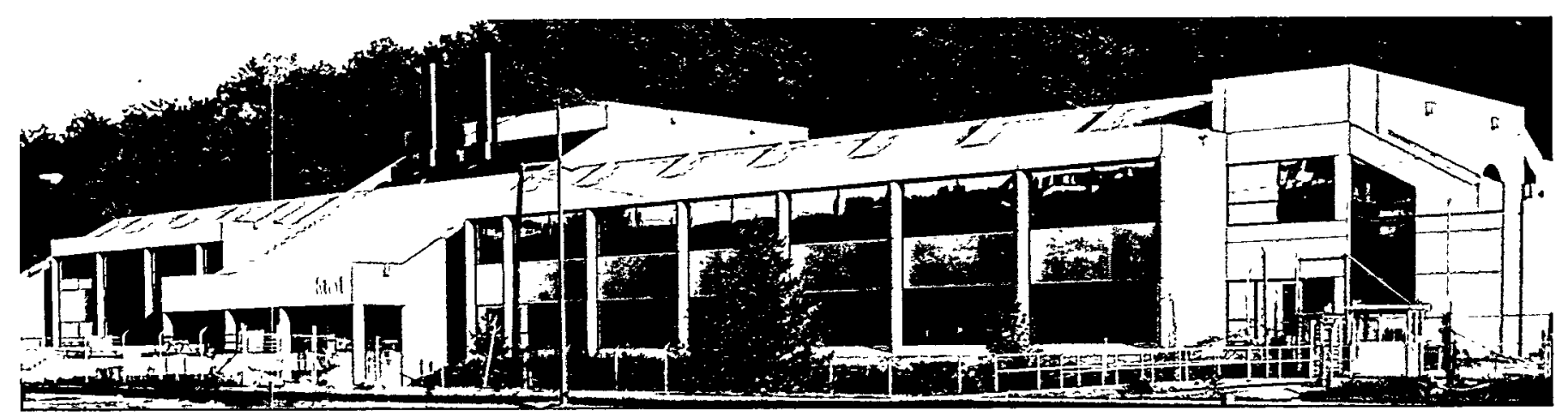

DOE's High-Temperature Materials Laboratory offers state-of-the-art facilities for multidisciplinary research on new ceramics and alloys for high-temperature applications. 
Since the materials laboratory became operational in June 1987, it has generated considerable interest within industry. The amount of user research carried out in the four User Centers has steadily increased since the first user agreement was signed in July 1987. By September 30, 1989, 27 universities, 24 industrial companies, and 3 government facilities had signed agreements to use the facility.

In August 1989, Coors Ceramics Co., the nation's largest producer of precision technical ceramics, announced its decision to build a ceramics production plant in Oak Ridge, Tennessee. Proximity to the High-Temperature Materials Laboratory and to the technology transfer opportunities from DOE's ceramic technology programs at the Oak Ridge National Laboratory were cited as major factors in Coors' decision to locate in the area.

\section{Gel Casting}

A method was needed to form ceramic materials into complex shapes at a high rate of production but at a relatively low cost. DOE research carried out under the Advanced Materials Development Program led to the novel method of gel-casting ceramic powders. This method overcomes the shortcomings of injection molding by separating the mold-filling operation from the setting operation. A water-based vehicle is used instead of a $100 \%$ wax- or polymer-based vehicle. The method also uses a new setting mechanism that is different from current practice. The outcome of this fast and economical technique is predictable, allowing product dimensions to be closely controlled.

The successful production of tensile and other alumina oxide ceramic specimens demonstrated the potential for gel-casting technology. Collaborative research agreements are being initiated to develop this technique for processing high-performance silicon nitride. The gel-casting process for other ceramics has already been licensed to a major U.S. ceramics manufacturer.

\section{Silicon Nitride Powder}

New engine technologies will rely upon ceramic engine parts that are lightweight, extend the life of engines (particularly car engines), and promote energy efficiency. Reliable and cost-effective ceramic components for these advanced engines are a major focus of DOE's Advanced Materials Development Program research. To date, their application has been limited by the inability to produce large volumes of quality material. Efforts within the program have focused on improving ceramics processing techniques. Recently, DOE-supported research has led to the development of a patented technique for producing high-quality silicon nitride powder for ceramic components. The process is based on the lowtemperature reduction of silicon chloride with ammonia.

A pilot plant has been designed for this process and discussions held with several chemical companies regarding potential technology licensing for domestic production.

\section{Microwave Processing of Ceramic Materials}

DOE has funded research to demonstrate the benefits of microwave processing of ceramic materials such as alumina. This technique has potential to facilitate fabrication of near-net-shaped components with the same properties as those produced using the conventional hot-pressed method. Microwave processing, by using pressureless sintering at lower temperatures, has the potential to save energy and reduce process cycle time through uniform, rapid heating of large shapes. The cost-reducing advantages of the increased throughput made possible by microwave processing include decreased operating inventories and increased manufacturing capacity. By lowering sintering temperatures and using selective coupling techniques, a whole new range of microstructures could potentially be created.

Sintering and microstructural studies on alumina showed that at 28 gigahertz, well beyond the normal commercially used frequency, large pieces of highpurity alumina can be uniformly heated and sintered. Densification of the material heated in the microwave field was significantly more rapid than that exhibited during conventional infrared processes. The apparent activation energy required for the microwave sintering process was also shown to be much lower than that required in current processing techniques. Together, these two factors indicate the enormous industrial potential of microwave sintering in terms of greater throughput with less energy required.

There are numerous applications for microwave sintering and heat treating, including electrical ceramics (varistors, capacitors, integrated-circuit substrates), parts subject to friction and wear, catalyst 
materials, and others. A technology transfer program is being established with the industrial sector.

\section{Advanced Inverter Technology}

Vehicles that run on electricity are attractive transportation options because they minimize pollution and conserve liquid fuels. As part of DOE's efforts to improve these vehicles, research carried out under DOE's Electric Vehicle Propulsion System Technology Program has led to the introduction of an advanced inverter technology. The new inverter, developed in support of DOE's ETX-II R\&D Program for vehicle propulsion applications, is greatly reduced in size and weight. Two technological advances central to the development of the advanced inverter are the metal-oxide semiconductor-controlled thyristor power switch and high-voltage multilayer capacitors. These technologies give the inverter greater power efficiency and better thermal management, while reducing capacitor volume and heat loss.

The inverter technology and design concepts used in DOE's ETX-II Program led to the development of an inverter and control system for a diesel/electric drive motor for the radiator cooling fan. This system is being used to regulate the cooling fan speed to maintain optimum engine operating temperature on commercial diesel/electric locomotives.

\section{Battery Combustion-Attenuation Material}

All batteries based on aqueous systems emit hydrogen and oxygen, combustible gases that could cause the battery case to rupture if the gases were to ignite. Under DOE's Electric and Hybrid Vehicle Testing and Evaluation Program, research has led to the development of an inexpensive device to manage the combustible gases emitted from electric vehicle batteries. Specifically, researchers designed a combustionattenuation material for both basic and acidic electrolyte batteries; it acts by filling the open volume or headspace of the battery, preventing the battery case from rupturing if the gases within the battery cells should ignite during charging or operation of an electric vehicle. This device was tested with nickeliron battery modules, which produce more gases than most batteries, and demonstrated a clear reduction in the level of risk of or damage from the ignition of combustible gases.
This technology was patented and incorporated into the nickel-iron battery packs being designed for the dual-shaft electric propulsion system. The first commercial orders for batteries equipped with the combustion-attenuation materials have been placed for sealed lead-acid batteries to be used in emergency stand-by power generation equipment.

\section{Hyperfiltration of Food}

Concentration of liquids, particularly concentration of fruit and vegetable juices, is one of the most energyintensive steps in the food-processing industry. Almost all concentrated juice made in the United States is produced using some type of evaporation process during which water is removed from singlestrength juice to yield a product consisting of $50 \%$ to $70 \%$ solid material. Membrane technology is also used to concentrate juices, using semipermeable membranes to separate water from the solution. This technology offers good potential for saving energy.

DOE funded an investigation by the National Food Processors Association into applying hightemperature hyperfiltration to food processing. The study focused on the use of thin-film composites, a new class of membrane with several advantages over standard cellulose acetate membranes. These new membranes can withstand higher temperatures, operate within a wider $\mathrm{pH}$ range, and have increased resistance to biological degradation. Membranes were tested using several configurations in selected hightemperature food-processing streams to characterize membrane performance as a function of time. A prototype unit for tomato juice concentration was built and tested successfully at a commercial host site.

\section{PET Bottle Separator}

The increased use of plastics in recent decades has resulted in increased levels of plastic wastes at both the consumer level and the producer/fabricator level. Recycling efforts are complicated because different types of plastic wastes must be separated from one another before further processing can occur. The nature of plastics makes such separation a difficult procedure. For example, selective incineration is hampered by the thermal degradation of plastics at high temperatures, and flotation techniques cannot be used because of the narrow range of densities in plastics. 
As part of a larger project to convert certain waste plastics to fuel oil, DOE and the Procedyne Corporation developed an innovative combination of separation processes for recycling PET (polyethylene terephthalate) beverage bottles. At a demonstration plant set up to use the processes, approximately 20 million pounds of bottles and cans were sorted for recycling according to those made of PET, highdensity polyethylene, or aluminum. The separator is currently being used at a Pepsi plant, where it is recycling 12 to 18 million pounds of PET annually. The energy savings associated with the recycling of waste plastics using the new separation technology are expected to reach 13.8 trillion Btus annually by 2010.

\section{Biodegradable Plastics}

The use of plastics has become a significant ecological problem as landfills become overwhelmed and plastic debris continues to pollute the environment. DOEsupported research shows that conventional materials can be used to make plastics that break down in a few years through biochemical mechanisms after exposure to soil and water. The new technology grafts polystyrene onto starch or cellulose. The process may provide the means to recycle items such as garbage bags, styrofoam cups, and milk containers, which currently end up as nondegradable trash.

Emulsifiers are used to allow the polystyrene to attach as a sidechain to the starch or cellulose backbone. The resulting copolymer has as much as $40 \%$ to $50 \%$ cornstarch or cellulose distributed throughout the plastic, compared with less than $10 \%$ in current commercial products. Microorganisms naturally present in the environment feed on the starches, degrading the polymer within a few years. The approach offers some versatility because different types of plastic polymers can be grafted to the starch or cellulose backbone.

The manufacturing rights are expected to be sold soon for applications of the new biodegradable materials to fast-food packaging and garbage bags.

\section{Bioreactions in Nonaqueous Media}

The efficient use of protein biocatalysts (enzymes) generally requires an aqueous environment, which is a poor medium for most industrial chemical processes. Many viable enzyme catalysts are only slightly soluble in water, creating mass-transfer limitations and low-productivity processes. In addition, the end products of many enzyme-catalyzed reactions polymerize in water, causing a decrease in biocatalyst activity, which results in low product concentrations. Furthermore, these processes often require the use of aqueous separation systems that are capital- and energy-intensive.

DOE is currently supporting research to overcome these problems and enhance the potential of biocatalysts to produce commodity chemicals. One such effort is the development of new methods for enzymatic oxidative catalysis in organic solvents. Such methods are needed for a variety of chemical processes, including the selective oxidation of aromatic compounds to form hydroxylated products and the peroxidase-catalyzed depolymerization of lignins.

The enzyme polyphenol oxidase has great potential for selective hydroxylation but cannot be used in an aqueous medium because of its low water solubility and the tendency of its products to spontaneously polymerize in water, which causes the catalyst to be modified and deactivated. Research shows that polyphenol oxidase in a p-cresol/chloroform solvent successfully catalyzes the formulation of hydroxylated quinone at yields of $80 \%$. The same reaction in an aqueous medium produces a yield of only $3 \%$ because of the formation of intractable polymers.

Scientists have also carried out peroxidase-catalyzed depolymerization of synthetic lignin in organic solvents. This process could potentially produce useful chemicals of low molecular weight from lignin or lignin waste products economically.

Two inventions developed from this work have been licensed for use in the commercial sector. Both use the enzymes as sensors.

\section{Dew-Point Hygrometer}

Drying operations represent approximately $5 \%$ of the total energy requirements for the U.S. industrial sector, and this energy is lost mainly through dryer exhaust gas. If optimum conditions are maintained in the exhaust gas systems through the use of sensors and controls that continuously monitor the humidity and temperature of the exhaust gas, dryer energy consumption can be minimized. However, existing sensors are often unsuitable for continuous use in many common industrial drying processes because of the high temperatures and contamination encountered. 


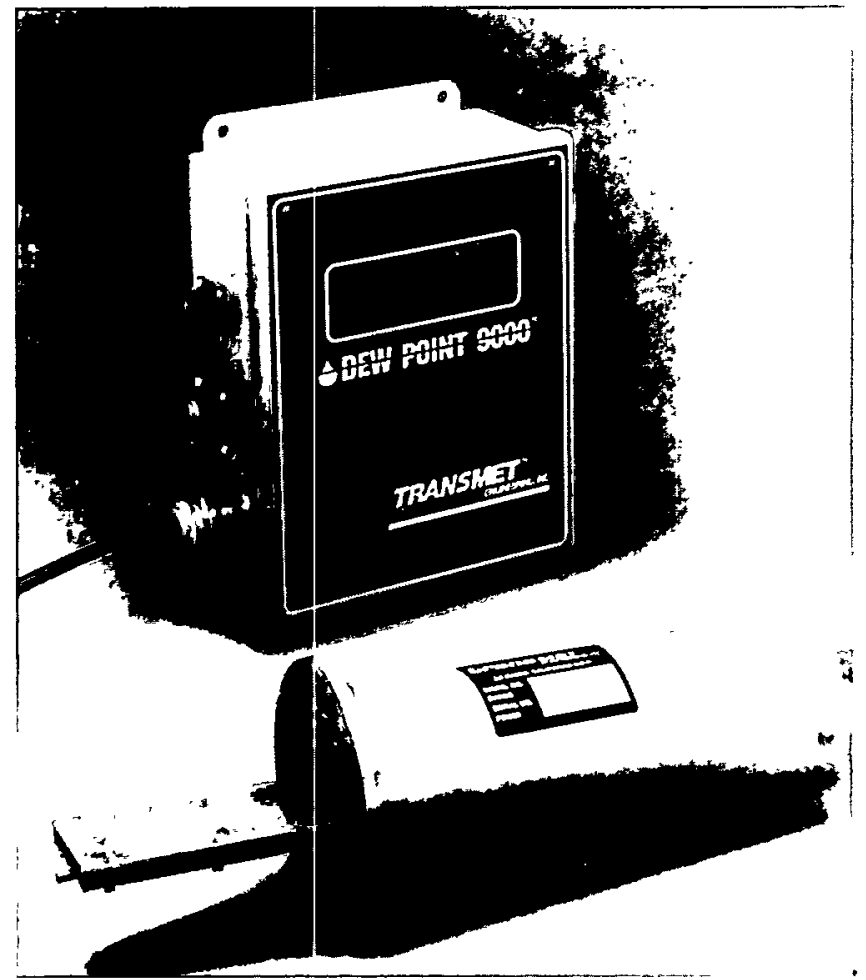

The dew-point hygrometer can withstand harsh industrial-dryer exhaust gases.

One sensor capable of withstanding these types of conditions is the heat-flux dew-point hygrometer, developed by Trans-Met Engineering with funding from DOE. This hygrometer is insensitive to dust and grease and can operate in temperatures up to $500^{\circ} \mathrm{F}$ and in relative humidities between $50 \%$ and $100 \%$.

A prototype unit of the new sensor was successfully tested at a textile mill. The hygrometer was subsequently commercialized and is being used in the food processing, pulp and paper, chemical, cement, and textile industries. Energy savings associated with this sensor are projected to be 10.5 trillion Btus in 2010.

\section{Optical Humidity Sensor}

The pulp and paper industry has long recognized the value of accurate humidity measurements during drying operations to optimize process control and minimize energy consumption. Although many types of humidity sensors were developed, they experienced reliability problems during operation in mill atmospheres.
With DOE support, Spectral Sciences and Pacer Systems developed a new hygrometer that determines humidity by measuring the absorption of ultraviolet light. Because the absorption of ultraviolet light is a property of the water vapor in the medium (air or process gas), the optical elements of the sensor can be kept from direct contact with the medium, protecting the sensor from contamination.

The primary applications of humidity measurement in the pulp and paper industry are to control the drying of paper and paperboard. The new hygrometer can be used as a feedback device in the control of a dryer loop, helping to maximize drying efficiency by optimizing the balance of exhausted air and makeup air. Achieving this balance results in energy savings and improved product quality.

After successful field testing, the hygrometer was commercialized and is installed in several pulp and paper mills. The sensor also has applications in the textile, food, and other industries. Energy savings in 2010 are projected to be 17.3 trillion Btus.

\section{Rapid Solidification of Metals}

The future of many high-efficiency energy systems depends on the development of metallic alloys that possess properties at high temperature beyond those that can be obtained from conventional processes. DOE-supported research shows that alloys with

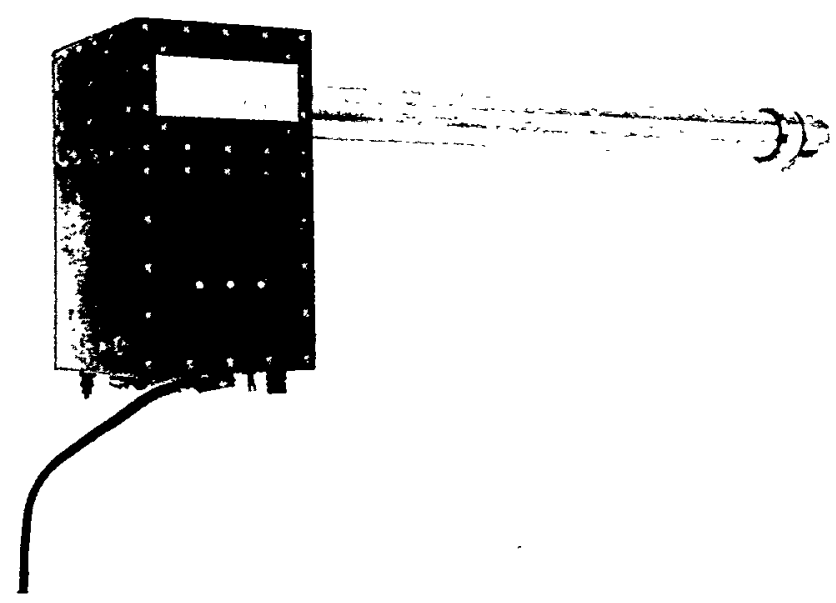

The optical humidity sensor uses ultraviolet light to measure humidity in industrial drying applications with temperatures of up to $950^{\circ} \mathrm{F}$. 
superior high-temperature properties can be developed through rapid cooling and gas supersaturation.

To achieve rapid solidification (at rates up to a million times faster than solidification of conventional ingots), a gas stream is used to impact and break up a stream of molten metal into fine droplets. The repetitive process produces a high concentration of atomic vacancies, which would normally anneal out of the alloy at high temperatures. The dissolved gas entrapped during rapid solidification stabilizes the vacancies in clusters, which then serve as sites for fine precipitates to form and strengthen the alloy.

Researchers have seen a 60-fold increase in the service life of austenitic stainless steels processed by this technique. Atomistic calculations were developed that accurately predict the experimentally measured solubility of inert gas in nickel. These calculations explain the evolution of the entrapped gas and produced microvoids, which may help engineers to develop new alloys and processing techniques.

This novel processing technology will have a significant effect on the advancement of more efficient energy systems through stronger, lighter alloys with longer lifetimes. The concept, which received an $R \& D$ 100 Award in 1988, also shows promise for processing iron, aluminum, nickel, and other metal-based alloys.

\section{A Computerized Tribology Information System (ACTIS)}

A significant portion of the energy used in mechanical operations is lost through friction, wear, and poor lubrication of moving parts. Tribology, the study of friction, wear, and lubrication, provides a basis for conserving energy by reducing energy losses.

Tribology research is interdisciplinary and involves lubricant chemistry, surface science and topography, interface contact, elastohydrodynamics, and mechanics. The incorporation of advances in tribology into engineering practice has been slow because of the cross-disciplinary nature of tribology research. In addition, the diversity of data often makes it difficult for engineers and scientists to locate information on advances in tribology that might help solve critical engineering problems.

DOE is trying to address this need through ACTIS. The system will facilitate validation of experimental results by tribology experts, keep researchers continually updated on new research results, serve as a clearinghouse of tribological news or research breakthroughs, and provide a central location for information on research in progress and tribological products.

The DOE Tribology Program has provided seed funding for developing ACTIS to make available to tribology researchers a broad range of data, design codes, abstracts, and bibliographies of research in progress. ACTIS is designed to allow users to access any data base through a main menu or through an interface that connects the data bases. For example, users of the design data base may require numeric data for a particular code, which they can then access in the proper format through the appropriate interface. The National Institute of Standards and Technology has taken a lead role in directing the development and management of the system. Other participants supporting the project include the U.S. Army, the U.S. Air Force, the American Society of Lubrication Engineers, the American Society of Mechanical Engineers, and several industries.

The system is now in the commercialization phase and will be available to the tribology community as IBM (or compatible) personal computer software. Revenues generated through the use of ACTIS by participating industrial sponsors and proceeds from sales of design codes will be used to support and maintain the ACTIS program. 


\section{Ongoing}

\section{Stories \\ in the Buildings Sector}

18 .....High-Efficiency Refrigerator Compressor Supermarket Refrigeration Systems

19 ....Appliance Efficiency Test Procedures Solid-State Ballast for Fluorescent Lighting Surface Wave Lamp

Low-Emissivity Window Coating

20 ....Ground-coupled Heat Pumps

Flame-Retention Oil Burner

21 ....Radiant Barriers for Single-Family Housing

Measurement Device for Thermal Resistance of Insulation District Heating and Cooling Development

22 ....District Heating and Cooling Development: Kent County, Michigan

Acoustic Leak Detection System

Infiltration Model

DOE-2

23 ....Program for the Energy Analysis of Residences Solar-5

WINDOW Computer Program

A Simplified Energy Analysis Method

24 ....Computer-based Conservation Standards for New Federal Residential Buildings

Indoor Air Qualify Field Studies Data Base

25 ....Building Foundation Design Manual

Single-family Retrofit Research and Technology Transfer Program

Energy Institutes

26 ....City-wide Energy Conservation: Phoenix, Arizona 


\section{Ongoing Success Stories in the Buildings Sector}

Commercial and residential buildings consumed 29.6 quads of energy in 1989 , about $36 \%$ of the primary energy used in the United States. Moreover, energy consumption in the buildings sector is growing rapidly; by 2010, it may exceed 40 quads annually. A national effort to conserve energy in this sector during the next 20 years could save up to $30 \%$ of this total or 12 quads - worth almost $\$ 74$ billion per year (in 1988 dollars).

To help realize this enormous potential for energy savings, the Office of Conservation and Renewable Energy is supporting research on five key building systems: building envelopes, building equipment, indoor air quality, lighting, and design and construction systems. In addition, DOE encourages community energy management and supports research on the centralized production and distribution of heating and cooling systems.

\section{High-Efficiency Refrigerator Compressor}

Household refrigerators consume about $12 \%$ of the primary energy used in the residential sector. In an effort to reduce this consumption, DOE supported research by the Kelvinator Company to develop a more efficient refrigerator compressor. Through design changes in the refrigerator motor and suction muffler, Kelvinator achieved a $44 \%$ improvement in efficiency over conventional refrigerator compressors. Kelvinator now has manufactured more than 30,000 refrigerators with this high-efficiency compressor.

Based on the success of the compressor design, Kelvinator introduced a more advanced compressor, the industry's first to be rated at more than 5 Btus per watt-hour. Kelvinator's (now called Americold) compressors are the industry's most efficient and are currently being offered to other refrigerator manufacturers. Full market penetration of high-efficiency compressors in household refrigerators would produce energy savings estimated at about 0.21 quad per year by 2010 .

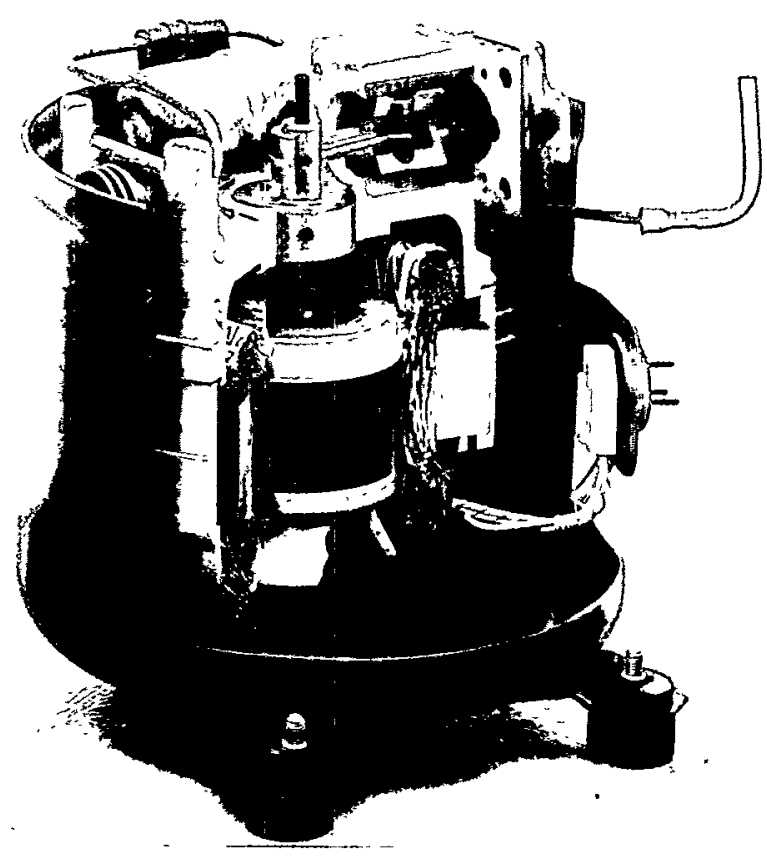

This high-efficiency refrigerator compressor was developed by $D O E$ and the Kelvinator Company.

\section{Supermarket Refrigeration Systems}

Supermarkets consume about $4 \%$ of the nation's electricity, much of which is used in refrigerated display cases. To reduce this energy consumption, DOE and a leading manufacturer of supermarket refrigeration equipment developed an innovative design, featuring multiple parallel compressors and advanced microprocessor controls, that reduces the energy consumed by more than $40 \%$.

As a result of this DOE research, all leading manufacturers now offer advanced refrigeration systems with multiple, unequal, parallel compressors. Such systems accounted for $25 \%$ of the market for supermarket refrigeration equipment in 1987. Advanced supermarket refrigeration systems are expected to save between 0.25 and 0.37 quad of primary energy annually by 2000 . 


\section{Appliance Efficiency Test Procedures}

Legislation passed in 1975 and amended in 1987 and 1988 requires DOE to develop standard test procedures to measure accurately the energy consumption and efficiency of 12 categories of major household appliances. Since the testing and labeling program began, the average energy efficiency of new major appliances has increased significantly. As consumers reject less efficient models with higher operating costs, manufacturers are producing new designs that are up to $50 \%$ more energy efficient than older models. Four national trade and professional associations representing manufacturers of major appliances have adopted the DOE appliance test procedures in their own industry guidelines and product certification programs.

\section{Solid-State Ballast for Fluorescent Lighting}

Although the theoretical output limit for a luminous light source is more than 350 lumens per watt, standard fluorescent lamps generate less than 70 lumens per watt. This inefficiency in standard lighting stimulated DOE to initiate a research program to improve the performance of fluorescent lamps.

The program initially focused on the potential of solid-state ballasts to power fluorescent lamps at higher frequencies. Working with two small contractors, DOE developed and tested prototypes of solidstate ballasts that improved lighting efficiency by $25 \%$. As a result of DOE-sponsored demonstrations of the benefits of solid-state ballasts in several office buildings, several major lighting manufacturers were convinced to adopt this energy-saving technology in their product lines. Today, more than 2 million solidstate ballasts are being used in U.S. buildings, saving more than 200 million kilowatt hours of electricity annually. Solid-state ballasts, currently installed in fewer than $3 \%$ of fluorescent fixtures in the United States, are expected to achieve a $50 \%$ market penetration by 1995 .

\section{Surface Wave Lamp}

In 1980, DOE began a program directed at improving the efficiency of converting electrical energy to useful light. DOE research indicated that fluorescent lamp efficiency was limited by self-absorption of ultraviolet radiation within the lamp's plasma and by the

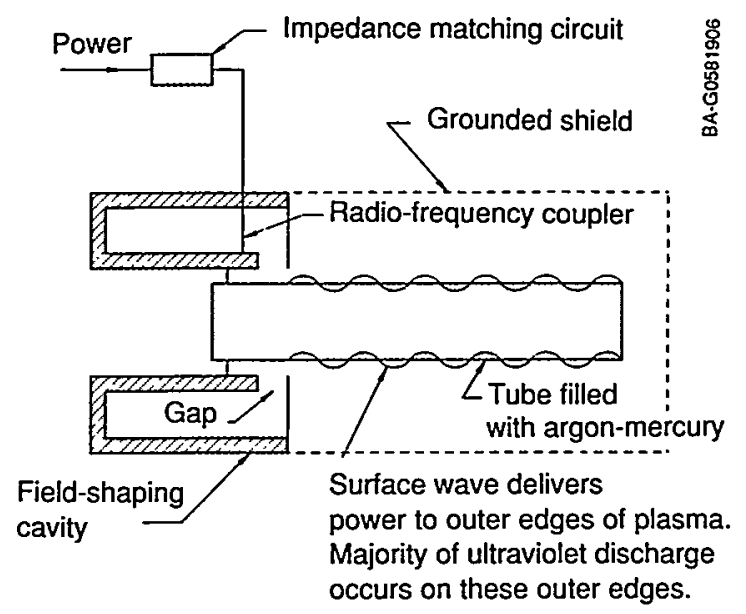

Surface wave lamps promise a $50 \%$ reduction in energy use and more than 40,000 hours of lamp life.

efficiency of the lamp's phosphor in converting ultraviolet radiation into visible light. Several techniques to improve efficacy, including exciting fluorescent lamps using very high (gigahertz) frequencies, were explored. Unlike lower frequency lamp excitation, which concentrates ultraviolet radiation generation in the fluorescent lamp's center, very high frequency excitation using surface waves creates greater ultraviolet generation close to the lamp's outer walls. Test results of surface wave lamps revealed a $40 \%$ efficiency improvement over conventional fluorescent lamps. When fully developed, this concept is expected to reduce by $50 \%$ the electrical energy requirements for fluorescent lighting and to improve lamp life to more than 40,000 hours.

\section{Low-Emissivity Window Coating}

In response to the energy crises of the early and mid1970s, DOE initiated a research program to identify innovative energy-saving technologies that could be applied to commercial and residential buildings. As part of this program, scientists determined long-wave infrared radiation through windows to be a major source of energy loss in buildings. Low-emissivity (low-E) glass coatings were known to reduce this problem, yet the window and glass industries were unable to commit sufficient research resources to solve numerous technological problems connected with these coatings. 


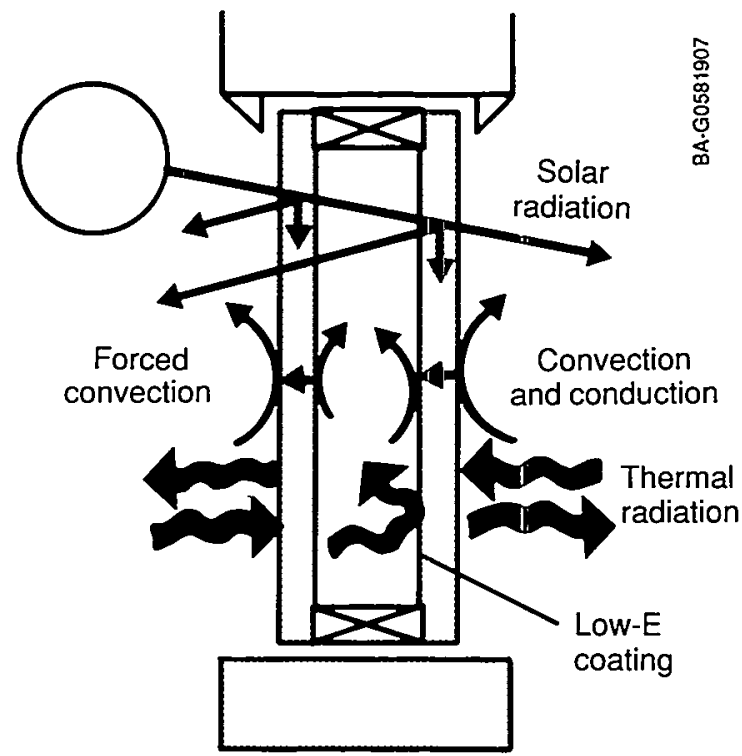

Low-emissivity coating reduces window heat loss resulting from radiation transfer.

Consequently, DOE sponsored a broad range of basic research on low-E coatings, including computer simulation of alternative window designs, creation of coating test facilities, and technology transfer programs to disseminate results. DOE's investment in low-E technology research directly stimulated the glass and window industries to invest heavily in advanced coating technology. Low-E windows became commercially available in 1983; and in 1986, 20 manufacturers sold more than 50 million square feet of low-E windows, representing almost $10 \%$ of all residential window sales. By 1992, more than $50 \%$ of all residential window sales should be low-E windows, and the cumulative value of energy savings should reach $\$ 1$ billion.

\section{Ground-coupled Heat Pumps}

About one-third of new homes are heated and cooled by air-source heat pumps. Because ground-coupled heat pumps can save more than half of the energy used by air source heat pumps, DOE initiated a multifaceted R\&D program to develop an advanced ground-coupled heat pump. Analytic design tools were developed, tested, validated, and distributed to the private sector to assist manufacturers in designing more cost-effective ground-coiled heat exchangers and more efficient mechanical packages for the heat pump. These design tools were then used to develop a prototype system.
$\mathrm{DOE}$, a utility company, and a leading heat-pump manufacturer collaborated on the design, fabrication, and field evaluation of two experimental prototypes. The advanced systems improved the costeffectiveness of ground-coupled heat pumps by reducing the payback period from 6-10 years to 3-5 years. The participating utility company estimates that the improvements should increase sales of these heat pumps by about $60 \%$. Heat pumps using this advanced design will save approximately 0.32 quad by 2010 .

\section{Flame-Retention Oil Burner}

The high-efficiency flame-retention-head oil burner, although not a new technology, did not achieve substantial penetration of the oil heating market until DOE investigated its potential in the late 1970s. In a carefully controlled field test, DOE established the energy conservation benefit of this oil burner by studying retrofit options, including the use of the burner alone or in combination with other measures.

A second DOE effort communicated the findings of this research through distribution to the public of more than 70,000 copies of a consumer-oriented information booklet. This booklet covered the energy conservation aspects of flame-retention-head oil burners and other components of oil-fired heating systems. As a result of these efforts, the number of

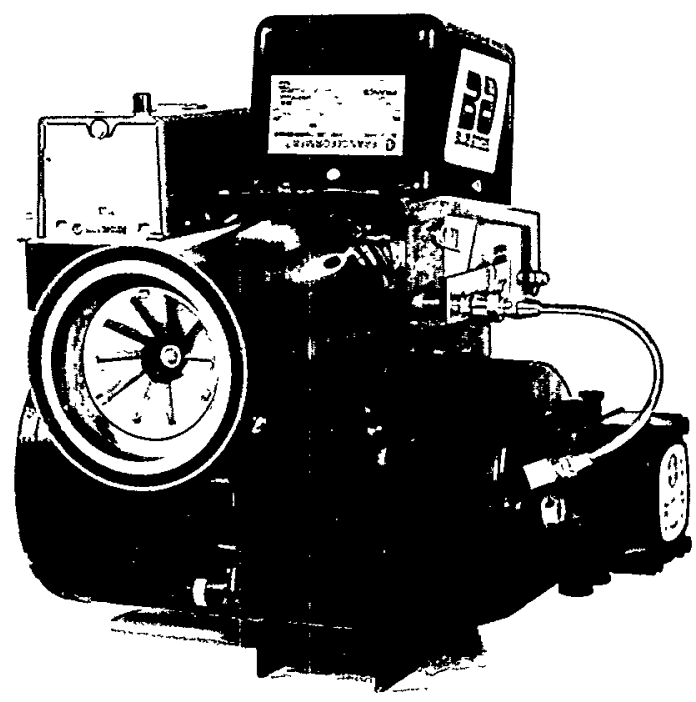

Consumer education efforts have boosted the popularity of energy-conserving flame-retention oil burners. 
flame-retention-head oil burners in use increased from 100,000 in 1979 to more than $4,200,000$ in 1989 , saving approximately 71 trillion Btus annually. The flame-retention-head oil burner is projected to save 0.155 quad annually by 2000 .

\section{Radiant Barriers for Single-Family Housing}

In single-family housing, $7 \%$ to $8 \%$ of winter heat loss and $17 \%$ to $20 \%$ of summer heat gain occur through attics. In a joint effort, DOE and the Tennessee Valley Authority performed field tests of a low-cost, easily installed aluminum foil product that promises significant reductions in attic heat transfer, and thus, savings in heating and cooling. The product's two reflective surfaces reduce the radiant component of heat transfer between the attic and the underside of the roof. Most homeowners can easily install this radiant barrier material over existing attic insulation.

Results of DOE tests of radiant barriers installed in three single-family homes in Tennessee indicate a reduction in cooling energy requirements by $17 \%$ and in heating energy requirements by $9 \%$. Assuming homeowner installation, radiant barriers produce a payback in energy savings in two years. Costeffective in hot climates, this product can save 0.17 quad per year in the South's 22 million homes. Its benefits are sufficient to make the radiant barrier also marketable in northern climates.

\section{Measurement Device for Thermal Resistance of Insulation}

The National Institute of Standards and Technology has conducted research on heat transfer through insulation for many years. Following the energy crises of the 1970s, thicker insulations (by several inches) were incorporated in many building designs. At that time, however, test methods to evaluate the properties of these thicker insulations did not exist.

In 1978-1979, the Federal Trade Commission proposed a plan to require manufacturers to label insulation material for thermal resistance and to base advertised thermal resistance values on product testing. Because precise measurement of the thermal resistance of thick, low-density insulation is difficult, DOE and the National Institute of Standards and Technology cosponsored the development of the one-meter line-source guarded hot plate to accurately measure insulation performance. This device is capable of measuring heat transfer in insulation up to 15 inches thick. The insulation industry was given calibration transfer specimens with which to measure and label its products. Accurate heat-transfer measurement eliminates the need to install insulation of excess thickness, thus reducing costs. In 1984, the U.S. Department of Commerce estimated that the improved measurement capability developed through this project saves consumers $\$ 90$ million annually.

\section{District Heating and Cooling Development}

Once prevalent in almost every metropolitan area in the northern United States, district heating and cooling systems have been almost completely replaced in today's cities by individual space conditioning systems that operate using oil or natural gas. Yet, the district systems have inherent advantages in terms of energy conservation and fuel substitution. Consequently, DOE embarked on a program of research, project demonstrations, and feasibility assessments in more than 50 communities to redevelop this concept. As a result, cogeneration/district heating systems have been constructed and are operating successfully at three large universities and in Trenton, New Jersey. Together, these four systems have saved the equivalent of several thousand barrels of oil annually through combined heat and electric power production.

Furthermore, DOE's feasibility assessments have formed a basis for subsequent design and development using local government and private sector funding. Thirteen cities are proceeding with detailed designs for constructing district heating and cooling systems. Cities with new district systems include Baltimore, Maryland; St. Paul, Minnesota; Galax, Virginia; Provo, Utah; Piqua, Ohio; and Lawrence, Massachusetts. Construction of these systems on college campuses has increased more than fivefold since 1950.

DOE's district heating and cooling development program currently yields energy savings of more than 5 trillion Btus per year nationwide and has produced more than $\$ 70$ million worth of construction activity. Net energy savings in the year 2000 are predicted to be 163 trillion Btus, equivalent to 28.1 million barrels of oil with a current value of more than $\$ 3$ billion. 


\section{District Heating and Cooling Development: Kent County, Michigan}

District heating and cooling systems can save substantial amounts of energy on a community-wide basis. When combined with a waste-to-energy facility, district heating has the added advantage of helping to solve one of the nation's most serious environmental problems-disposal of municipal solid waste.

In 1986, DOE provided Kent County, Michigan, with $\$ 50,000$ to assess the feasibility of a district heating/ cogeneration system. As a result of this study, Kent County constructed a 625 ton-per-day waste-toenergy cogeneration facility at a cost of about $\$ 62$ million. Kent County's state-of-the-art air pollution control system contains scrubbers and a baghouse. These bags trap particles and prevent them from being emitted into the atmosphere. Their use is expected to remove $99.8 \%$ of total particulate mass and more than $99 \%$ of the smaller particles.

The facility will serve six communities with a total population of approximately 320,000 , including Grand Rapids, Michigan. The system will deliver approximately 115,000 pounds of steam per hour to the county-owned district heating loop and generate 14 megawatts of electricity to be sold to a local power company. Revenue from tipping fees is estimated at approximately $\$ 38$ per ton. The project serves as an example of how a community government can develop a community energy system to provide an alternative to the use of oil or gas.

\section{Acoustic Leak Detection System}

Many industries use pipelines to carry steam, water, gas, and oil. The costs for detection and repair of leaks in these pipelines are high in terms of lost productivity and repair time. The District Heating and Cooling Leak Detection Research program, cofunded by Consolidated Edison and the Fluid Conservation Systems Corporation, allowed scientists at the Argonne National Laboratory to develop a computer-based acoustic monitoring system that can accurately locate underground pipe leaks. The detector records sounds created when pressurized gas or liquid escapes from a damaged pipe. The data are fed into a computer that provides information on the location, size, and type of the leaks. Experiments on district heating pipes demonstrated that water leaks can be detected at a distance of 500 feet and escaping steam at 1500 feet. Utility companies may be able to save thousands of dollars per week by using the acoustic leak detector system for location and repair work.

\section{Infiltration Model}

Infiltration, the uncontrolled flow of air through a building's shell, is responsible for one-third to onehalf of residential and commercial building energy requirements. Before 1980, no adequate method existed to predict energy losses owing to infiltration. To meet this need, DOE sponsored the development of an infiltration model that provides simplified techniques for estimating infiltration rates in residential buildings based on building-envelope parameters and climatic conditions.

To predict the performance of air infiltration in the building shell, the model uses the leakage properties of the building envelope and site weather data. The model may be used with a hand calculator and is usually accurate to within $20 \%$ of actual figures.

Described in detail in the ASHRAE Handbook of Fundamentals, the infiltration model is currently being used throughout the professional design community and has been incorporated into major energy performance computational programs (CIRA, DOE-2, BLAST, and TRNSYS). Residential building designs that incorporate the results of the infiltration model are typically $10 \%$ to $15 \%$ more energy efficient. The residential infiltration model is currently being extended to analyze infiltration in commercial buildings.

\section{DOE-2}

The DOE-2 building energy simulation program was developed as an unbiased analytical tool to assist in designing buildings and evaluating building performance from the perspective of energy use, efficiency, comfort, and cost. Operating on a wide variety of computers ranging from personal computers to mainframes, DOE-2 has become the standard by which similar commercially developed programs are evaluated. DOE- 2 has been used in developing building industry standards, such as the ASHRAE Standard 90, the California Building Code, and the ASHRAE Handbook of Fundamentals; as an aid in developing simplified analytical tools (ADM-2, Trackload, ASEAM [A Simplified Energy Analysis Method], BLAST, and PEAR); and as an educational tool to train engineers, designers, and architects. Since its release in 1977, 
several hundred copies of DOE-2 have been distributed. DOE-2 is recognized in the technical community as the most accurate building energy simulation program available.

\section{Program for the Energy Analysis of Residences (PEAR)}

DOE recognized the need for an easy-to-use, nontechnical energy analysis tool to assist residential builders in making choices among energy-conserving building design options. These options include home insulation levels, window types and glazing layers, infiltration levels, amount of thermal mass, and equipment efficiency. PEAR enables builders and designers to estimate the annual energy use of new houses equipped with typical conservation measures such as ceiling, wall, and floor insulation and thermal or storm windows with different infiltration rates. Using PEAR, builders and designers can also determine the effects of innovative measures such as changes in roof and wall color or an attached sun space. PEAR can perform energy analyses for residential buildings throughout the continental United States.

\section{Solar-5}

A building's future energy efficiency is often determined in the early stages of the design process, but designers historically lacked a way to assess the effect of different design strategies on energy performance. In response to this need, DOE developed the computer program Solar- 5 to provide a visual display of building energy flows in residential and commercial buildings. Solar-5 uses a matrix to display data and quickly provides the results of its energy analysis. This enables users to revise a design and instantly see the results displayed in the matrix. A user can combine up to nine different schemes into one design and see a graphic presentation of the resulting energy flows.

Solar-5 has received the Progressive Architecture magazine award citation and a DOE award for excellence. It is the most popular computer program available from the Designers Software Exchange, with approximately 500 copies sold to date.

\section{WINDOW Computer Program}

Windows play an important role in the energy efficiency of a building, yet today there is no widely

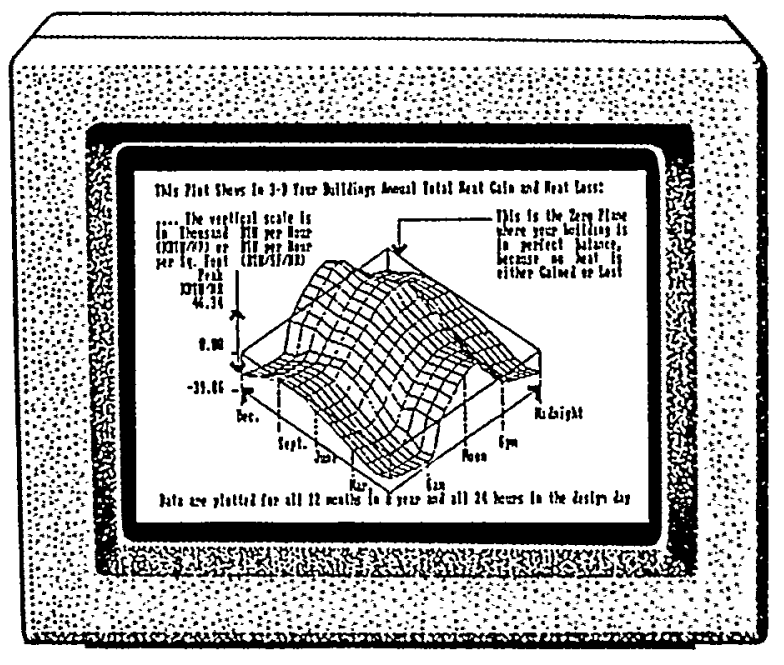

This computer-generated plot, produced with the Solar-5 program, shows a building's total heat gain and heat loss. Data are plotted for all 12 months and all 24 hours.

accepted standard in the United States for determining the thermal performance of window systems. There is growing industry support for establishing a standard based on calculation procedures validated with laboratory or field tests. Developed by DOE through the Lawrence Berkeley Laboratory, the WINDOW series of IBM personal-computer-based programs is used to calculate numerous thermal and optical properties of windows including thermal transmission, shading coefficients, and surface temperatures of glass. The WINDOW program is expected to become a key element in a national uniform rating system, which might include a windowlabeling program.

The program is now widely used in the industry. ASHRAE used WINDOW to calculate new guidelines for window performance and incorporated the guidelines into the ASHRAE Handbook of Fundamentals. The program is facilitating the design of Lawrence Berkeley Laboratory's "superwindow" technology. Other uses range from design of more conventional windows by architects and engineers to development of data by manufacturers for product specification sheets.

\section{A Simplified Energy Analysis Method (ASEAM-2)}

Architects typically design heating, ventilating, and air conditioning (HVAC) systems for commercial and 


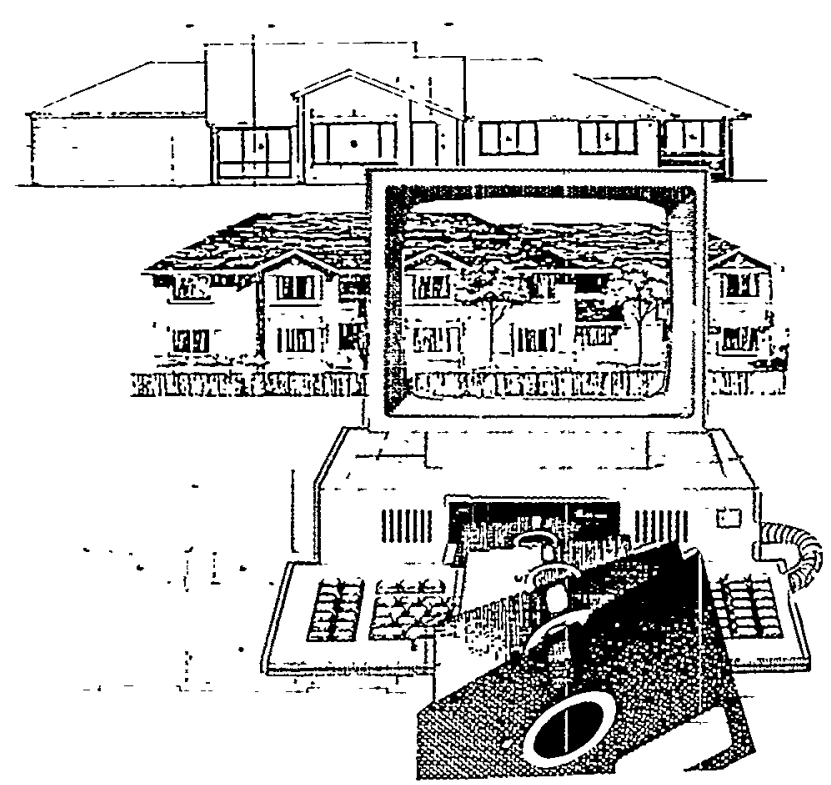

Computer-based standards for new federal residential buildings facilitate the calculation of the most cost-effective combination of energy conservation measures.

residential buildings using proprietary software provided by equipment manufacturers. DOE developed ASEAM-2 to provide an accurate, easy-to-use energy analysis tool for design and retrofit applications. This computer program is modular in design, allowing users to integrate it with other software, such as life-cycle costing and daylighting programs.

ASEAM-2 can simulate 13 different types of HVAC distribution systems, model up to 10 energy load zones within a building, and size systems automatically. Users can evaluate the effects of changes in lighting, heating and cooling equipment, or increased insulation; estimate energy results for life-cycle cost analysis; and assess the benefits of retrofit options.

The system is of great benefit to state governments; the effects of proposed changes in state energy codes can be analyzed, consistency in the results of energy audits can be established, and the effects of different weatherization techniques can be reviewed. Applications for utilities include assessment of conservation programs, forecasts of system loads, and development of load shifting and load reduction programs.

\section{Computer-based Conservation Standards for New Federal Residential Buildings}

Early energy conservation standards for Federal housing projects used simple criteria to guarantee improved energy efficiency in new homes. Unfortunately, these criteria often did not capture the most cost-effective energy conservation measures. In addition, there was no way to account for nonadditive effects of combining conservation methods.

These shortcomings prompted DOE to develop Energy Conservation Standards for New Federal Residential Buildings, the first computer-based standards in the United States. The associated userfriendly computer program calculates the most costeffective combination of conservation measures and checks compliance with standards. Today builders can explore a wide variety of energy conservation measures quickly and inexpensively, submitting the most cost-effective combination when bidding on Federal housing projects.

\section{Indoor Air Quality Field Studies Data Base}

Many experts believe indoor air quality is one of the most important public health issues of the 1990s. Yet the understanding of indoor contaminants and their effect on people is inadequate, and the growing number of field studies on indoor pollutants makes obtaining information from technical literature very time consuming. Consequently, DOE, the Environmental Protection Agency (EPA), the Electric Power Research Institute, and the Gas Research Institute have begun an effort to create and support a computer data base of field studies that monitor concentrations of indoor pollutants in buildings in the United States and Canada. The microcomputer-based Concentrations of Indoor Pollutants Data Base provides information on indoor air pollution concentrations in buildings from more than 300 references. This data base can be used to calibrate, verify, or modify macromodeling efforts designed to predict or characterize indoor pollutant concentrations. More than 200 groups or individuals have used the data base. 


\section{Building Foundation Design Manual}

A 1985 DOE study found that more than $95 \%$ of existing and $70 \%$ of new residential buildings lack foundation insulation. The DOE/Industry Foundations Review Panel suggested that clear information on the cost-effectiveness of foundation insulation in most U.S. climates was not readily available to builders and designers. With the help of extensive industry review and technical support provided by the DOE/ Industry Foundations Review Panel, DOE prepared the Building Foundation Design Manual, a comprehensive handbook for architects and engineers. The manual covers energy-efficient building foundation design and recommends practices for structure, drainage, waterproofing, radon mitigation, and termite control. The volume includes a simplified method to estimate cost-effectiveness for foundation insulation in all regions of the United States. The residential manual is applicable for small commercial buildings.

The design manual serves as a source document for other products and activities, including future research, the Builder's Handbook, the ASHRAE Handbook of Fundamentals, the 1989 CABO Model Energy Code, the proposed revision of the Housing and Urban Development's Minimum Property Standards, and several articles in builder magazines. National savings derived from adopting designs recommended in the handbook could approach 0.5 quad annually.

\section{Single-Family Retrofit Research and Technology Transfer Program}

In a recent analysis of home ownership costs, the Alliance to Save Energy found that energy costs are the second largest expense after mortgage payments. Reductions in energy costs through greater efficiency would improve housing affordability.

$\mathrm{DOE}$, in conjunction with the alliance, has sponsored a program that leverages state and private sector resources to improve conservation programs, provide better technical training of weatherization providers, and increase research activities in the field and in the national laboratories. The program brings together product manufacturers, utilities, national laboratories, local community groups, and private contractors to use the latest research innovations to improve the effectiveness of residential energy conservation efforts.
During the past several years, the program has improved the energy savings and cost-effectiveness of 27 state weatherization programs, provided training to 1600 energy auditors and private heating contractors in new efficiency technologies, and developed an innovative approach to leverage state and private sector resources to stretch limited DOE research funds. More than 20,000 homes have been retrofitted through this program.

\section{Energy Institutes}

Institutes on Energy and Engineering EducationThe objective of the institutes is to provide engineering educators with a variety of resources to help them teach engineering students how to design, construct, and operate energy-efficient buildings. The program creates a communications link among university faculty, government and industry researchers, and practitioners. Nine 4-day institutes have been held since 1980. About 375 professors from 150 of the nation's engineering schools have attended one or more of these. The institutes and the publication of the model HVAC curriculum used have resulted in the introduction and refinement of building energy topics in engineering courses throughout the country.

Working in teams, institute participants analyze the heat flow patterns and energy budgets of case-study buildings and review building plans and equipment data. Each team then identifies alternative energy conservation options, models its base building, and evaluates the options using the ASEAM-2.1 software. This case study method, which has been successful for educators in their engineering curricula, has accelerated the transfer of knowledge of energy-efficient building technologies to future engineers.

Summer Institutes on Energy and Design-The summer institutes provide university faculty with resources to teach architecture students how to design energy-efficient buildings and provide a forum for information exchange among government researchers, private industry, and the academic community. Eight institutes have been held since 1981. Each four-day institute involves a variety of workshops and field trips. The workshops are led by professors of architecture and supported by resource books, which attendees subsequently use in their design courses. About 380 faculty members from more than $90 \%$ of the architecture schools in the United States have participated. 
City of Phoenix Energy Conservation Program

Annual savings, 1978-1989, at major municipal facilities

\begin{tabular}{|c|c|c|c|c|}
\hline Facility & $\begin{array}{l}\text { Estimated } \\
\text { lnergy Savings } \\
\text { (kWh) }\end{array}$ & $\begin{array}{l}\text { Energy Use } \\
\text { without } \\
\text { Savings } \\
(\mathrm{kWh})\end{array}$ & $\begin{array}{l}\text { Cost } \\
\text { Avoidance } \\
\text { (Dollars) }\end{array}$ & $\begin{array}{l}\text { Energy } \\
\text { Savings } \\
\text { (\%) }\end{array}$ \\
\hline Human Resources Dept. & 847,524 & $1,927,284$ & 79,667 & 44 \\
\hline Municipal Building & $5,776,977$ & $13,572,977$ & 543,036 & 43 \\
\hline Cultural Centers & $1,742,941$ & $4,152,501$ & 163,836 & 42 \\
\hline Libraries & $2,642,179$ & $6,951,008$ & 248,365 & 38 \\
\hline Police Department & $6,887,013$ & $13,501,944$ & 647,379 & 34 \\
\hline Service Center & 474,556 & $2,153,524$ & 44,608 & 28 \\
\hline Fire Stations & 430,230 & $3,772,016$ & 40,442 & 11 \\
\hline Other Downtown Buildings & $4,465,897$ & $9,529,643$ & 419,794 & 47 \\
\hline
\end{tabular}

The 1989 Summer Institute on Energy and Design was held in July at the University of Washington in Seattle in cooperation with the university's School of Architecture. Nine faculty-led workshops were presented during the institute. About 60 architectural educators and guests participated in the workshops, lectures, field trips, and presentations.

\section{City-wide Energy Conservation: Phoenix, Arizona}

As a result of skyrocketing oil prices throughout the 1970s, the city of Phoenix, Arizona, made a firm commitment to energy conservation. Since 1978, Phoenix has saved more than $\$ 30$ million through a comprehensive energy conservation program costing $\$ 4.5$ million. A series of annual DOE grants provided a $\$ 652,000$ supplement to the city's investment through the Urban Consortium Energy Task Force. These DOE grants resulted in more than $\$ 3$ million in energy savings and cost avoidance since 1981. The projects focused on energy savings in the areas of wastewater treatment, water treatment and pumping efficiency, and heating and cooling efficiency in municipal buildings. In 1983, the city established the Energy Convservation Reinvestment Plan to reinvest $50 \%$ of general fund energy savings into new projects.

In 1989 , the city successfully completed two projects: it demonstrated a small-scale cogeneration project that incorporated thermal energy storage and absorption cooling, which reduces the use of CFCs (chlorofluorocarbons), and a district cooling assessment project, which is ready for implementation.

Phoenix has also participated in workshops sponsored by the Energy Task Force to help other cities develop conservation programs. The Phoenix program demonstrates that city-wide energy conservation is feasible and economically sound. 
Ongoing

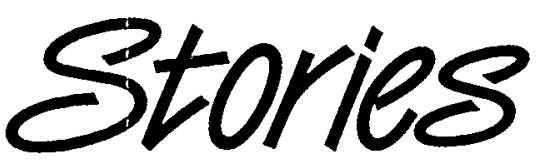

\section{in the Transportation Sector}

28 ....Electric Vehicle Site Operations Program

Dual-Shaft, Advanced Alternating-Current Propulsion System

29 ....Gel-Cell, Lead-Acid Battery-powered Electric Vehicles Single-Shaft Electric Propulsion Vehicle

30 .....Nonautomotive Stirling Engine Applications Alternative Transportation Fuels

31 ....Understanding "Engine Knock" Combustion Characteristics of Alternative Diesel Fuels Sources of Unburned Hydrocarbon Emissions from Automotive Engines

\section{2 ....RAPRENOx Process}

Thermal-Boundary-Layer Measurements in Engines

33 ....Thermal-Barrier Coatings Transformation-foughened Ceramics Data Base

34 ....Tensile Testing System for Ceramics Alumina-based Ceramic Composite Ceramic Rotors for Turbochargers and Turbines

36 .....Low-Cost, High-Temperature Alloy Simulation of Automobile Engine Processes with Color Graphics-KIVA II Lubrication at Elevated Temperatures

37 ....Base Oil Separation and Characterization Intermediate- and High-Temperature Lubricants 


\section{Ongoing Success Stories in the Transportation Sector}

Because the transportation sector is $97 \%$ dependent on oil, an important focus of the Office of Conservation and Renewable Energy is to reduce oil use in vehicles. This is a formidable but important task; transportation systems in this country used $10.7 \mathrm{mil}-$ lion barrels of oil per day in 1988, accounting for $27 \%$ of all energy and $63 \%$ of the oil used in the United States. By reducing oil consumption, the nation should realize numerous economic and environmental benefits.

Toward this end, DOE conducts R\&D programs designed to improve energy efficiency and enhance the flexibility of fuel-use options in transportation-related technologies. Accordingly, DOE focuses on the development of electric and hybrid vehicles; research on advanced engine systems, such as the automotive gas turbine and heavy duty (low heat-rejection) diesel engines; application of advanced materials (e.g., ceramic engines and parts); and development of alternative motor fuels. In addition, DOE publishes the Gas Mileage Guide and conducts a variety of other technology transfer and assessment activities.

\section{Electric Vehicle Site Operations Program}

DOE supports a wide range of research on electric vehicles in conjunction with academic institutions, other Federal agencies, and the private sector. This research is consistent with directives contained in the Electric and Hybrid Vehicle Research, Development and Demonstration Act of 1976. The DOE Electric Vehicle Site Operations Program provides a means of testing and evaluating the effectiveness of new electric vehicle technology, primarily in the areas of advanced systems, subsystems, and components.

Numerous technological developments have occurred since DOE-sponsored research activities began. Since its inception, this program has evaluated more than 20 electric vehicle types and 16 specific product improvements. The results of testing indicate that research objectives are being met and often exceeded. Electric vehicle energy consumption has been reduced by more than $50 \%$, reliability levels have increased by $78 \%$, maintenance costs have been reduced by $60 \%$, and overall life-cycle costs have been reduced by $67 \%$. The Electric Vehicle Site Operations Program provides potential private sector investors with design validation and unbiased information on specific applications for these vehicles.

\section{Dual-Shaft, Advanced Alternating-Current Propulsion System}

Market studies have determined that commercial vans could be the first market niche for electric vehicles. DOE's Dual-Shaft Electric Propulsion System Technology Development Program responded to this opportunity by successfully developing an electric propulsion system for a lightweight van. The major emphasis of this program was to advance existing battery and power train technologies through integrated development of a nickel/iron battery, an alternatingcurrent motor and controls, and an automatic twospeed transaxle. The program involved an industrial research team made up of Eaton Corporation's Corporate $R \& D$, the prime contractor, responsible for power train technologies and propulsion system integration; Eagle-Picher Industries, responsible for battery technology; and ASC, Inc., responsible for vehicle modification.

Program participants designed, built, and tested three advanced, proof-of-concept propulsion systems, which were installed in Chrysler T-115 minivans. The first of these vehicles was evaluated on the testbed; the other two were delivered to DOE as demonstration vehicles for further evaluation. The program achieved all of its objectives, with the exception of anticipated battery life. Vehicle performance goals for acceleration, gradability, top speed, range, and energy efficiency were reached or surpassed.

The program has provided industry with an advanced propulsion system technology for electric 


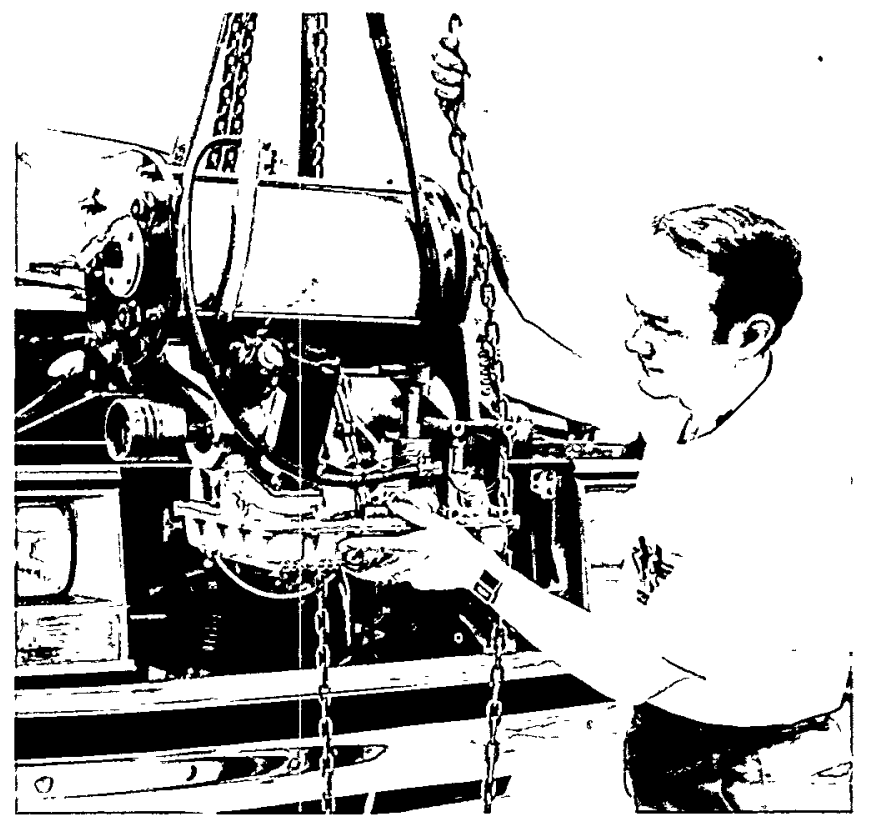

A researcher is installing a power train in a dual-shaft electric-propulsion system.

vehicles that is not only practical for lightweight van applications in the near term but quite sensible from the standpoint of the overall system technology.

\section{Gel-Cell, Lead-Acid Battery-powered Electric Vehicles}

DOE has sponsored numerous research activities with the goal of achieving viable, cost-effective electric vehicle technology. Yet maintenance costs have remained a major barrier to the marketability of these vehicles.

Beginning in 1982, DOE initiated an aggressive research effort with universities, the private sector, and Federal agencies to develop technology to reduce vehicle maintenance costs. In particular, gel-cell leadacid batteries were identified as a technology that could reduce maintenance requirements and improve safety conditions and efficiency levels. Specific results of the gel-cell battery research program include a $50 \%$ reduction in vehicle maintenance costs, a greater than $50 \%$ increase in energy efficiency, and increased levels of operating safety owing to the sealed design of the batteries.

Gel-cell battery technology developed in this program can also be used in mobile communications systems, mining, computer power supplies, and other applications requiring low-maintenance, long-life, and high-efficiency batteries.

\section{Single-Shaft Electric Propulsion Vehicle}

One of the most successful of DOE's electric vehicle research programs was the ETX project (ETX-I and ETX-II) conducted by the Ford Motor Company and General Electric Company. By applying an integrated systems approach, this project advanced electric vehicle technology through the use of alternating current (instead of direct current) and zinc-bromine, sodiumsulfur, and tubular plate batteries.

The ETX-I vehicle was the first electric vehicle to demonstrate a useful range in excess of 100 miles. The ETX-I power train met or exceeded its design objectives for energy efficiency, acceleration, gradability, and drivability. For example, the ETX-I demonstrated a $50 \%$ reduction in weight, a $40 \%$ reduction in size, and a $25 \%$ improvement in acceleration compared with the ETV-1 and other earlier electric vehicles. The project validated the use of the integrated system design for effective use of resources in electric vehicle R\&D.

The ETX-I Program was considered an unqualified success. It demonstrated that electric vehicles can effectively compete with conventional vehicles in certain market segments, such as light-duty vans. Small commercial vans were established as the form of electric vehicle most likely to gain acceptance in the marketplace. Accordingly, DOE awarded a new contract to the Ford Motor Company with a subcontract to the General Electric Company to adapt the ETX concept to a small commercial van and take the major subsystems a step closer to production. This second phase, the ETX-II Program, is furthering the propulsion system technology by developing a sodium-sulfur battery subsystem and an advanced, single-shaft, alternating-current power train. The ETX-II is the first of its kind in this country.

The ETX-II Program has resulted in several major technological advances including a new, interior, permanent magnet motor that is much smaller and lighter than a conventional induction motor; an integrated motor and transaxle on one common shaft; high-power transistors capable of handling more than 400 amperes of current; an advanced alternatingcurrent inverter; and integrated-vehicle and electricsubsystem controllers. In addition, a test-bed vehicle 
powered by an advanced sodium-sulfur battery was successfully run, demonstrating a range of more than 100 miles on a single battery charge.

\section{Nonautomotive Stirling Engine Applications}

Stirling engines use an external heat source to provide usable mechanical energy. These engines feature low noise, high efficiency, low pollution, and low vibration levels, making this unique technology particularly useful in several applications. In particular, the capability to use any source of heat as fuel, including solar or nuclear power, makes this technology an attractive candidate for remote applications such as in-orbit power supplies, where conventional power systems are not feasible.

As DOE-sponsored Stirling engine technology research began to demonstrate the validity of using Stirling engines in automobiles, other uses for this technology became apparent, including applications in solar power modules, irrigation systems, and mobile power generation systems. Associated research programs, such as the high-temperature, low-cost alloys projects, will result in increased levels of Stirling engine efficiency. Remote power generation systems already have limited market penetration, and demonstrations of Stirling engine technology sponsored by other Federal agencies and private sector firms are currently under way.

\section{Alternative Transportation Fuels}

The transportation sector relies almost entirely on petroleum products as a source of energy. Recognizing the vulnerability of this sector, DOE has sponsored research activities to develop alternative fuels. In cooperation with the Department of Transportation, numerous academic institutions, and private sector firms, DOE research has focused on long-term, high-risk, basic research oriented toward developing alcohol-fuels technology to supplement, and eventually replace, conventional hydrocarbon fuels.

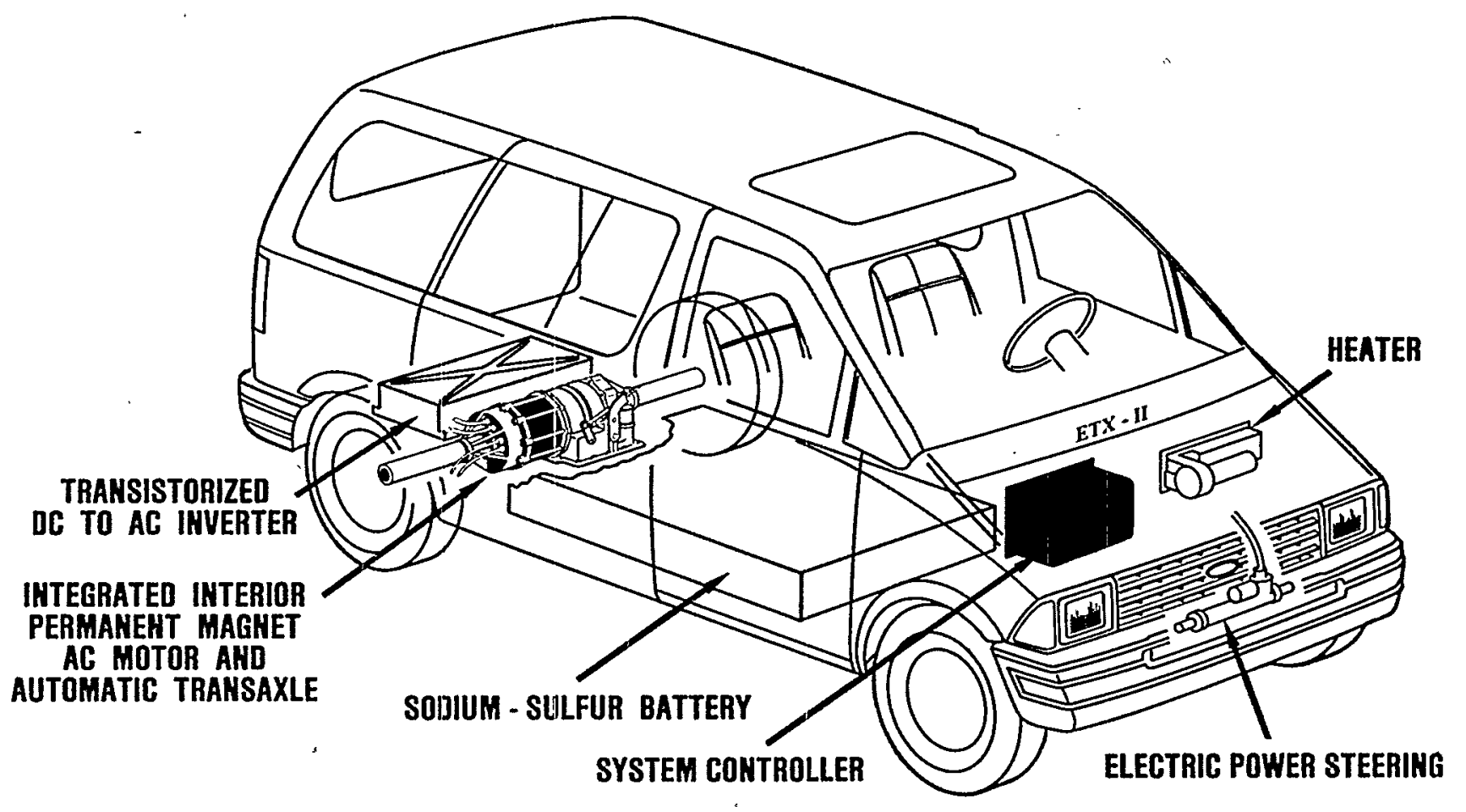

The Ford ETX-II, a state-of-the-art electric vehicle, integrates advanced sodium sulfur battery technology with advanced single-shaft, alternating-current power train technology. 
This initiative developed neat and near-neat alcoholfueled vehicles and stimulated private industry to develop and market oxygenated fuels and additives such as ethanol, methanol, tertiary butyl alcohol, and methyl-tertiary-butyl ether. These and other oxygenates are now blended with gasoline in quantities up to $10 \%$ by volume, replacing more than 24 million barrels of oil (139.2 trillion Btus) on an annual basis. Oil import requirements were reduced as a result of the implementation of these research results, and a broad technology base was established that directly contributes to national security.

The combustion characteristics of oxygenated fuels, particularly ethanol and methanol, also benefit the environment, especially in regions that have not attained air quality standards, such as southern California. DOE is working with the Environmental Protection Agency, the California Energy Commission, and the California Air Resources Board to develop alcohol fuels implementation strategies that will simultaneously reduce petroleum dependence levels and enhance environmental conditions.

\section{Understanding "Engine Knock"}

A significant increase in the thermodynamic efficiency and a corresponding decrease in the fuel consumption of automotive spark-ignition engines can be achieved by increasing the compression ratio. However, the extent to which the engine compression ratio may be increased is limited by the onset of engine knock and the possible risk of engine damage. Knock is the engine response to a rapid, nonuniform pressure rise in the combustion chamber. Such high rates of pressure rise appear to be caused by the nearly uniform autoignition of the end gases before the flame passes through them.

The results of recently completed experiments and kinetic modeling simulations of the compression ignition process provided new insight into the problems of autoignition and engine knock. It is now known that the role of low-temperature chemistry in the end gases is to provide enough heat to cause the end-gas to ignite by itself. The exact kinetic mechanism is under continued investigation.

DOE research provides clarification on which factors are most important, so future work can be better directed toward possible mitigation of problems. It may even be found that these thermal, fluid mechanical, and chemical mechanisms can be harnessed and controlled to provide rapid energy release, high compression ratio, and minimum risk of mechanical damage. These should lead to higher efficiency, cheaper operation, and a better competitive position for U.S. products.

\section{Combustion Characteristics of Alternative Diesel Fuels}

Since the 1930s, cetane numbers have been used successfully to rate the ignition quality of diesel fuels on the market. However, attempts to rate the ignition quality of a wider variety of alternative fuels for diesel engines have met with limited success. The lack of an accurate rating procedure poses a serious problem for engine manufacturers and fuel producers as they try to assess engine designs and alternative fuels for use when the current supply of high-quality diesel fuel is depleted or disrupted. In particular, recent tests of several alternative fuels found that ignition quality did not always correlate with cetane number.

With DOE support, the ignition characteristics of several alternative fuels for diesel engines were measured in a constant-volume combustion "bomb" to investigate the shortcomings of the current American Society for Testing and Materials cetane rating method when applied to these fuels. In a parallel effort, the same fuels were tested in direct- and indirect-injection diesel engines. Scientists found that combustion-bomb testing provides additional essential and complementary information to conventional engine testing. For example, important differences in the low-temperature ignition kinetics of alternative fuels were detected with the bomb technique that were not evident in the existing cetane rating procedure.

The bomb tests indicated that the current procedure must be modified to enable accurate evaluation of the broad range of future alternative fuels. This fundamental method of characterizing the combustion of fuel sprays in diesel engines should lead to better approaches to improving ignition and combustion properties of alternative fuels.

\section{Sources of Unburned Hydrocarbon Emissions from Automotive Engines}

Lack of knowledge of basic thermochemical processes involved in the combustion of fuels has resulted in escalating equipment costs for pollution control and 
in the failure of designers and developers to exploit potential efficiency improvements in combustion systems and devices. For more than 20 years, the quenchlayer theory dominated the technical literature as the model for unburned hydrocarbon emissions from automotive engines. Today, a new understanding of the sources of unburned hydrocarbon emissions from dilute homogeneous-charge engines has developed from the collective efforts of eight industry and DOE-contractor research teams.

The researchers have completed the experiments and analyses to prove conclusively that conventional wisdom was incomplete regarding the origin of unburned hydrocarbon emissions in piston engines. The process of flame quenching by the cold walls, which had been previously thought to be the main cause of unburned hydrocarbon emissions from dilute homogeneous-charge engines, has now been determined to be of negligible importance. It is now understood that piston ring and head-gasket crevice volumes and the absorption/desorption by lubricating oil filters and combustion chamber deposits are largely the controlling factors.

This new understanding of the physical processes allows engine designers to focus their efforts on the difficult engineering tasks of reducing these crevice volumes and solving the continuing problems in warm-up and transient operation. These efforts should lead to the resolution of a major technical limitation in use of this engine concept.

\section{RAPRENO $_{\mathbf{X}}$ Process}

Nitrogen oxides are the leading contributors to air pollution today. In fact, more than 21 million tons of nitrogen oxides are released into the atmosphere in

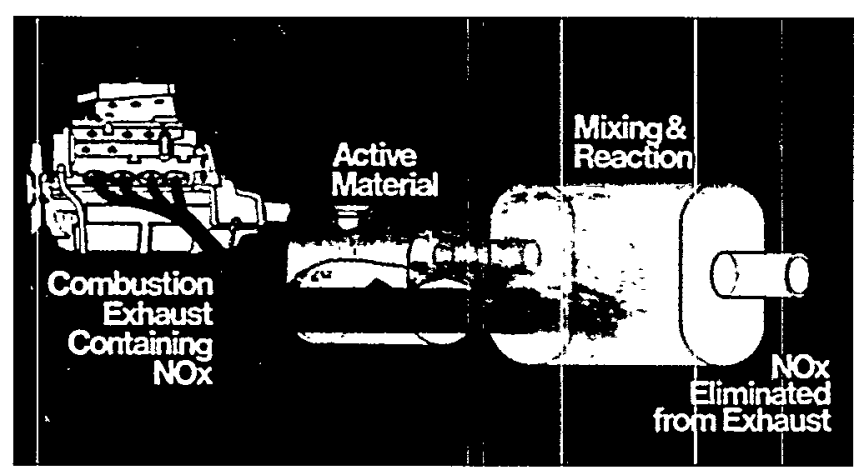

The RAPRENO $\mathrm{O}_{x}$ process can eliminate nitrogen oxides from the exhaust streams of diesel engines and coal-burning generating plants. the United States each year as a by-product of burning fossil fuels. DOE has sponsored research to combat this problem. As a result of this work, Sandia National Laboratories announced in 1986 the discov-

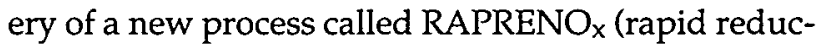
tion of nitrogen oxides), which could eliminate nitrogen oxides from diesel engine exhausts and coal-burning generating plants.

The first phase of the research, funded by the DOE Office of Basic Energy Sciences, included a series of experiments that determined the basic chemistry of the process. Later, with funding from the Office of Conservation and Renewable Energy, scientists extended the fundamental chemistry research by applying the process to the exhaust gases of a real diesel engine. In these applied experiments, it was shown that RAPRENO $\times$ could reduce 400 parts per million of nitrogen oxides to less than 5 parts per million in diesel exhaust at characteristic operating temperatures.

The RAPRENO $\times$ process can significantly reduce nitrogen oxide emissions from practical combustion systems, including stationary and mobile diesel engines, industrial scale furnaces and boilers, and other fossil-fired generating systems. In fact, the successful development of the process could provide an inexpensive way for industry and utility companies to comply with mandated Federal clean air standards.

DOE waived patent rights to the inventor, who consequently formed a private company, the Technor Corporation, to commercialize RAPRENO $\mathrm{x}_{\mathrm{x}}$ for use in diesel engines, natural gas-fired engines, and wood-fired boilers. Technor just completed a feasibility study to determine the applicability of the RAPRENO $\times$ process for coal combustion. In addition, major engine manufacturers, electric utility companies, air quality interests, and industrial processors in the United States and abroad have shown widespread interest in the process, and many have begun R\&D activities.

\section{Thermal-Boundary-Layer Measurements in Engines}

Despite the importance of the thermal boundary layer in understanding engine combustion processes, the temperature profile has never been measured quantitatively near a wall in an operating internal combustion engine. In most engine combustion heat-release 
computations, the thermal boundary layer is calculated theoretically because direct measurements are not possible. Because nitric oxide emissions from an engine chamber are highly sensitive to peak temperatures in the chamber, it is important that these temperatures be calculated correctly with an accurate model of the thermal boundary layer.

With DOE funding, researchers were able to acquire the first detailed in-cylinder measurements of the thermal boundary layer evolution in an operating internal combustion engine. These techniques demonstrated excellent spatial resolution of more than 0.08 millimeter and were able to traverse to within 0.05 millimeter of the wall. Profiles were generated several times during the expansion stroke, showing the growth of the layer from fractions of a millimeter to nearly 2 millimeters.

These measurements are a necessary first step in developing a complete picture of the combustion/ wall interactions. Combined with wall heat-transfer measurements being performed collaboratively with researchers from the General Motors Research Laboratory, the fundamental knowledge developed should lead to new engine designs that simultaneously optimize emissions control and fuel efficiency.

\section{Thermal-Barrier Coatings}

The fuel economy and emissions performance of diesel engines need to be improved. DOE is addressing this need through its Heavy Duty Transport Technology Program. The program supports research to develop a technology base applicable to advanced, high-temperature diesel engines.

One area of particular interest to DOE is the development of thick, thermal-barrier coatings to achieve effective insulation of the combustion chamber. When used in diesel truck engines, thermal-barrier coatings improve fuel economy, increase engine power density, and reduce parasitic losses.

To date, several applications of thermal-barrier coatings have emerged from DOE-supported work. For example, the first diesel engine piston to incorporate thermal-barrier coatings was recently designed. The piston uses a thick thermal-barrier coating (zirconia ceramic) on the crown surface. The plasma-sprayed zirconia ceramic coatings, processes, and equipment developed in DOE's Heavy Duty Transport Program

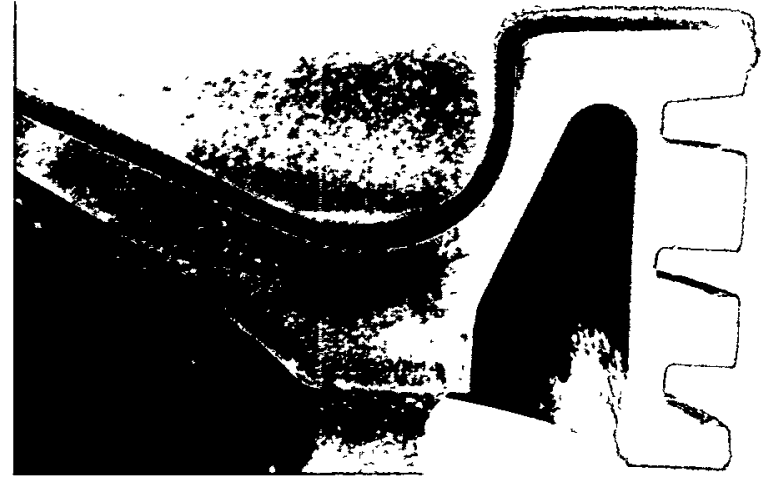

Thermal barrier coatings for diesel engines improve fuel economy, increase engine power density, and reduce parasitic losses.

also led to the development of a coating for marine and stationary engines. In these applications, the coating is used to protect against corrosion and to extend valve life.

\section{Transformation-toughened Ceramics Data Base}

Transformation-toughened ceramics, such as partially stabilized zirconia, tetragonal zirconia polytypes, and zirconia-toughened alumina, offer important options for advanced engines because of their high strength and toughness, high coefficient of thermal expansion (similar to that of cast iron), and good thermal insulation properties. Yet ceramics are highly complex materials, and early experiments found that their performance in engines was unpredictable. Under the Advanced Materials Development Program, researchers developed a comprehensive data base of the mechanical and physical properties of ceramics as a function of time, temperature, stress, relative humidity, and thermal history.

The data base of properties now contains results of 3924 tests for 23 properties of 282 different batches of ceramic materials. Approximately one-half of these are zirconia-based ceramics; the other half includes silicon carbides, silicon nitrides, whisker-reinforced silicon nitrides, and alumina-based (including whisker-reinforced) materials and mullites. The data from this research were compiled in a computerized data base and released to industry. The information helps designers develop advanced engines for commercialization. 


\section{Tensile Testing System for Ceramics}

A major thrust of the Advanced Materials Development Program has been to produce uniaxial tension test data on structural ceramics to be used in advanced engines. For tension testing data to be useful to engine designers, the testing system must be able to apply pure uniaxial loads to the test piece, but the high modulus and brittle nature of ceramics make this very difficult. Many past attempts had limited success or were abandoned because of the high cost of performing the test or the questionable results obtained.

Under this program, DOE developed a hightemperature ceramic tensile test device with selfaligning grips. The device uses a hydraulic flexible coupling that will not transmit bending moments and is completely self-aligning during a test, thus achieving the required alignment on most testing machines.

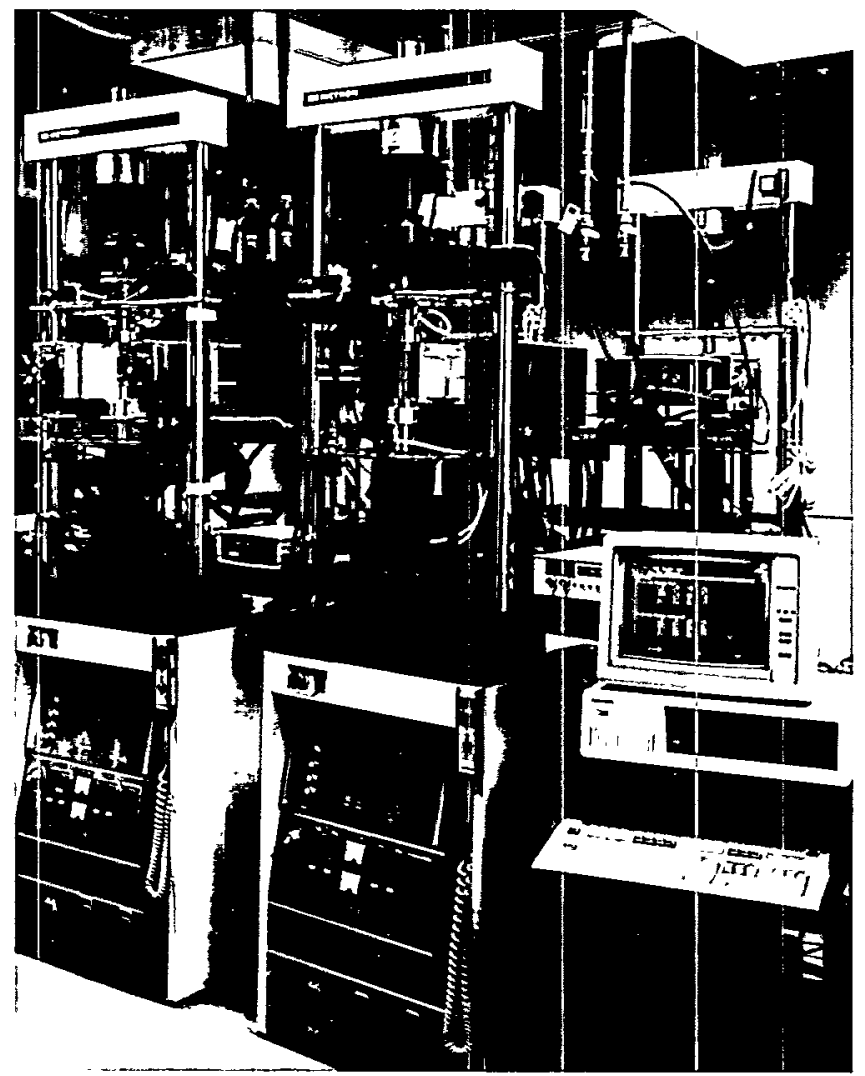

This high-temperature tensile test device with self-aligning grips produces uniaxial tension test data on structural ceramics to be used in advanced engines.
This testing methodology and the data generated will be critical to the designers of future advanced engines.

The technology has been licensed to USA Instron and is being marketed as the "Super Grip System." To date, more than 70 systems have been sold worldwide.

\section{Alumina-based Ceramic Composite}

DOE has supported basic materials science research focused on developing high-strength, hightemperature materials for use in automotive and lighttruck engines. During the past six years, research has concentrated on alumina-based ceramic composite materials. But, as is often the case with basic research, successful results occurred in unanticipated areas.

In this case, significant advancements in machine tool technology resulted from the alumina-based ceramics research. Although the composites developed possess many of the attributes required for automotive applications, they do not yet have sufficient hightemperature resistance.

Although not yet fully developed for automotive applications, alumina-based ceramics have been marketed for use in cutting tools and have potential applications for manufacturers of various products subject to mechanical wear. Cutting tools and machine tools and dies that use this material demonstrate increased strength and improved performance compared with conventional machine tool technology.

Oak Ridge National Laboratory began an aggressive technology transfer program to disseminate alumina ceramic composite technology; ten U.S. companies have already become whisker ceramic licensees. Oak Ridge estimates that the cutting tool industries represent a $\$ 500$ million market and that licensing agreements can be reached with $80 \%$ of the firms in those industries. The benefits of this product will include substantial energy savings because of increased productivity, reduced weight, and reduced levels of friction.

\section{Ceramic Rotors for Turbochargers and Turbines}

Turbocharged automotive engines have long been recognized as offering significant advantages over naturally aspirated engines. These advantages 
include improved performance, energy efficiency, power density, and, in the case of diesel engines, lower exhaust emissions. Almost all heavy-duty trucks already use turbocharging for these reasons. About 500,000 turbocharged light-duty vehicles are sold annually in the United States, primarily for high-performance applications.

A major barrier to turbochargers penetrating the automobile market, however, has been the lack of a reliable, low-mass, high-response rotor capable of withstanding the high temperatures and loads inherent in turbochargers. If such a lightweight, highstrength ceramic turbocharger rotor could be developed, it could reduce the response time of the turbocharger, thereby increasing engine responsiveness and drivability. In addition, it would replace superalloy material (currently used in turbocharger rotors) containing large amounts of strategically important elements such as cobalt, chromium, and nickel.

DOE has sponsored extensive research in developing advanced ceramic materials and designing and fabricating ceramic rotors for automotive gas turbines. Although gas turbine rotors are considerably larger than automotive turbochargers and operate at higher temperatures, substantial similarities exist between them. DOE's research has focused on ceramic material development, fabrication processes, ceramic-tometal joining, and nondestructive evaluation techniques. Great progress has been made in constructing prototype ceramic gas turbine engines, with hundreds of hours of successful testing completed.

The success of DOE's research has already resulted in the commercialization of ceramic turbocharger rotors in Japan and substantial fleet testing in the United States. Nissan, working with the Garrett Corporation and Japanese ceramic suppliers, has sold several hundred thousand ceramic turbochargers on highperformance vehicles in Japan during the last three years. Not one in-service failure has been reported. Garrett engineers also claim that one ceramic turbocharger has better response than two smaller metal turbochargers. It is expected that Nissan will introduce ceramic turbocharged vehicles in the United States in the 1990s.

General Motors has also produced 500 ceramicturbocharged, specially prepared Buick Grand National GNX vehicles and has tested hundreds of turbocharged Pontiac Sunbirds using Garrett ceramic turbochargers.

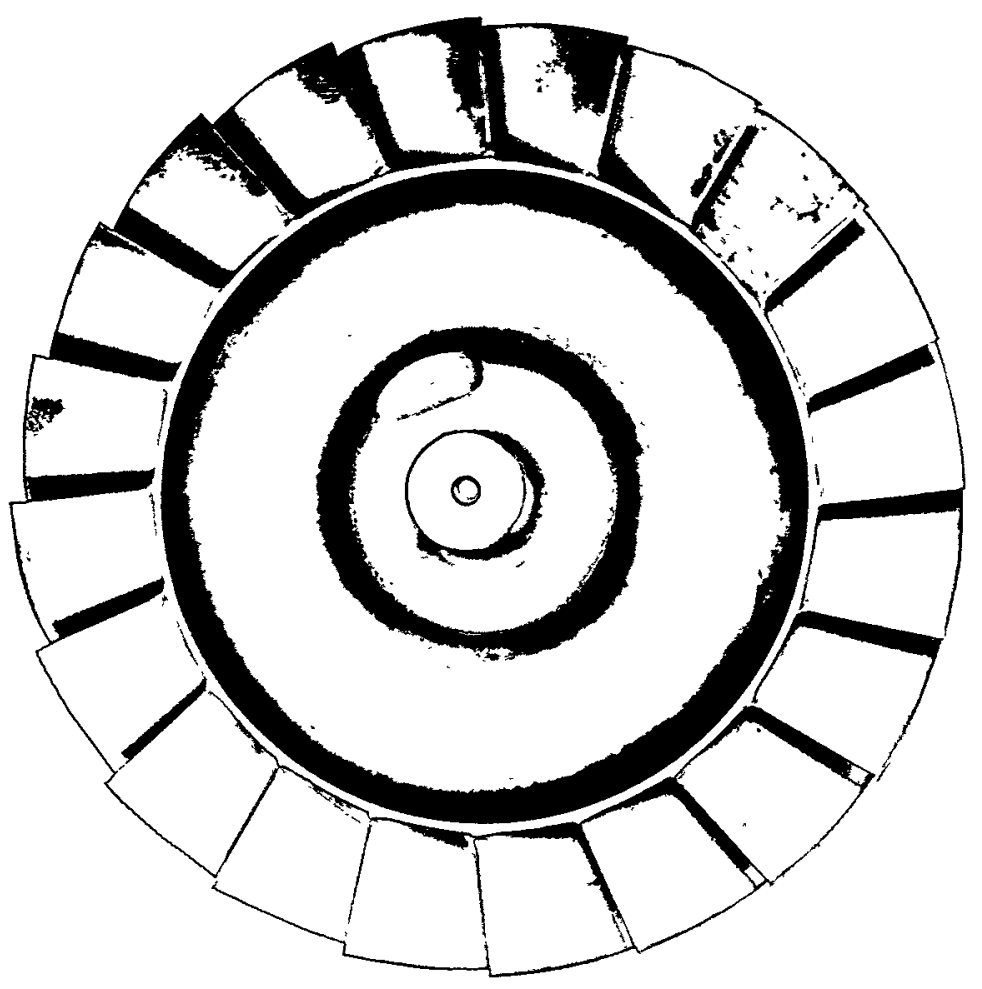

Ceramic rotors developed by Allison (a division of General Motors) improve performance and engine efficiency in automotive gas turbines.

Cost remains a concern with ceramic turbochargers, because the current low-volume production means that the ceramic rotor assembly still costs about five times more than conventional superalloys. However, estimates of worldwide market potential exceed six million units annually by 1992; if ceramic turbocharger production volumes can be increased so that prices can be lowered to about two times premium, as much as $75 \%$ of the total demand might then be met using ceramic material technology. In fact, in a worldwide survey of ceramic engine experts, ceramic turbochargers were projected to capture $20 \%$ of the U.S. light-duty and $27 \%$ of the heavy-duty turbocharger market by 2000 and $38 \%$ of the light-duty and $48 \%$ of the heavy-duty market by 2010 .

Typically, turbocharging results in a 5\% improvement in efficiency in spark-ignition engines and $10 \%$ in diesel engines. In addition, the extra power produced by turbocharging allows engine sizes to be reduced, improving the energy efficiency of this technology by an additional $10 \%$. Based on the survey data, ceramic turbochargers could save 5.3 trillion Btus or 39 million gallons of fuel in 2010 . 


\section{Low-Cost, High-Temperature Alloy}

Stirling engine technology uses power from an external heat source to fuel vehicles. The engine transmits thermal energy and must operate in adverse environments of extreme heat, corrosion, stress, and repeated cycling. Engine efficiency increases with higher operating temperatures, requiring special alloy materials for high efficiency, reliability, and longer lifetimes.

Before 1981, Stirling-engine structural components were fabricated from high-cost imported materials, such as cobalt, chromium, and nickel. Although these materials performed well, commercial introduction of Stirling engine technology has been impeded by economic factors and by the lack of a reliable source for the alloy components. Consequently, DOE with the National Aeronautics and Space Administration sponsored research by academic institutions and private sector firms to develop a low-cost replacement alloy with equivalent properties.

The new alloy surpassed expectations. It exhibits a superior lifetime, is far cheaper, and uses entirely domestic resources, with the exception of nickel imported from Canada. In addition to its Stirling engine applications, this alloy could penetrate hightemperature structural material markets throughout the United States, particularly for conventional automotive heat engine applications.

Energy efficiency benefits are expected to rise as the alloy achieves market penetration because this material will make higher engine operating temperatures possible. By reducing dependence on strategic imported materials, this research effort has directly enhanced our national security.

\section{Simulation of Automobile Engine Processes with Color Graphics-KIVA II}

The transportation sector consumes about 20 quads of liquid fuels each year, creating a tremendous incentive to develop more efficient engines. Engine efficiency largely depends on the fuel spray in the combustion chamber of the engine and on the ability of the engine to consume the fuel/air charge completely. Therefore, it is of increasing interest to designers and manufacturers of internal combustion engines to be able to represent an evaporating fuel spray by numerical calculations of chemically reactive fluid flows.
KIVA II is the latest in a series of multidimensional computer codes that allows numerical simulation of internal combustion engine processes. Developed at Los Alamos National Laboratory, KIVA II solves unsteady equations of motion in a turbulent mixture of gases that react chemically, and these are coupled to equations for a vaporizing fuel spray. The user provides the engine specifications (e.g., bore, stroke, compression ratio, and piston-top geometry), a specific starting time (e.g., the time the intake valve closes), and an ending time (e.g., the time the flame completely consumes the mixture of fuel and air). KIVA II solves the equations for a finite number of very small computational cells that represent the space in which combustion takes place, i.e., between the fixed engine cylinder and the top of the moving piston.

The user can also combine the results of the KIVA II computations with a computer graphics package to visualize the combustion process. For example, different colors may be used to differentiate ranges of temperatures that are computed for the various cells. By plotting the colors for each cell in threedimensional space, the user can see how the fuel/ air mixture is initially ignited and how the flame grows from the initial ignition point and spreads throughout the combustion chamber.

KIVA II has been accepted as the industry standard for development of automotive engine models. The program now is being used extensively by the automotive industry worldwide to help develop energyefficient, EPA-compliant engines. General Motors has used KIVA II in developing engines such as the direct-injection, stratified-charge and the fastburn, homogeneous-charge engines. Cummins Engine Co. uses the KIVA II code to help engineers examine fuel spray-airflow interactions in their diesel engines.

KIVA II can easily be adapted to a variety of other applications by modifying the general structure of its program. Such applications include continuous spray combustors, Bunsen burner flames, and nonreacting sprays.

\section{Lubrication at Elevated Temperatures}

Advanced designs for low-heat-rejection engines present two significant tribological challenges, namely, lubrication at elevated temperatures and lubrication of ceramic materials. Anticipated peak 
temperatures for these engines will be $600^{\circ} \mathrm{C}$ to $1200^{\circ} \mathrm{C}$, far exceeding the performance limits (about $250^{\circ} \mathrm{C}$ ) of all currently marketed lubricants.

DOE has conducted research into a new method for attaining effective lubrication at elevated temperatures by depositing lubricating films from the gas phase. Completed studies show that bearing lubrication may be continued to temperatures well above the stability of the liquid lubricant by delivery to the high-temperature bèarings in a vapor state. Experimental data indicate that a wide variety of conventional liquid lubricants can be used in a homogeneous gas phase, diluted with an inert carrier gas such as nitrogen or mixtures of nitrogen and oxygen, to produce a low-friction, polymer-like film on metalbearing surfaces at high temperatures. Studies were successfully carried out at temperatures as low as $200^{\circ} \mathrm{C}$ and as high as $1600^{\circ} \mathrm{C}$.

This technology should be useful in high-temperature lubrication of adiabatic or low-heat-rejection engines as well as in high-temperature, metal-forming operations. Further research on gas-phase lubricant delivery to ceramic surfaces will also affect development of ceramic parts for new, more efficient, advanced engine designs.

\section{Base Oil Separation and Characterization}

The Research Committee on Lubrication of the American Society of Mechanical Engineers estimates that friction and wear losses in mechanical systems account for up to $11 \%$ of total annual U.S. energy consumption. A wide variety of lubricants are currently required for reducing energy losses from friction and wear in many important energy conversion applications. To formulate better lubricants and establish lubricating base oil specifications and standards, an understanding of the influence of the molecular structure of the lubricant on its friction/wear characteristics needs to be developed.

An extensive series of experiments to determine the tribological properties of base stock oils was completed with DOE funding. Three lubricating base oils of various viscosity grades from Mideastern crude oils were separated into various molecular compound classes using high-performance liquid chromatography. The fractions were characterized using infrared spectroscopy, high-resolution mass spectroscopy, nuclear magnetic resonance spectroscopy, Fourier transform infrared spectroscopy, and elemental analysis. Each class of compounds was subjected to microsample, four-ball wear testing for friction/wear characterization and free radical titration testing for oxidation stability.

Results indicated that the organic acids subfraction of the polar fraction of the Mideastern 600 neutral base oil exhibited the lowest coefficient of friction. Having isolated and characterized the desirable components of base stock oils, researchers should now be able to further investigate and understand the relationship between the molecular structure and the lubricating qualities of base stock oils and, subsequently, to synthesize the "slipperiest" fraction en route to formulating superior energy-saving lubricants.

\section{Intermediate- and High-Temperature Lubricants}

New laboratory techniques and procedures are necessary to enable lubrication engineers to characterize and evaluate candidate lubricants with a range of important properties for elevated-temperature and energy-conserving applications. In response to this need, DOE developed a thermogravimetric analysis method for screening candidate high-temperature lubricants. The procedure uses a pair of experiments to obtain measures of volatility and oxidative stability, both of which are key parameters in the consideration of specifications for oxidation stability.

This analysis method was successfully used to evaluate two phosphate esters: trixylyl phosphate (TXP) and diphenyl t-butylphenyl phosphate (DPBP). Although both materials exhibited good oxidative stability, DPBP appeared to be somewhat more resistant to oxidation than TXP. At temperatures above $280^{\circ} \mathrm{C}$, TXP showed an oxidation-induced, high-molecularweight residue, and DPBP showed only normal (nonoxidative) evaporation.

As new candidate intermediate- and hightemperature lubricants are evaluated by this technique, in concert with other tribological tests, an extensive data base will be developed. This data base will be invaluable to lubrication engineers in improving the tribological performance of mechanical components and systems that operate at elevated temperatures. 


\section{Ongoing}

\section{Stories \\ in the Industrial Sector}

40 ....Catalytic Distillation

41 ....Membrane Distillation

Beck Dyeing Modifications

42 ....Solid-on-Solid Processing

Foam Processing

Hyperfiltration in the Textile Industry

43 ....Membrane Separation in the Sweetener Industry Energy-Efficient Fertilizer Production

44 .....Irigation Systems

Oxygen Production by Chemical Air Separation

Carbon Dioxide Recovery from Industrial Waste Streams

45 .....Nitrogen-based Carburization

High-Performance Slot-Forge Furnace

Ductile-ordered Alloys

46 ....Separation of Impurities from Molten Metals High-Purity Silicon Powder Process

Whisker-toughened Ceramic Composites

47 ....Ceramic Surface Modifications

Ceramic Joining

Magnetic Resonance Imaging for Advanced Ceramics

48 ....Cement Particle Size Classification Coatings for High-Speed Cutting Tools High-Efficiency Welding Unit

49 ....Improved Pulse Combustion Technology Fluid-Elastic Instabilify in Heat Exchangers Industrial Air-Dryer Membrane

50 ....Genetic Engineering for Efficient Biochemical Processes Efficient Aerobic Fermentation

51 ....Designing Biocatalysts for Energy-Efficient Chemicals Production

High-Productivity Bioreactor

Coal-fired Steam Turbine Cogeneration

52 ....Organic Rankine Bottoming Cycle

53 ....Slow-Speed Diesel Cogeneration Fluidized-Bed Waste-Heat Recovery System

54 ....High-Temperature Recuperators Innovative Coil-coating Ovens

55 ....Brayton-Cycle Solvent Recovery

56 ....Electroplating-Wastes Concentrator Black Liquor Gasification

57 ....Recycling of Postconsumer Plastic Scrap Boiler Workshops Energy Analysis and Diagnostic Centers 


\section{Ongoing Success Stories in the Industrial Sector}

Industrial energy consumption is expected to increase $43 \%$ by 2010 , the largest increase of the three end-use sectors. Two factors contributing to this projection are an increase in industrial use of electricity and a leveling off of the trend toward more energy-efficient process improvements. The impact of these two factors is somewhat mitigated by a shift in the U.S. industrial mix toward less energy-intensive products.

To address the energy conservation needs of this key economic sector, the Office of Conservation and Renewable Energy sponsors research aimed at improving the energy efficiency of industrial processes and energy conversion equipment, develops systems for the simultaneous production of electricity and process heat (cogeneration), and explores the potential of technologies that can use multiple or alternative fuels. DOE also ensures that the technologies it develops are environmentally sound, and it is particularly active in technology transfer activities designed to assist small- and medium-sized industrial facilities in analyzing their energy use.

\section{Catalytic Distillation}

The petroleum refining and petrochemical industries often use equilibrium reactions to produce hydrocarbons. Equilibrium reactions tend to be energy intensive because, once equilibrium is reached, the product must be removed through

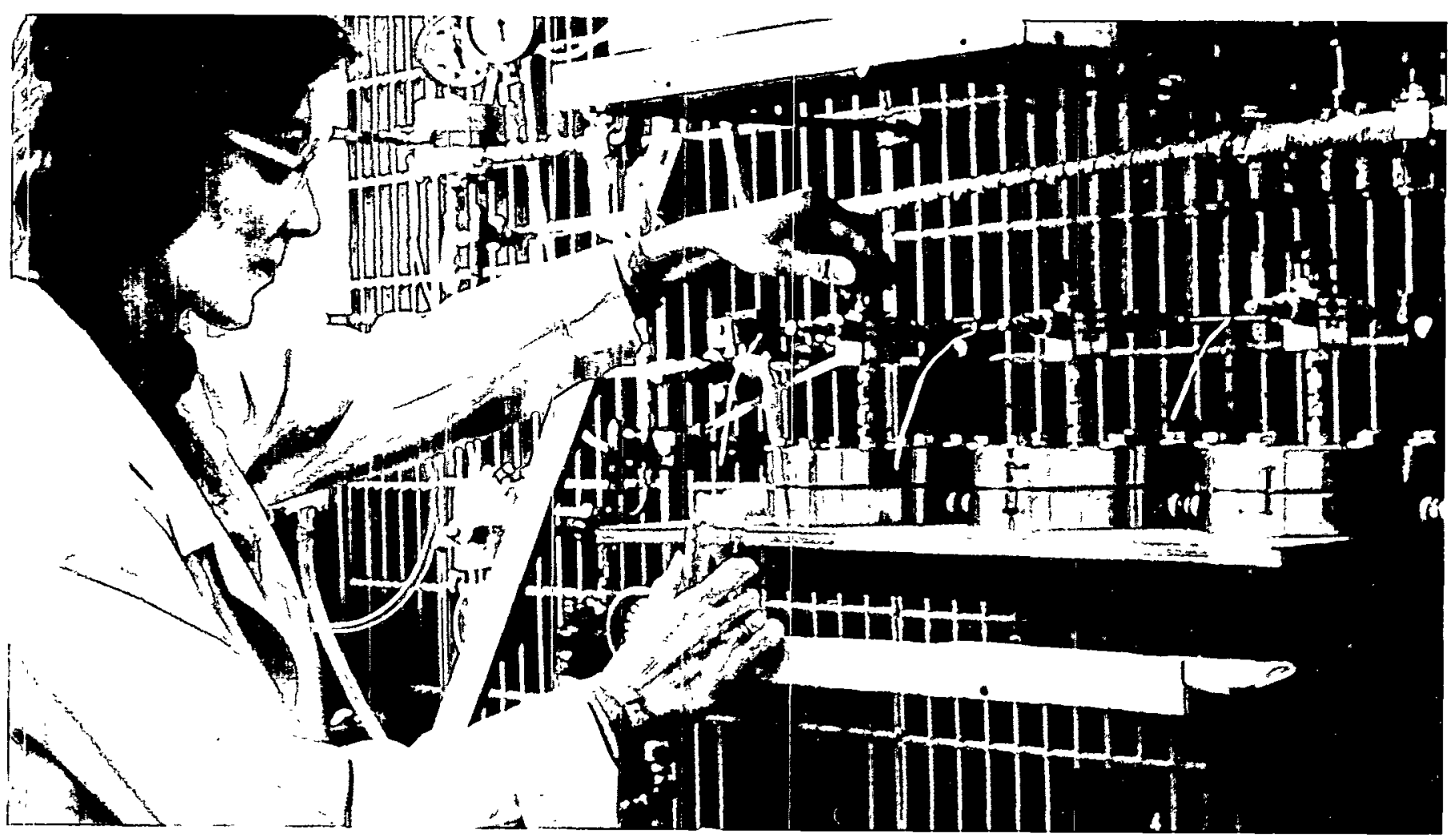

Membrane distillation can replace heat processes used to recover solvents in the petroleum refining industry. 
distillation before the reaction can proceed. The reaction and product separation steps must be repeated until the concentration of product and reactant is too low to warrant further processing. In the conventional procedure, the chemical reaction (which produces waste heat) and distillation are performed in separate vessels, and an external heat source must be applied for the distillation stage.

DOE and Chemical Research and Licensing developed a new single-stage, catalytic reaction/distillation process for producing hydrocarbons such as MTBE (methyl tertiary butyl ether), isobutylene, ethyl benzene, and cumene. When compared with the conventional, multistage process, the new catalytic distillation process is more energy efficient and is also lower in capital cost. The new process saves energy because heat released by the equilibrium reaction is used directly for distillation, eliminating external heat exchange and its consequent energy losses.

At the end of 1988, six units were operating in the United States and one each in China, France, and Spain. Estimated current energy savings in the United States are 0.32 trillion Btus per year; estimated savings in 2010 are 99 trillion Btus per year.

\section{Membrane Distillation}

The petroleum processing industry uses thermal distillation to separate feedstock components of differing boiling points. As much as $30 \%$ of the industry's energy consumption is used to perform these separations. With DOE support, researchers at Allied-Signal Corporation developed a more energy efficient separation method that uses a membrane system to separate light hydrocarbons from a stream of heavy oils in the petroleum refining process. This process recovers solvents used in the deasphalting of heavy oils, reducing the amount of solvent to be stripped through evaporation by as much as $43 \%$.

In the membrane distillation process, a gel layer, consisting of heavy molecules from crude oil feedstock, is allowed to build on the surface of the membrane, and its growth and stability are controlled by a proprietary method. This gel layer serves as a backing material and performs the actual separation process. The system is stable in a hydrocarbon environment up to $50^{\circ} \mathrm{C}$. Potential savings by 2010 are estimated at 24.8 trillion Btus per year.

\section{Beck Dyeing Modifications}

Certain textile products are batch-dyed in a beck, a large stainless steel tub vented to the atmosphere. The conventional dyeing process involves loading the beck with undyed textile, filling it with water, adding the necessary chemicals and dyes, and bringing the water to a boil with steam injection. Once the boiling cycle is satisfactorily completed, the used dye-bath solution is discharged as waste, and the beck is refilled with water to rinse the textile. After the load is rinsed, the used water is discharged.

In cooperation with the Georgia Institute of Technology, Salem Carpets, and Adams-Mills, a DOE program tested three process modifications that reduce the use of energy, water, and materials in conventional dyeing. These modifications are known as bump-and-run, dye-bath reuse, and hot pull. The bump-and-run technique reduces the demand for steam during the dyeing process. Dye-bath reuse involves reconstituting and recycling the spent dye bath. The spent dye bath is analyzed to determine the amount of dye remaining, and additional dye is added to obtain the desired color. Small amounts of auxiliary chemicals are also added to replace those lost in the dyeing process. Hot pull is a handling procedure that eliminates the final rinse step, thus minimizing handling of the spent dye bath and saving the water used by the final rinse.

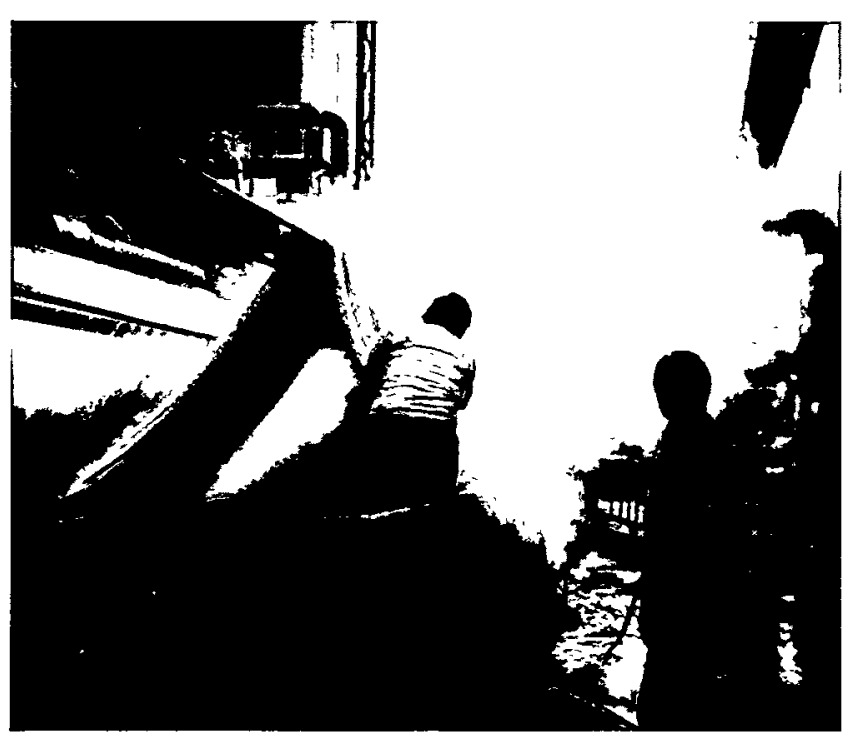

Process modifications in beck dyeing save energy in textile manufacturing. 


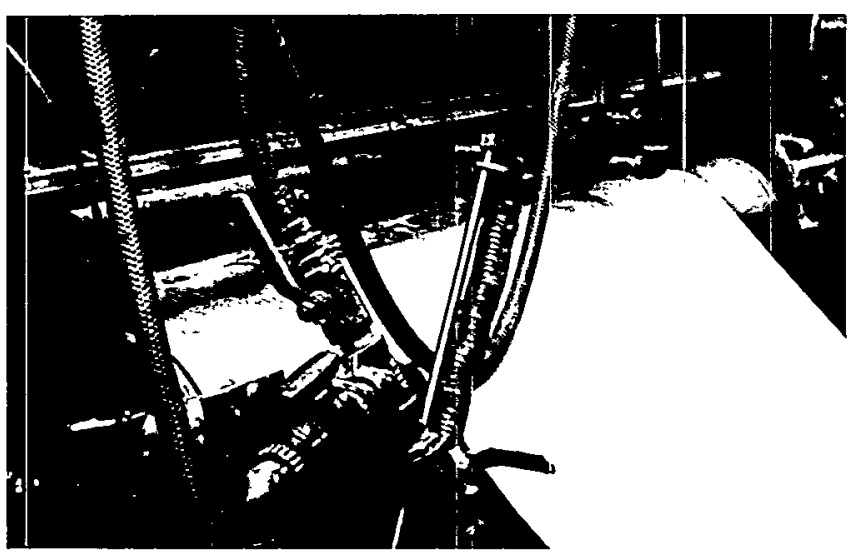

Foam processing prompted the development of other technologies that reduce energy consumption in textile sizing, dyeing, printing, and finishing processes.

In 1989,69 dye units used one or more of these innovations, saving 0.25 trillion Btus. Energy savings in 2010 are projected to be 7.6 trillion Btus.

\section{Solid-on-Solid Processing}

Eliminating liquids in applying finishes and colorants to textiles can drastically reduce the drying requirement, which currently accounts for half of all energy consumption in the textile industry. Three new electrostatic powder concepts could help bring this about. The new processes, successfully demonstrated at bench scale, allow the dry application of chemicals to textile materials. DOE funded the research conducted by Electrostatic Technologies of Connecticut and Nordson of Ohio in cooperation with the Georgia Institute of Technology.

The solid-on-solid processing technique uses powdered chemicals containing a thermoplastic polymer. The chemicals are deposited on the textiles through electrostatic attraction. The low heat capacities of the dry polymeric powders allow rapid heat transfer in the curing ovens. This process avoids the use of extraneous liquids in the chemical application process, thus reducing energy consumption and increasing process speeds. Researchers at the Georgia Institute of Technology estimate that if half the textile industry were to convert to solid-on-solid processing (where appropriate), energy savings would amount to about 10 trillion Btus per year.

\section{Foam Processing}

In conventional wet processing of textiles (e.g., desizing, bleaching, dyeing, printing, and finishing), water is used to distribute pigments or other chemicals throughout the fabric. Wet processing is energy intensive because the fabric is repeatedly wetted and dried, and drying requires large amounts of thermal energy.

Working with United Merchants \& Manufacturers, DOE developed a more energy-efficient process and has seen it through laboratory investigations, pilot plant trials, and commercial production. The process replaces some of the water with foam in the dyeing, printing, and finishing of a variety of fabrics, thereby reducing the energy required for drying, reducing water consumption and pollution control requirements, and increasing plant productivity.

Foam processing has led the way for the development of several low- and medium-wet pick-up processes (e.g., squeeze roll, spraying, and kiss roll coaters) that have been successfully implemented by the textile industry. In 1989, more than 550 million square yards of carpet and more than 2 billion linear yards of broad woven and knit fabrics were processed using these technologies, saving 1.37 trillion Btus. Low- and medium-wet pick-up processing could save about 33.6 trillion Btus per year by 2010 .

\section{Hyperfiltration in the Textile Industry}

Textile industry scouring, bleaching, and dyeing processes produce hot water waste streams containing dyes and other chemicals. The heat content and chemical content of this contaminated wastewater is usually lost when it enters the plant's wastewater cleanup system.

With support from DOE, EPA, and the U.S. Department of the Interior, Carre, Inc. developed a hyperfiltration technique that uses a pressure-driven membrane to separate the hot water, dyes, and other chemicals for direct reuse in textile processes. The hyperfiltration unit consists of zirconium oxide polyacrylate membranes dynamically formed on the interior of sintered stainless steel support tubes. The unit was designed to recycle $90 \%$ of the dye wash water in a continuous dye range at a process temperature of $185^{\circ} \mathrm{F}$ and remove $97 \%$ of the color. 
Current energy savings from two units in operation are 0.1 trillion Btus per year. Other potential uses of hyperfiltration include the extraction of apple juice in the food industry, recovery of caustic solutions in the textiles industry, and concentration of radioactive sludge. The potential savings estimated for this new technology in 2010 are 111 trillion Btus.

\section{Membrane Separation in the Sweetener Industry}

The most energy-intensive process in the corn sweetener industry is the dewatering of waste streams. Industry-wide, evaporators consume 5 trillion Btus per year to concentrate about five billion gallons of steep water. With DOE support, Bend Research Corporation developed an energy-efficient hollow-fiber membrane system to preconcentrate corn steepwater. The process uses reverse osmosis, leaving a concentrated solution of organic compounds (such as sugars) on the feed side of the membrane.
The technology for the process was tested at a Midwestern corn milling plant. The system can extract more than $50 \%$ of the water from the corn steep stream before evaporation, significantly reducing energy requirements. Compared with a conventional mechanical vapor recompression system by itself, the membrane distillation process, combined with a mechanical vapor recompression evaporator, provides a capital cost savings of $13.5 \%$ and an operating cost savings of $20 \%$. Projected savings in 2010 are 4.5 trillion Btus per year.

\section{Energy-Efficient Fertilizer Production}

Conventional production of fertilizer is an energyintensive process. With financial support from DOE, the Tennessee Valley Authority developed a reactor that can substantially reduce energy use in producing many types of pellet fertilizers. The reactor, which uses a newly devised ammonia-granulation

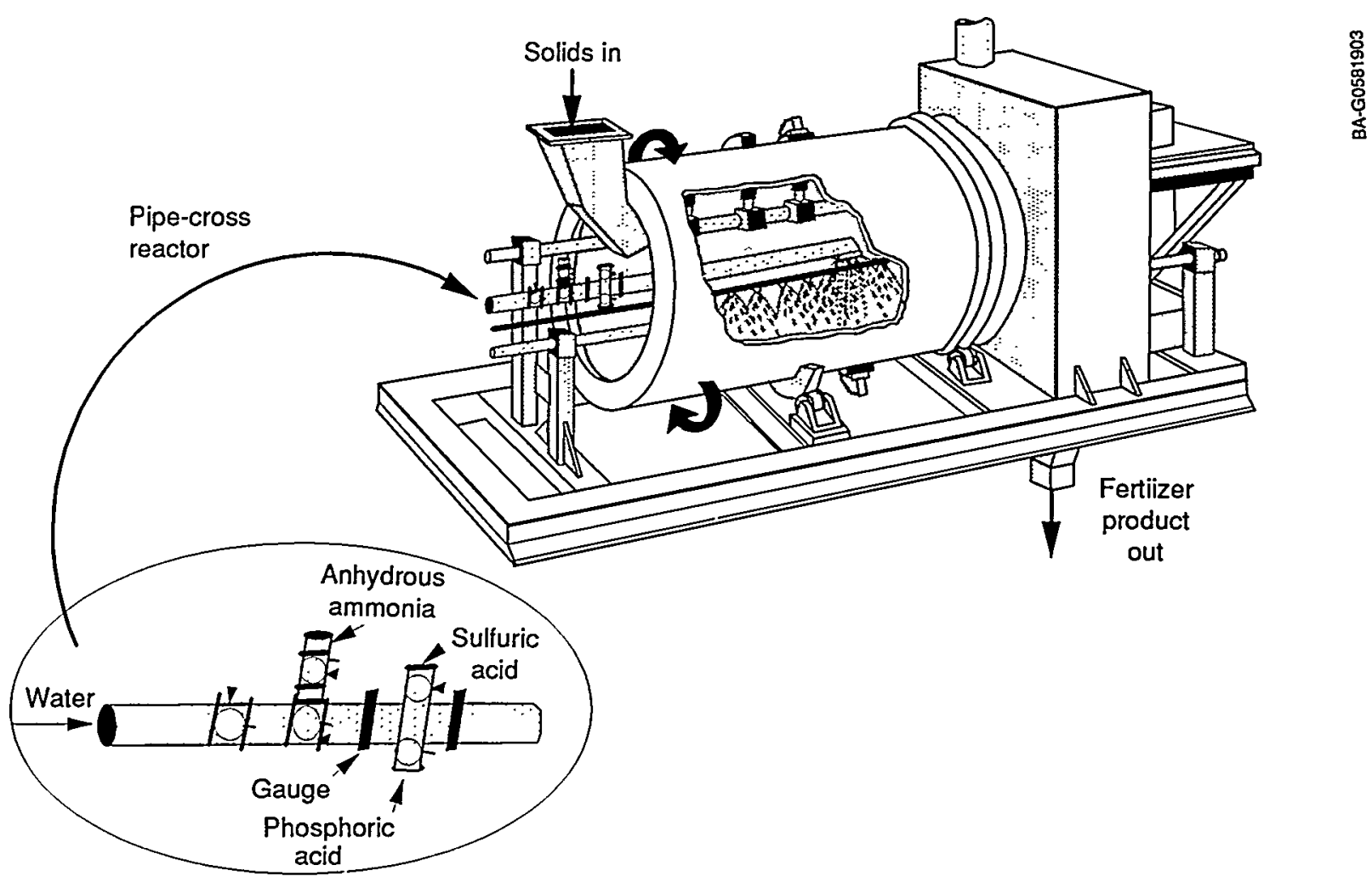

A novel configuration allows fertilizer granules to be dried by the heat produced during chemical reactions in the production process. 
technology, has a pipe-cross configuration in which liquid raw materials are mixed. This assembly is mounted within the granulator so that heat produced by the chemical reactions helps to form and dry the granules. With this design the final product has less than $1 \%$ moisture, in contrast with the $5 \%$ to $7 \%$ moisture content found in conventional fertilizers before drying. In addition to reducing or eliminating the drying operation, this technology yields a superior product and reduces pollution control problems.

Seven innovative reactors are now operating in the fertilizer industry, saving about 0.12 trillion Btus per year. Projected annual savings in 2010 are 5.4 trillion Btus.

\section{Irrigation Systems}

An estimated 60 million acres of agricultural land are irrigated in the United States, consuming nearly 270 trillion Btus annually at a cost of $\$ 1.4$ billion. $\mathrm{DOE}$, in cooperation with five universities and five private businesses, funded a program to develop and demonstrate new energy-saving technologies for irrigation. Three technologies resulting from the program have yielded significant energy and water savings. The new technologies are computerized scheduling, reduced-pressure application systems, and drop-tube application systems. Reduced-pressure sprinkler irrigation technology is used at about 15,000 sites across the country, and the three technologies together are saving about 4.3 trillion Btus annually. They could save 40 trillion Btus per year by 2010 .

\section{Oxygen Production by Chemical Air Separation}

Industrial oxygen is used in many thermal processes at metal, chemical, and utility plants. Currently, it is produced by the cryogenic process in which air is compressed, liquefied, and distilled into its components. For this process, thermal energy must be converted to mechanical energy to compress the air, and about two-thirds of the thermal energy is lost during this conversion. Typically, about 2000 Btus are used to produce each pound of oxygen.

With DOE cost-sharing, Air Products and Chemicals is developing a continuous chemical separation process (known as MOLTOX) invented by the Energy Concepts Company. The process is based on the ability of some salts to absorb and release oxygen with changes in temperature and pressure. Because this process uses thermal energy directly and recovers energy from the exhaust air, it requires $40 \%$ less energy (when combined with a steam boiler) than current cryogenic processes. Thermal energy can be conveniently supplied from high-temperature plant waste heat. The chemical air separation process produces oxygen at $99.8 \%$ purity.

Potential applications include use in the steel, chemi$\mathrm{cal}$, and electric utility industries. Operation of the process was demonstrated in a quarter-ton-per-day process development unit. Electricity consumption in the new process is also lower than in the conventional process, resulting in an overall energy savings of $44 \%$. Annual savings in 2010 are estimated at 44.1 trillion Btus.

\section{Carbon Dioxide Recovery from Industrial Waste Streams}

The rapid expansion of enhanced oil recovery has resulted in a demand for carbon dioxide, which is used to make crude oil flow more readily. Currently, the only economical sources of carbon dioxide are natural deposits and process vents at hydrogen plants.

In cooperation with the Argonne National Laboratory, DOE has successfully completed a test to recover carbon dioxide from dilute waste streams from industrial furnaces. The process involves burning coal in an environment of oxygen and carbon dioxide rather than relying on the natural mixture of nitrogen and oxygen. The process uses $25 \%$ less energy than the conventional process and creates an effluent stream that is rich in carbon dioxide (about 95\%). The process also eliminates the need for flue gas desulfurization and carbon dioxide purification.

The major costs of the coal-oxygen process are the capital costs of the air separation plant and the cost of the electricity required to run the plant. The capital cost of a separation plant is approximately $\$ 21,000$ per ton per day for a plant with a daily capacity of 1818 tons. The electrical requirement is 242 kilowatthours per ton of gaseous oxygen produced. Production of a ton of carbon dioxide with the process requires 0.8 ton of oxygen.

Within a 300-mile radius, the recovered carbon dioxide can be transported to most oil fields at a total cost that would be competitive with other sources. It was estimated that enhanced oil recovery techniques could recover $50 \%$ of the reservoir potential by 2000 
and that carbon dioxide injection could account for $30 \%$ of that amount.

\section{Nitrogen-based Carburization}

Carburization is a method of heat-treating steel parts in a carbon-containing atmosphere to give them improved strength, hardness, and resistance to wear. The conventional carburizing furnace atmosphere contains $20 \%$ carbon monoxide, $40 \%$ hydrogen, and $40 \%$ nitrogen. With DOE funding, a more energyefficient nitrogen/methanol carburization process was developed and tested by Air Products and Chemicals. The process improves energy efficiency by increasing the carbon monoxide concentration in the furnace. This accelerates the rate of carburization and allows a reduction in the cycle time, thus saving energy. The advanced process is now operating in 2419 furnaces, saving 1.1 trillion Btus annually. Savings in 2010 are estimated at 2.3 trillion Btus annually.

\section{High-Performance Slot-Forge Furnace}

Conventional slot-forge furnaces, which are used to heat metal stock to about $2300^{\circ} \mathrm{F}$ prior to forging, are highly inefficient. Thermal losses can amount to about $90 \%$ of their energy consumption. These losses occur as a result of hot combustion gases escaping through the exhaust system and heat loss through the furnace walls, roof, and slot.

Under a DOE cost-shared project, Hague International developed a high-performance slot-forge furnace that minimizes these and other heat losses. The furnace incorporates certain design features that offer energy savings of $50 \%$ or more, while retaining the simplicity of a conventional slot furnace. The key feature is a ceramic recuperator that preheats incoming combustion air to $1500^{\circ} \mathrm{F}$ with furnace exhaust gases. Other energy-saving modifications include new recirculation burners, improved temperature and air/fuel ratio controls, slot closure doors that open only for metal stock insertion or removal, and lightweight furnace wall insulation.

As a result of this project, other manufacturers have developed similar furnaces that are even more energy efficient. Seven of the Hague-designed units were in operation during 1989, saving an estimated 0.4 trillion Btus. Projected savings in 2010 are 88 trillion Btus per year.

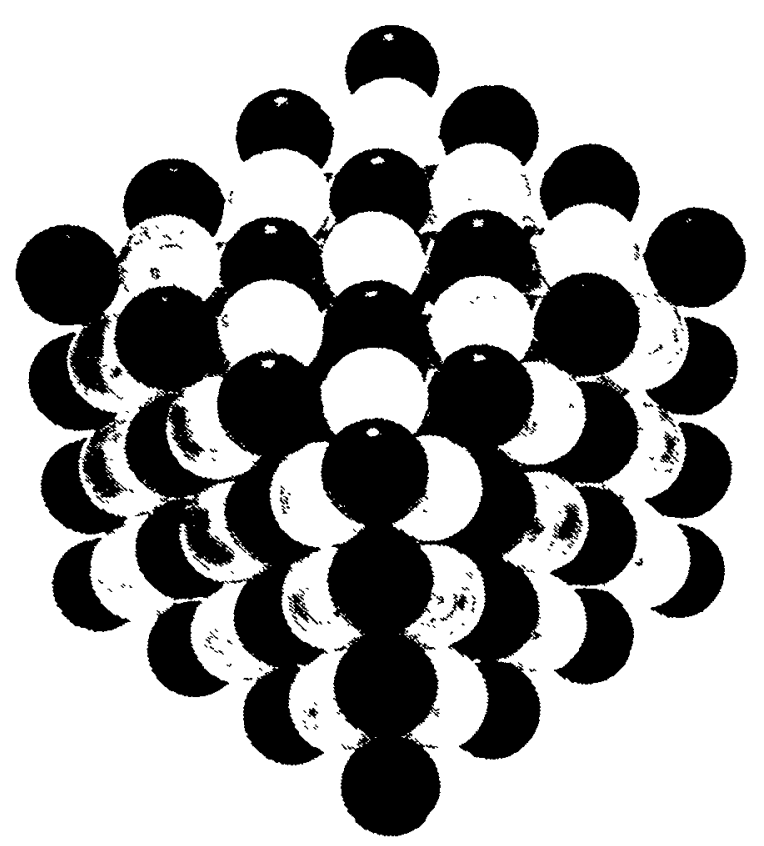

Nickel aluminide, the first ductile-ordered alloy that can withstand high temperatures, provides an alternative to ceramics in advanced, energy-conserving technologies.

\section{Ductile-ordered Alloys}

The development of advanced, energy-conserving technologies is constrained by the lack of materials capable of withstanding high temperatures, high pressures, and highly corrosive environments. However, development of metallic materials of ordered crystal structure with high-temperature capabilities has provided an alternative to ceramics in overcoming these material limitations. In particular, intermetallic compounds offer the advantages of excellent hightemperature strength, good response to work hardening, superior creep properties, and excellent oxidation and corrosion resistance for certain intermetallics (e.g., aluminides). However, using aluminides as structural materials results in poor ductility and fabricability, which are major problems.

Developed at the Oak Ridge National Laboratory through research supported by DOE, nickel aluminide is the first truly ductile-ordered intermetallic alloy that can withstand high temperatures. The new hightemperature alloy is moving rapidly toward commercialization, with five licensing agreements to date: Cummins Engine Company, for use in large diesel engine applications; Armco, Inc., one of the five largest steelmakers in the United States, for commercial 
mass production; Armada Research Corporation, for heating elements in electric appliances and industrial furnaces; Metallamics, for tool and die components; and Valley-Todeco, for aircraft fasteners.

\section{Separation of Impurities from Molten Metals}

The manufacture and fabrication of steel and other metallic materials is often complicated by the presence of nonmetallic particulates in the solidified metals. In the steel industry, the movement toward thinner castings requires more stringent control of the particulate content of the metal. Earlier casting techniques that used large ingot molds and, later, continuous casting, required hot-rolling reductions followed by cold rolling to produce sheet material. This large amount of energy-intensive mechanical working was sufficient to break up and disperse the particulates and make them relatively harmless. In contrast, newer near-net-shape casting technologies that are less energy intensive do not require such substantial reductions; therefore, the particulates remain as originally formed, with possible deleterious effects to the metals' properties.

To alleviate the problems associated with particulate contaminants in metals, DOE developed a magnetohydrodynamic separator for use with liquid metals. Early work confirmed the value of using the molten metal as a current-carrying conductor passing through a magnetic field. The resulting force on the

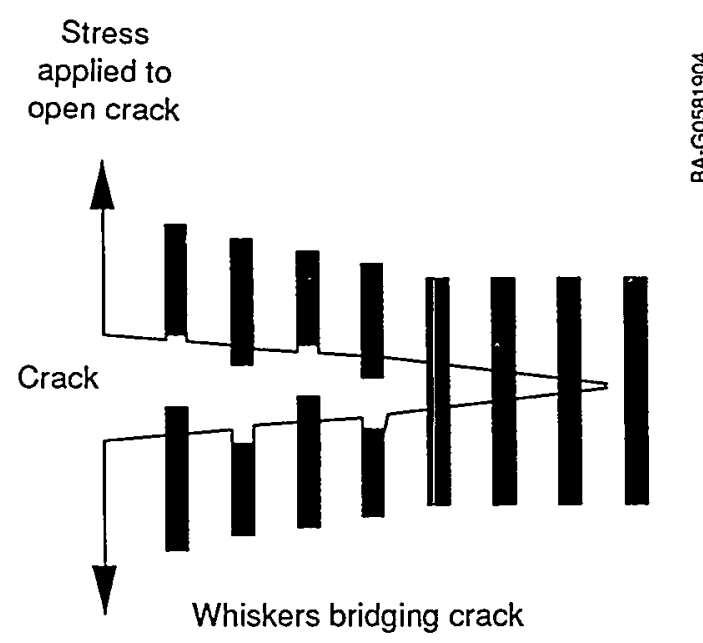

Whisker-reinforced ceramic composites increase resistance to fracture at elevated temperatures. metal causes it to act as if it had a higher density. This makes the nonconducting particulates flow quickly to a region where they can be skimmed or separated from the metal.

Successful experiments were performed using molten aluminum and either alumina or silicon carbide as the impurity particles. Two patent applications for the process were filed, and industrial interest in the process is growing. Further technology development is being undertaken by the DOE Steel Initiative.

\section{High-Purity Silicon Powder Process}

Traditionally, the production of ceramics has relied on comminution to reduce materials to a uniform particle size. This is done through grinding and crushing operations that are typically less than $1 \%$ energy efficient.

Now a high-purity, low-cost silicon powder process, developed by the Oak Ridge National Laboratory and Advanced Refractory Technologies, eliminates most of the comminution required in producing ceramics. In the new process, powder is produced using a rotary kiln technique. Quantities of sample powder have been distributed to major ceramic component producers for manufacturing evaluation and properties testing. Projected material costs for this pure silicon carbide powder are estimated at one-third to one-fourth of current costs, making high-temperature ceramic recuperators much more economical and providing a higher-quality product.

\section{Whisker-toughened Ceramic Composites}

Ceramics such as alumina have excellent wear resistance and high-temperature strength, but are too brittle for wide commercial use. DOE researchers have developed a novel approach using "designed microstructures" in brittle ceramics that provides major gains in fracture resistance. The technique produces a ceramic composite reinforced with silicon carbide whiskers, disproving the conventional wisdom that only long fibers would work. To date, this new technology has yielded nine licensing agreements with the private sector.

Based on the results of research conducted with alumina composites, further DOE-supported efforts have produced a new, high-strength structural material based on reinforced molybdenum disilicide. This 
unique composite, fabricated using both vapor-liquidsolid and vapor-solid silicon carbide whiskers, exhibits a $100 \%$ increase in room temperature strength and a $30 \%$ increase in fracture toughness. The elevated temperature strength of this composite is $300 \%$ greater than that of nonreinforced molybdenum disilicide.

These unique alloys are already finding several applications in the energy technology field. In fact, use of whisker-toughened alumina for machine cutting tools has already gained widespread industrial acceptance and should dominate the market in the near future. Sales of industry products, including cutting tools, gears, wear parts, and other items, is estimated at \$25 million for 1995.

\section{Ceramic Surface Modifications}

Ceramic materials fail catastrophically because of the growth and propagation of defects, particularly cracks initiated at free surfaces. Surface modification techniques can reduce the size and number of defects and provide a secondary phase in the ceramic matrix that can absorb the crack propagation energy.

DOE-funded research has established that ion and laser surface modifications are capable of arresting surface-initiated crack propagation, thereby significantly increasing the strength and reliability of ceramics. An increase of about $40 \%$ in the fracture toughness of silicon carbide was achieved by laser treatment of nickel deposited on the ceramic surface. Implanting partially stabilized zirconia with aluminum ions, followed by annealing, results in a $70 \%$ increase in fracture toughness and a $30 \%$ increase in microhardness. The development of tougher ceramic materials using these surface modification techniques may permit the substitution of ceramics for metals in many end-use applications at elevated temperatures, at high-stress levels, and in oxidizing environments.

\section{Ceramic Joining}

The potential for structural ceramics in advanced energy-conservation applications has not been realized because little research has been conducted on the joining of ceramics. In 1982, DOE decided to fill this gap by initiating long-term, applied R\&D in the area of ceramic attachments for high-temperature applications. Subsequent research defined the current limits of room-temperature strengths of brazed ceramic/ ceramic joints.
Brazes were developed for silicon carbide and alumina with acceptable room-temperature strengths and toughness. The brazes will allow ceramic components to be used economically in large operational systems such as high-temperature heat engines and heat exchangers or in any other application requiring resistance to high temperatures, stresses, or oxidizing atmospheres. This project was transferred to other DOE programs for subsequent applications development.

In a complementary effort, highly refined, finiteelement mathematical models were developed to obtain an understanding of stresses and fracture mechanisms in ceramic/metal joints. These models were validated experimentally for rectangular and cylindrical joint geometries, and a three-point flexure test geometry was developed to experimentally validate adhesion models for zirconia/nodular cast-iron braze joints. This research was transferred to the DOE Ceramic Technology for Advanced Heat Engines Project for further applications development.

\section{Magnetic Resonance Imaging for Advanced Ceramics}

Processing of the high-performance, hightemperature structural ceramics planned for use in advanced heat engines requires a much greater level of understanding than has been achieved to date. Part of processing science is the development of practical, nondestructive evaluation methods to identify problems at the earliest possible stages. One such method with the potential to affect processing science is magnetic resonance imaging, a chemically sensitive, noncontacting, nondestructive technique.

DOE funded a project to study the potential of this imaging technique to directly map the distribution of organic binders and plasticizers used in injection molding processes and of porosity after the binder/ plasticizer has been removed (i.e., dewaxed). Because the polymeric organic binder/plasticizer used contains a high concentration of protons, it was an excellent candidate for magnetic resonance imaging. It was shown that this technique can be used to directly image distributions of organic binders/plasticizers as used in injection molding and in image-porosity distribution if a carefully selected filler fluid is used with a proper infiltration procedure. Follow-on work with the technique is currently under way by the DOE Ceramic Technology for Advanced Heat Engines Project. 


\section{Cement Particle Size Classification}

A major cost component in cement production involves grinding and separating fine and coarse cement particles. Now, through research under a costshared effort with Construction Technology Laboratories, a subsidiary of the Portland Cement Association, DOE found that these costs can be substantially reduced by using controlled particle size distribution cement, by applying high-efficiency classifiers, and by implementing mill configuration and operating changes. Full implementation of this technology would produce a superior cement product and save the average U.S. producer $\$ 400,000$ per year in finish-grinding costs alone. In addition, plant finish-grinding capacity would be increased by more than $25 \%$. Thirty-seven plants are currently using the new technology and saving an estimated 1.01 trillion Btus per year. Annual energy savings from use of this technology are expected to be 20.5 trillion Btus in 2010.

\section{Coatings for High-Speed Cutting Tools}

Improved tooling systems for automated machining operations can increase production rates, reduce tool replacement times, and improve energy use. These new tooling systems for high-speed machining can be developed based on an improved understanding of tool wear mechanisms. A cooperative effort funded by DOE has developed processes for depositing hard coatings. It also developed a theoretical understanding of the wear behavior of hard coatings, which explains the differences in performance of one coating over another in cutting operations.

The two commercially viable processes are the highrate reactive sputtering and the activated reactive evaporation processes. Cutting performance tests indicated that sputtering coatings outperform uncoated tool inserts by factors of between 3 and 10, depending on coating composition. Activated reactive coatings were found to outperform uncoated inserts by a factor of 3 . Two patent applications were filed covering the high-rate reactive sputtering processes, and two licensing negotiations are under way.

The theoretical model includes the effects of chemical dissolution of the tool into the workpiece in addition to the effects of mechanical wear. Cutting test results with high-speed steel (T-15) inserts coated with carbides and nitrides of titanium and zirconium showed that wear resistance increased about 3 times for zirconium nitride compared with titanium nitride, verifying predictions made using the theoretical model.

This research has advanced understanding of tool wear to a point where it is feasible to use computer searches of a data base on thermodynamic and mechanical properties with the objective of identifying the best coating compositions for wear resistance. As a result, industry should be able to systematically implant less expensive substrate materials with coatings that have low friction and wear properties.

\section{High-Efficiency Welding Unit}

Improving power supply efficiency is the key to achieving significant energy savings in welding processes. Conventional arc-welding power supplies use a low-frequency transformer, which is responsible for their inefficient use of power and for the large size and weight of the units. Because current continuously flows through the transformer, considerable energy is wasted when the unit is idling between steps in a welding job.

With funding from DOE, Cyclomatics has applied a new inverter technology to arc welding power supplies, bringing significant savings to the welding industry. The DOE/Cyclomatics inverter technology uses a silicon-controlled rectifier and a highfrequency, high-efficiency transformer, which together dissipate little energy. The rectifier shuts off power to the transformer when the system is idling, greatly reducing electrical energy consumption.

Typical power losses for the high-efficiency welding unit are $15 \%$, compared with $45 \%$ to $55 \%$ for a conventional unit. Power supply size and weight are drastically reduced as well, improving the portability of the unit. This joint effort is a good example of what can be achieved through cooperative government / industry R\&D activities.

In 1988 , there were more than 48,600 of these highefficiency welding units in operation, saving an estimated 3.06 trillion Btus per year. In addition, the technology was recently applied to plasma cutting devices; more than 2500 of these high-efficiency cutters had been built and sold by the end of 1988. By 2010, this technology could save about 12.2 trillion Btus annually. 


\section{Improved Pulse Combustion Technology}

\begin{abstract}
Although pulse combustion technology has been known for many years, devices using pulse combustion have not been widely implemented in spite of attractive characteristics such as high heat transfer and combustion intensity, low emissions of nitrogen oxides, high thermal efficiencies, and self-aspiration. The lack of information about fundamental fluid dynamics and combustion processes has caused the design and development of pulse combustors to proceed largely by trial and error, a method that does not guarantee an optimum design.
\end{abstract}

In a DOE-funded research effort, a wide variety of in situ optical diagnostics were applied to an experimental pulse combustor to elucidate reignition, unsteady valve dynamics, and the mixing and combustion processes. A simple model for combining the effects of fluid mixing time and ignition delay time (a property of the fuel used) was developed and will be incorporated into a one-dimensional, nonlinear pulse combustor model. The model incorporates valving dynamics, improved heat transfer estimates, inlet and exhaust decouplers, and a method for determining combustor resonant frequency.

In a complementary effort, the feasibility of using alternative fuels in pulse combustors was established. A modified version of a Rijke pulse combustor was successfully tested using various liquid fuels, including kerosene and No. 2 to No. 6 fuel oils. Combustion efficiencies of more than $99 \%$ were obtained when burning fuel oil No. 6 .

This new understanding of pulse combustion processes will provide useful knowledge and design guidelines for the development of pulse combustion systems that may capture the inherent advantages of this technology.

\section{Fluid-Elastic Instability in Heat Exchangers}

Increasing the fluid pumping rate of shell-and-tube heat exchangers can increase the overall rate of heat transfer. However, a high rate of pumping can often generate fluid-elastic pressure waves at a frequency high enough to be close to the natural frequency of the heat exchanger assembly. When this occurs, tube vibration at high amplitudes is induced and, unless corrected, ultimately leads to heat exchanger failure.
Research in fluid-elastic instability of shell-and-tube heat exchangers was supported by DOE to provide a better understanding of the flow regimes in which an actual heat exchanger must operate to avoid structural failure. Using an instrumented laboratory setup capable of accommodating industrial-sized heat exchangers, pressure drop and tube vibration data from water-flow tests were developed. In cooperation with Heat Transfer Research, actual cases of industrial heat exchanger failures were documented and incorporated into the extensive data base.

A multidimensional flow-velocity model for numerical simulation of shell-side flow distribution was also developed for predicting tube-bundle fluid-elastic instability thresholds and pressure drop. The model was validated using the extensive data base of experimental results and documented cases of actual heat exchanger failure.

Improved understanding of fluid-elastic instability in shell-and-tube heat exchangers should lead to more reliable designs, improved heat-exchanger effectiveness, and subsequent reductions in process energy requirements. Heat exchangers are used extensively in industry, so this work should lead to substantial energy savings nationwide.

\section{Industrial Air-Dryer Membrane}

Drying is an energy-intensive process used throughout industry to remove moisture from products. Energy contained in the latent heat of the moistureladen exhaust from these processes is lost to the atmosphere. With DOE funding, Bend Research developed a membrane-based process to recover this energy from dryer exhaust streams.

In the membrane modules, a compressor draws a vacuum on the permeate side of the membrane, reducing the pressure of the water vapor in the exhaust stream. This creates a driving force that causes the water vapor to cross the membrane. The result is a hot, relatively pure stream of water vapor that is ready to undergo conventional vapor recompression. The water vapor is then sent to a condenser and the latent heat transferred to a convenient heat sink.

The membrane-based process was successfully tested at the Crown Zellerbach paper plant in Wauna, Oregon. The process may be applied to drying a variety of products, such as fertilizer, sugar, paper, and coal. When applied to fluid-bed coal drying, for example, the membrane-based process can recover about $30 \%$ 


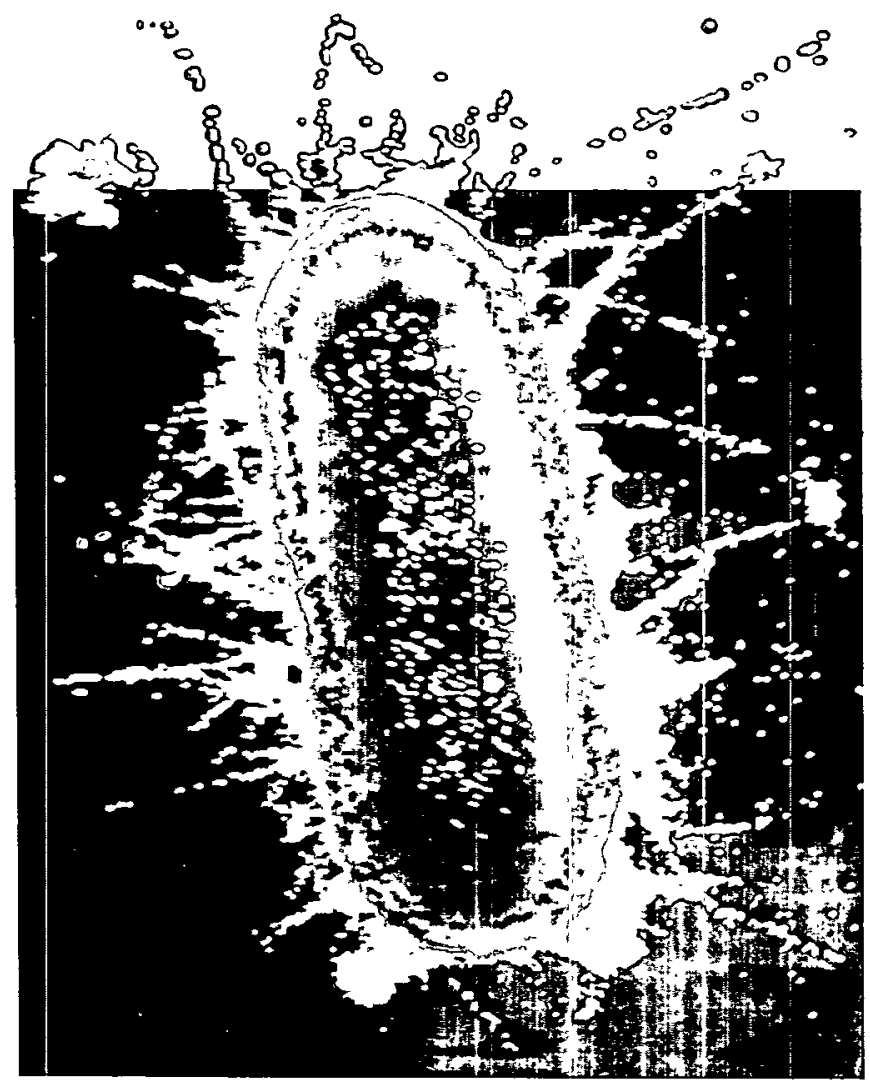

Genetic techniques to stabilize recombinant microorganisms, such as E. Coli bacterium, could provide the basis for efficient, economical, large-scale bioproduction of chemicals and fuels.

(Photo by J. A. Engler, T. R. Broker, and J. I. Garrels. Reprinted with permission from Molecular Cloning: A Laboratory Manual, 1982, Cold Spring Harbor Laboratory.)

of consumed energy, with an estimated payback period of 3.7 years. It is estimated that the process can save approximately $10 \%$ to $20 \%$ of the 1.89 quads of energy used annually in process drying applications.

\section{Genetic Engineering for Efficient Biochemical Processes}

The application of genetic engineering to certain microorganisms should lead to greatly reduced production costs for some organic chemicals. Microorganisms can be grown on relatively inexpensive feedstocks, such as biomass. Production costs for some organic chemicals will be lower if genetically engineered processes can be scaled up. Yet, before this potential can be realized in large-scale industrial processes, a method must be developed for stabilizing and retaining genetically engineered traits in large quantities (cultures) of microorganisms.

In response to this need, DOE developed a new method of gene cloning and amplification that will be far superior to the standard method in supplying stable strains of microorganisms for large-scale applications. In the new method, foreign genes or genes of interest carried on a plasmid are introduced directly into the main chromosome of the microorganism. In one experiment, for example, a specific gene of interest was inserted into the bacteriophage $E$. coli and was subsequently observed to be amplified.

This process will lead to improved stability and productivity of recombinant DNA microorganisms. In addition to the potential for aiding in large-scale chemical production by biocatalysis, this research should also be applicable to the production of pharmaceuticals and biological materials.

\section{Efficient Aerobic Fermentation}

Biocatalysts can facilitate desired chemical reactions in one step by lowering the activation energy barrier. Unfortunately, the availability of oxygen necessary for microorganisms is a major constraint in the growth and production of microorganisms within the bioreactor used in aerobic fermentation. Biochemical engineers devised a variety of bioreactor geometry and stirrer configurations to minimize this problem. But now, under DOE sponsorship, a breakthrough technology with broad application has been developed for aerobic fermentation using genetically engineered microorganisms.

Researchers at the California Institute of Technology have shown that the oxygen limitation problem can be minimized by genetically inserting a hemoglobin gene into $E$. coli bacteria. It was clearly demonstrated that $E$. coli-possessing plasmids containing

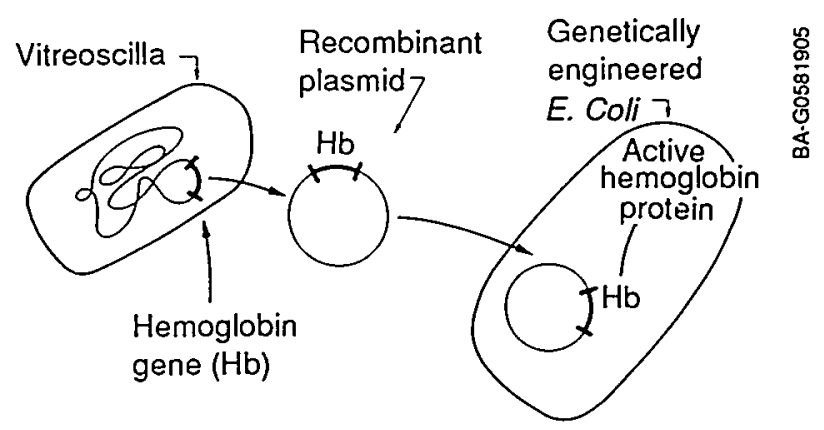

By implanting a hemoglobin'gene in an E. Coli bacterium, researchers can improve the growth and productivity of genetically engineered aerobic microorganisms. 
hemoglobin, an oxygen carrier, grew more efficiently at a lower oxygen concentration (by two times) than those without the hemoglobin gene. This method can dramatically improve the growth and productivity of genetically engineered aerobic microorganisms.

The production of aerobically fermented products in the United States in 1987 was about 300 million pounds. Use of these genetically engineered microorganisms can help resolve critical barriers that currently impede the production technology of energy- efficient aerobic fermentation processes. Two broad-based patents for the above technology were filed.

\section{Designing Biocatalysts for Energy-Efficient Chemicals Production}

There are several technical barriers to the development and application of biocatalysts for producing fuels and chemical feedstocks. The development of a molecular-level reaction model for enzyme systems is an initial scientific step toward removing these barriers. During the past three years, the California Institute of Technology, with DOE funding, has developed software for computer-based graphic displays of three-dimensional structural models of molecules. The models permit the user to display and rotate a three-dimensional representation of the structure of any biological molecule of interest, such as an enzyme or pharmaceutical. The interaction of the atoms in the molecule and any structural changes imposed by the user-specified conditions (e.g., increases in temperature, pressure, or the removal/ substitution of any given atom) can be displayed. The models simulate real molecules by using a set of analytic force fields to describe the interactions among the atoms. When the models were used for predicting the molecular structure of the enzyme thermolysis as a function of temperature and inhibitors, excellent agreement with crystallographically determined structures of thermolysis resulted.

This tool is now being used to design new molecular structures for drugs, catalysis, and a wide variety of other applications. The simulation models may enable the design of supports for immobilizing enzymes without degrading performance and enable the design of enzymes for selectivity and resistance to poisons.

\section{High-Productivity Bioreactor}

Batch fermentation processes using microorganisms suspended directly in the fermenting broth suffer from low product yields, accumulation of impurities that contaminate the desired product, and loss of microorganisms from the batch when processing is completed. To increase productivity sufficiently for industrial fermentation processes to be competitive, more efficient continuous processing techniques need to be used.

DOE research in continuous fermentation processes has increased ethanol productivity 10 times in an advanced fluidized-bed reactor system. In addition, the study of the kinetic properties of immobilized microorganism biocatalysts has led to a better understanding of the behavior and predictability of bioreactors.

The A.E. Staley Company has expressed interest in the research and has provided raw corn dextrose slurry and corn light steepwater for laboratory tests. Experiments in a continuously stirred tank reactor using yeast extract as a nutrient source have been completed. The steady-state productivity was not changed when glucose was substituted for crude corn dextrose or when yeast extract was replaced with a 1:5 dilution of light steepwater. The only operational difficulty was some fouling because of the high lipid content of corn dextrose. During the 300-hour run, 25 grams per liter-hour of ethanol were produced at a $90 \%$ conversion rate. These results suggest that higher productivities for a fluidized-bed column at greater than 200 grams per liter-hour are possible when industrially acceptable feedstocks and media such as corn dextrose and light steepwater are used.

\section{Coal-fired Steam Turbine Cogeneration}

Cogeneration systems for industrial processes can potentially save thousands of dollars per year. Cogeneration is not widely used in such industries as textiles manufacturing, however, either because of space limitations or because the temperature of the turbine exhaust is too low for process use. To encourage use of cogeneration systems in this industry, DOE and Riegel Textile cofunded the design, installation, and evaluation of an innovative 4.1-megawatt, high-backpressure steam cogeneration system at one of the firm's textile plants. 


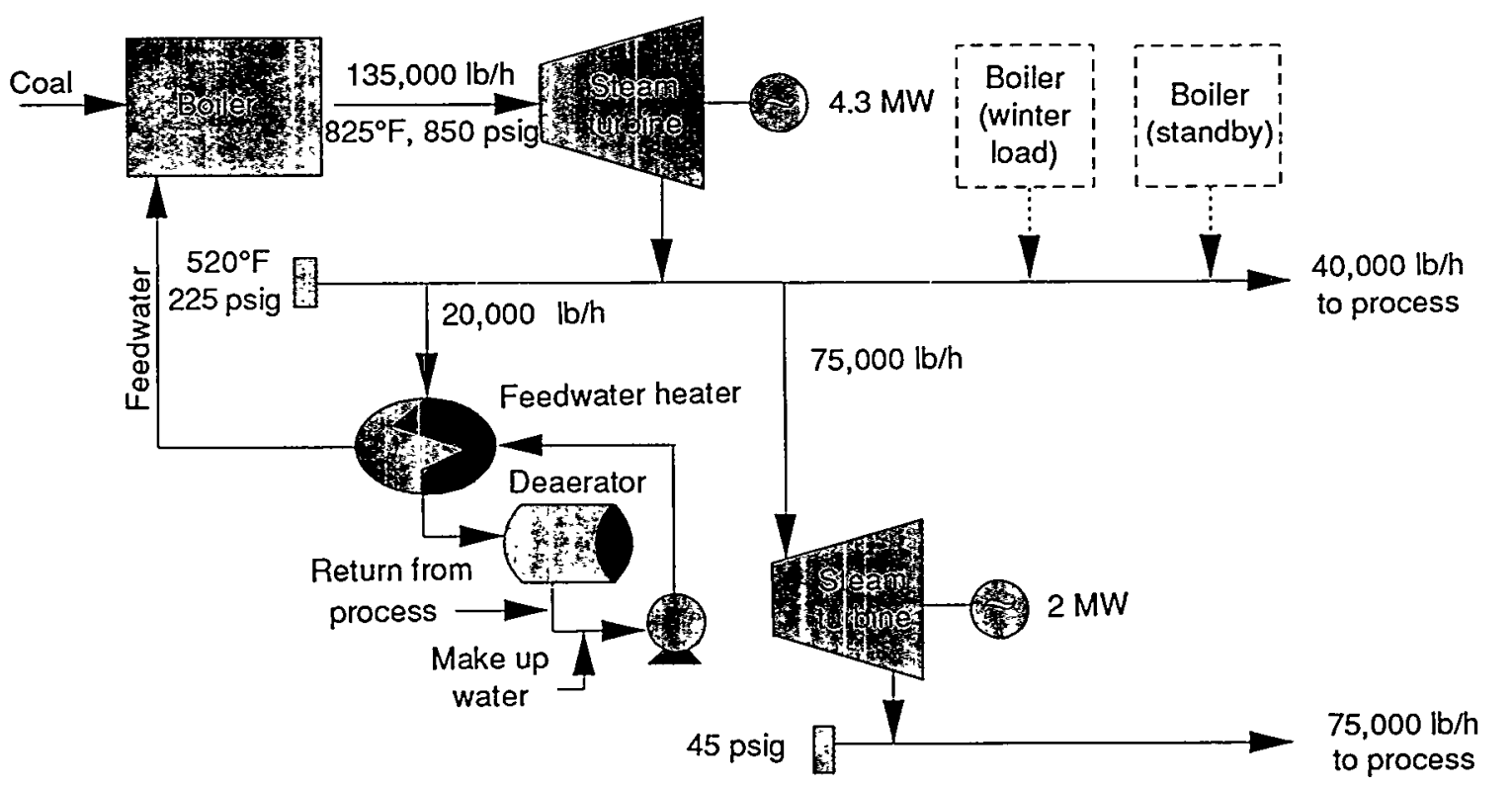

New equipment

Existing equipment

The steam from high-back-pressure steam cogeneration systems can be used for process heat and space heating.

The new system uses a coal-fired boiler that was modified to solve retrofitting space problems. The boiler generates steam to power a turbine that produces electricity. The turbine exhaust steam temperature is high enough to be used for process heat requirements and to provide space heating. The prototype system's net energy cost savings are $\$ 250,000$ per year.

Although the system was originally developed for the textile industry, it also applies to several other industries. Eight systems were in operation in 1989, saving about 10.8 trillion Btus. Energy savings for 2010 are estimated at 469 trillion Btus.

\section{Organic Rankine Bottoming Cycle}

In a conventional Rankine-cycle electricity generating system, water is alternately vaporized and condensed. These Rankine-cycle systems have been the mainstay of electric power generation for nearly a century. Large power-generating steam plants can attain efficiencies of about $39 \%$. However, at heat source temperatures below $700^{\circ} \mathrm{F}$, steam systems become less efficient and are too expensive to use. Conventional steam Rankine-cycle systems, therefore, cannot be used to economically generate electricity from many industrial waste-heat streams.

DOE and Sundstrand Energy Systems developed and tested a new waste-heat electric power generation system consisting of a standard Rankine-cycle engine, an organic working fluid (toluene), a waste heat boiler, a waste gas flow-control valve, system controls, and an electric generator. The system is rated at 600-750 kilowatts, depending on the temperature and mass flow rates of the waste-heat stream. This organic Rankine-cycle system is suitable for use with many types of waste-heat sources: gaseous streams above $600^{\circ} \mathrm{F}$, liquid streams above $550^{\circ} \mathrm{F}$, and condensing streams above $500^{\circ} \mathrm{F}$. It is also readily adaptable to a wide variety of solar and geothermal energy applications. One unit installed at a manufacturing plant saved 0.01 trillion Btus during 1989. 


\section{Slow-Speed Diesel Cogeneration}

Slow-speed, two-stroke diesel engines, which are used extensively in marine applications, have a higher electrical-to-thermal output ratio than steam turbines currently used in cogeneration systems. In addition, when fired with residual oil, these slowspeed diesel engines offer a more compact size, higher efficiency, greater load flexibility, lower fuel costs, and lower maintenance costs than cogeneration options currently used.

To prove the advantages of such systems, DOE and Hoffman-LaRoche cofunded the design, installation, and evaluation of an industrial cogeneration system using this technology. The system uses a low-speed, two-stroke diesel engine, fired with low-sulfur fuel oil and coupled to an electric generator; a supplementary oil-fired waste-heat boiler that burns the diesel's exhaust for steam production; and heat exchangers for recovering waste heat from the engine to provide hot water. The system generates 23.3 megawatts of electricity.
Evaluations are continuing at the Hoffman-LaRoche pharmaceutical plant where this system was installed. This unit and three others are operating at a Florida utility, saving 1.93 trillion Btus per year. Energy savings from this technology are estimated at 167 trillion Btus per year by 2010 .

\section{Fluidized-Bed Waste-Heat Recovery System}

In this cost-shared project, Aerojet General developed a self-cleaning waste-heat recovery system that can operate in dirty exhaust gas streams (those that cause fouling and corrosion problems for conventional heat recovery systems). Heat is recovered by finned heatexchange tubes submerged in a bed of spherical alumina particles. As hot waste gases flow through the bed, the particles absorb the heat and transfer it to the tubes. Water circulated through the tubes is heated to form steam for use elsewhere in the plant. Because the flow of the waste gas constantly agitates the alumina particles, the particles tend to distribute the heat

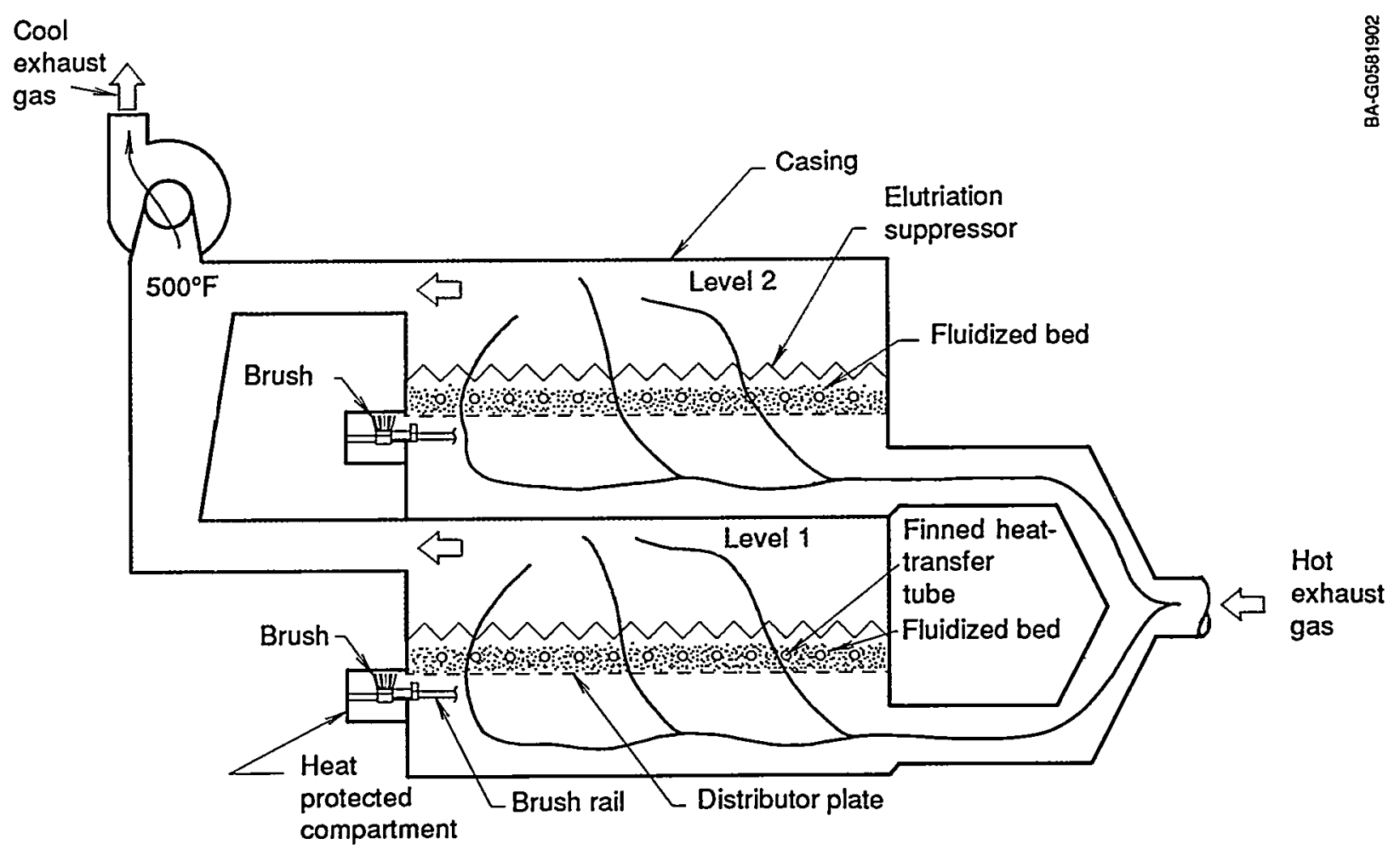

The fluidized-bed waste-heat recovery system uses finned heat exchange tubes submerged in a bed of spherical alumina particles to recapture waste heat. 
evenly and clean the outside of the finned tubes, thus reducing corrosion.

The first U.S. industrial fluidized-bed waste-heat recovery system has been operating for more than a year on an aluminum remelt furnace at an ALCOA plant. The system can save 13 billion Btus per year, representing $85 \%$ to $90 \%$ of the energy entering the waste-heat boiler. Aerojet General is now commercializing this technology, which could save about 40 trillion Btus per year by 2010 .

\section{High-Temperature Recuperators}

Industrial processes that rely on combustion heating are highly energy-intensive. This is particularly true at high combustion temperatures, where more than $50 \%$ of the energy consumed as fuel is lost in the process exhaust. Recuperators can recover significant portions of this wasted energy by capturing heat from the exhaust and returning it to the combustion process in the form of preheated air. Conventional recuperators provide combustion air at a maximum temperature of $1300^{\circ} \mathrm{F}$. The development of hightemperature burner-duct recuperators now allows recovery of heat from exhaust gases to produce preheated combustion air with temperatures as high as $2000^{\circ} \mathrm{F}$. This significant increase in combustion air temperature results in correspondingly significant energy savings.

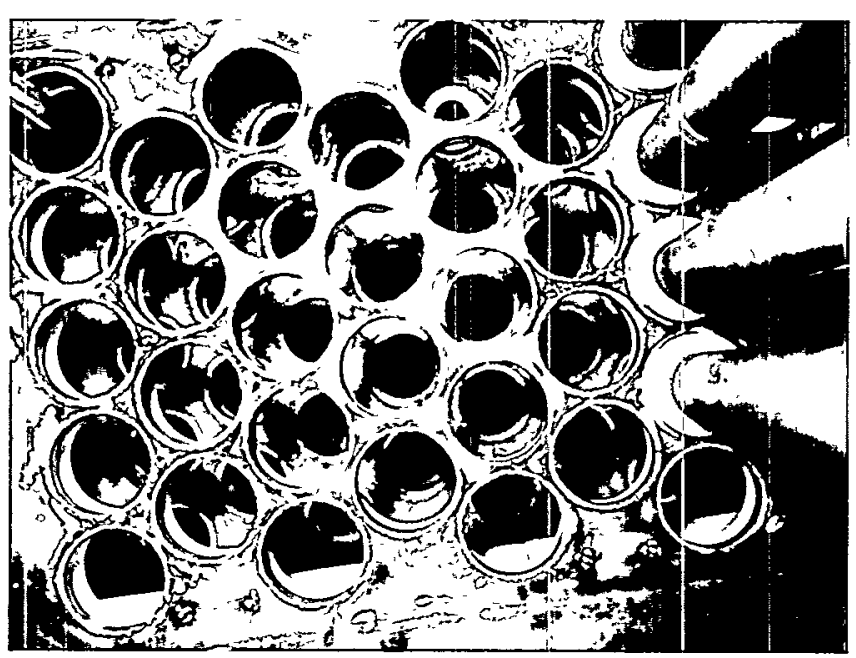

Bayonet-style ceramic tube assemblies are used in high-temperature burner-duct-recuperators to increase fuel efficiency.
Bayonet Ceramic-Tube Recuperator-DOE and Babcock \& Wilcox Corporation developed a ceramictube recuperator for use in steel plants. The recuperator is a two-stage unit; the first stage is a ceramic recuperator that can withstand continuing high temperatures, and the second stage is a metallic recuperator that provides a higher level of heat recovery efficiency. A unit installed at a Pennsylvania steel mill in 1982 achieved fuel savings exceeding $40 \%$. Projected annual savings for this type of recuperator in 2010 are estimated at 51.1 trillion Btus.

Cruciform Ceramic-Tube Recuperator-The cruciform ceramic-tube recuperator, developed by DOE and Garrett AiResearch, uses a unique design to recover heat in harsh combustion exhaust environments where conventional heat exchangers fail. By preheating combustion air to $2000^{\circ} \mathrm{F}$, the recuperator can save up to $50 \%$ of the fuel consumed in the combustion process. The first production unit of the cruciform ceramic-tube recuperator was tested in a rotary forging furnace at Cameron Iron Works in Houston, Texas. Potential energy savings by 2010 are estimated at 65.7 trillion Btus per year.

Ceramic Recuperator-A new cross-flow, ceramic recuperator for use in high-temperature $\left(1600^{\circ} \mathrm{F}\right.$ to $2600^{\circ} \mathrm{F}$ ), relatively clean exhaust environments was developed and tested by GTE with DOE support. The heat exchange core is composed of alternate layers of ceramic (magnesium aluminum silicate) passages oriented at right angles to each other. The recuperator is applicable to a wide variety of industrial furnaces in several industries with resultant energy savings of $26 \%$ to $50 \%$ over unrecuperated furnaces. As a result of DOE's technology acceleration program and the developer's marketing efforts, the recuperator is achieving widespread industrial acceptance and implementation. More than 700 recuperators of this type are currently saving industry an estimated 1.06 trillion Btus per year. Estimated 2010 energy savings are 26.2 trillion Btus per year.

\section{Innovative Coil-coating Ovens}

The coil-coating industry uses a significant amount of natural gas to cure solvent-based paints applied to metal coils. Gas-fired ovens evaporate the solvent and set the resin for each coat of paint. During this process, large volumes of preheated combustion air are required to keep solvent concentrations within safe 
limits. The oven exhaust is usually incinerated at temperatures up to $1400^{\circ} \mathrm{F}$ to meet hydrocarbon air emission standards. This incineration process requires additional energy in the form of natural gas fuel.

In a DOE cost-shared project, $B \& \mathrm{~K}$ Machinery and Roll Coater tested an innovative coil-coating system that can reduce the natural gas requirements by $74 \%$. The innovative system recovers the heat content of the solvent vapor in newly designed zone incinerators. This heat is then used in the curing oven to vaporize more solvent. The thermal incinerators are replaced by afterburners and waste-heat boilers to produce process steam. Additional energy is saved in pollution control, because the volume of gases is reduced by $50 \%$.

A coil-coating facility was retrofitted with this system, leading to the adoption of this technology by additional coil-coating facilities. Twenty-five operating units saved 2.7 trillion Btus in 1989. Projected savings in 2010 are 7.8 trillion Btus per year. The development of this technology has led coil-coating system manufacturers to develop even newer and more energy efficient systems.

\section{Brayton-Cycle Solvent Recovery}

In 1980, about 19.3 million tons of volatile organic solvents were lost through waste emissions from industrial processes in the petroleum, organic chemicals, paint, adhesive, printing, and dry-cleaning industries. Under a DOE contract, Garrett AiResearch developed a Brayton-cycle heat pump designed to recover such volatile organic solvents from waste vapors. The inherent cooling and heating capabilities of a Brayton-cycle heat pump provide a means to recover solvents economically and efficiently through condensation.

With this system, solvent-laden gas enters the Brayton-cycle compressor, where part of the heat of compression drives turbines, thereby augmenting the electrical energy supplied to the motor-driven compressor. The rest of the heat of compression is returned, via a regenerator, for reuse in the industrial process. Solvent precipitation begins in the condenser and continues as the gas mixture expands through the turbine. Expansion of the gas causes further condensation of the solvent, which is collected in a coalescing separator.

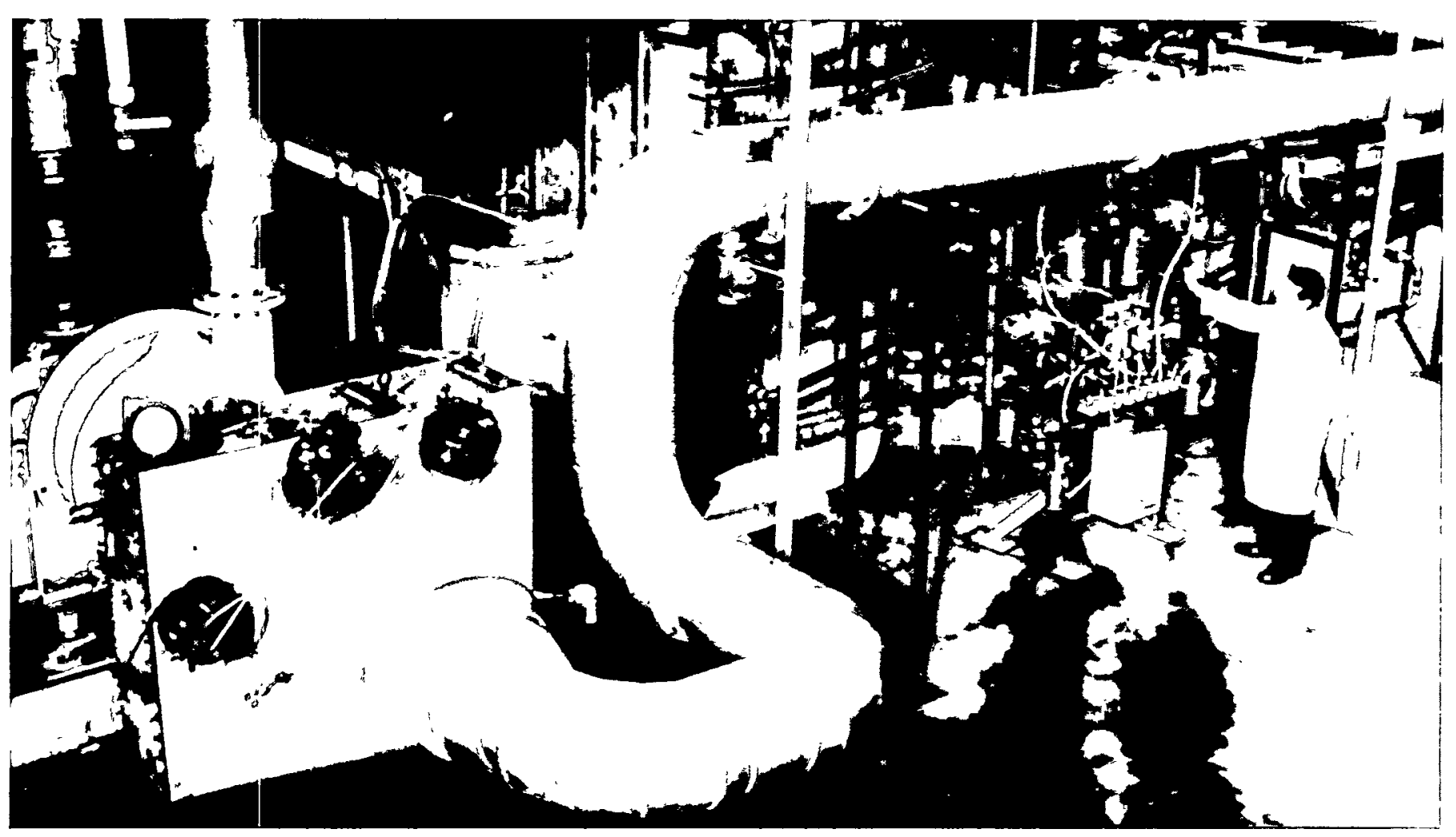

The Brayton-cycle heat pump recovers volatile organic solvents from waste vapors. 


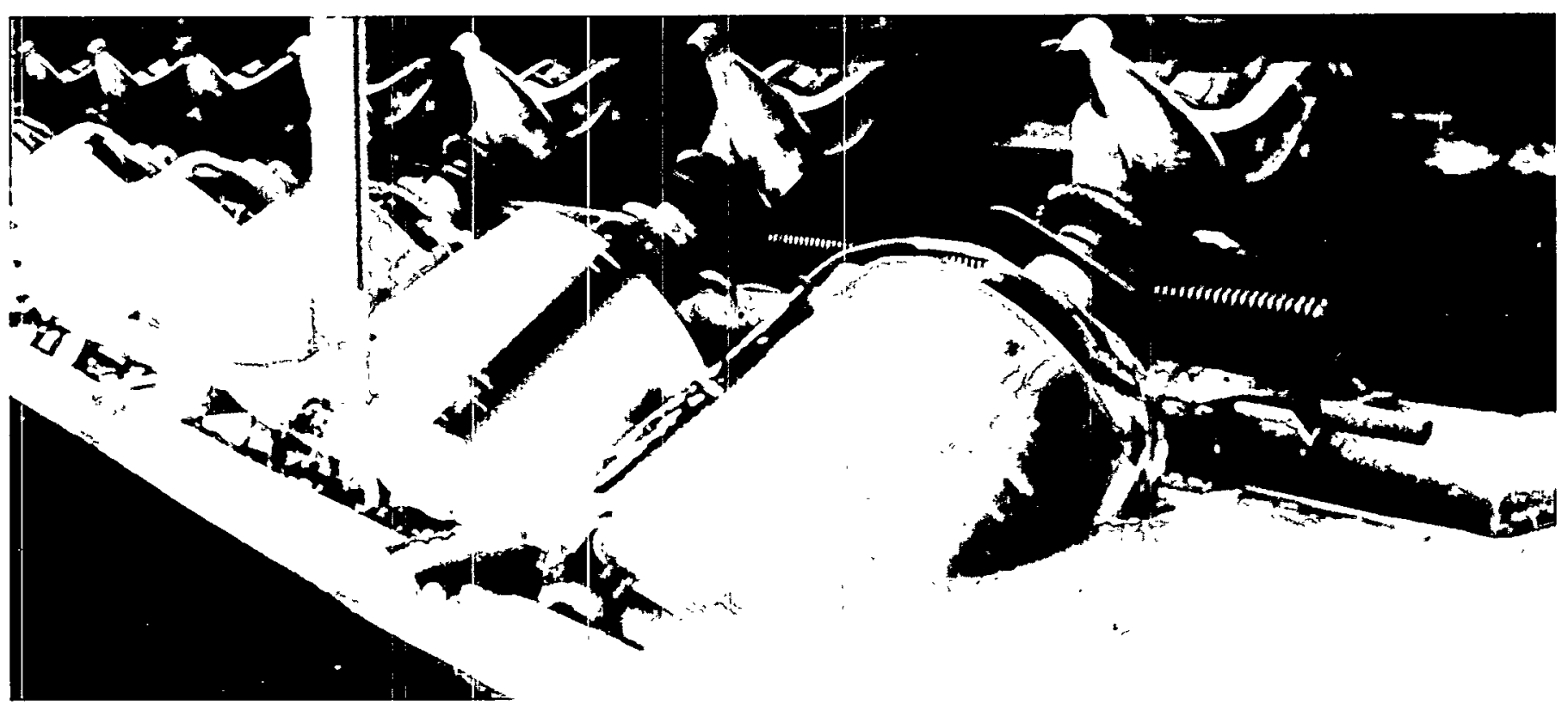

Researchers have developed a low-cost system to concentrate the chemical pollutants in electroplating rinse waters.

The Brayton-cycle solvent-recovery system was first installed by the 3M Company at its magnetic tape production facility in Hutchinson, Minnesota, where it saves about 38 billion Btus annually. By ensuring a consistent solvent quality, the system also improves productivity in the tape-making process. Based on the waste-solvent emissions industry-wide in 1980, the Brayton-cycle system could potentially recover 6.3 million tons of solvent, which is equivalent to 0.25 quad. Savings in 2010 are estimated at 10.1 trillion Btus per year.

\section{Electroplating-Wastes Concentrator}

The waste rinse water from electroplating processes contains high concentrations of chemical pollutants such as chromic acid, nickel sulfate, and zinc cyanide. Currently, excessive pollutant discharge is avoided by using high-temperature evaporation or chemical precipitation to produce a concentrate for disposal or recycling. These processes consume substantial amounts of energy and have high operating costs. An alternative method for concentrating large volumes of aqueous wastes is to boil the liquid at belowatmospheric pressure because liquids under lower pressure will boil at lower temperatures. This approach is used in multiple-effect evaporators that evaporate liquid in successive stages (or effects), each stage being at a lower pressure than the previous stage.
DOE and LICON, developed a low-cost, vaporrecompression evaporation system for use in concentrating electroplating wastes. The energy efficiency of this system is equivalent to that of a complex 10- to 12-effect evaporation system. In the vaporrecompression evaporator, the energy in the latent heat of the liquid, which is normally lost to the condenser by evaporation, is recycled through the compressor. This provides a temperature difference across the heat exchanger that promotes further evaporation. The only additional energy needed is power to increase the pressure that provides the temperature difference. The result is a substantial reduction in energy requirements per pound of water evaporated. Eighteen systems were operational in 1989, saving an estimated 0.1 trillion Btus per year. Projected savings are expected to reach 19.1 trillion Btus by 2010.

\section{Black Liquor Gasification}

Kraft black liquor, a by-product of paper manufacturing, provides a significant source of energy for the paper production process. The energy content of the kraft black liquor has traditionally been recovered by the Tomlinson boiler process, which is characterized by low energy efficiency, high capital and operating costs, significant air emissions, and a potential for explosions. 
Champion International Corporation and Rockwell International demonstrated on a laboratory and limited pilot-plant scale that kraft black liquor can be gasified in a fused-salt reactor to produce low-Btu gases. The clean gases can be burned directly in a gas turbine to produce electrical energy, and the combustion products can be fed to a waste-heat boiler to raise steam. The gasifier will have a throughput sufficiently high and a heat loss sufficiently low to produce product gases with a heating value of about 100 Btus per standard cubic foot.

Compared with the Tomlinson boiler process, the gasification of kraft black liquor offers high energy efficiency, reduced air emissions, modularity, a higher output ratio of electricity to steam, and improved safety. Economic analysis indicates significant potential savings in both capital and operating costs compared with alternative systems.

\section{Recycling of Postconsumer Plastic Scrap}

The energy that could be saved through recycling postconsumer plastic scrap might be as much as $1 \%$ of U.S. annual energy consumption. These savings would be in premium fuels, oil, and natural gas used as feedstocks and fuels in plastics production. In addition, because more than 40 billion pounds of plastics are produced annually in the United States, recovering and recycling plastics would alleviate a major disposal problem. Also, the capability to recycle plastics from scrapped automobiles may make the use of plastics for major structural parts, such as fenders and hoods, more acceptable to automobile manufacturers and environmentalists.

Under DOE funding, the Plastics Institute of America at the Stevens Institute of Technology, in a coordinated effort with Lowell University, Lehigh University, and the Polytechnic Institute of New York, successfully showed the technical feasibility of recycling plastic scrap from shredded automobiles. These studies were complemented by an industrial scale-up effort coordinated by the Plastics Institute and funded by DOE.

In June 1986, the Plastics Institute of America held a technology exchange workshop on "Plastics Recycling as a Future Business Opportunity." This workshop, supported entirely by the institute, was primarily aimed at entrepreneurs, representatives of local governments, and congressional staff members.
Workshop attendees concluded that there is a potential constituency for plastics recycling in the private and local government sectors.

\section{Boiler Workshops}

Steam boilers are used in every industrial and commercial sector to produce process steam, hot water, and building heat. Because boilers are the most prevalent energy conversion technology in industry, even small efficiency improvements in boiler operation can save large amounts of fuel. In response to this opportunity for energy conservation, DOE developed a national information and instruction program to promote more cost-effective and efficient maintenance and operating practices among boiler operators.

Through this program, university faculty and boiler technology specialists taught well-attended courses all over the country. Many local and industrial organizations then expanded on the pilot DOE program by continuing the courses with their own funding. These workshops are still held periodically in many areas of the United States by groups such as the Association of Energy Engineers, which conducts about five each year.

This DOE project, which was completed in 1987, yields energy savings estimated at 2.8 trillion Btus per year.

\section{Energy Analysis and Diagnostic Centers}

Many small- and medium-sized manufacturing companies lack the technical resources to perform thorough energy audits of their plants. Consequently, DOE has sponsored a program that provides free energy analyses by engineering faculty and students from U.S. universities. The program has grown from its experimental beginnings in 1976 to include 16 universities participating across the nation. To date, the Energy Analysis and Diagnostic Centers have performed more than 2800 plant audits. Conservation measures often recommended include using lower wattage lamps; insulating bare storage tanks, vessels, and lines; adjusting burners; and installing compressor air intakes in the coolest locations. About $50 \%$ of the recommended measures are routinely implemented, generally those involving low capital cost. The energy savings from this program are estimated at 11.4 trillion Btus per year. 